\title{
Development of a Full-flight Simulator for Ab-initio Flight Training with Emphasis on Hardware and Motion Integration
}

by

\section{Jonathan Plumpton}

A thesis submitted to the

Faculty of Graduate and Postdoctoral Affairs

in partial fulfilment of

the requirements for the degree of

Master of Applied Science

in

Mechanical Engineering

Ottawa-Carleton Institute for Mechanical and Aerospace Engineering

Department of Mechanical and Aerospace Engineering

Carleton University

Ottawa, Ontario, Canada

May 2014

Copyright (C) 2014

Jonathan Plumpton 


\section{Abstract}

As commercially-available flight simulators are tailored mostly for commercial airlines, there is currently a lack of low-cost, type-specific, high-fidelity aircraft simulators for introductory flight training. A project was undertaken by the Carleton University Applied Dynamics Laboratory to assess the feasibility of developing a viable economical alternative to the currently-available small aircraft flight training devices, thereby providing a supplementary means of training that could be available to small flight schools.

This thesis presents the development of a simulator prototype, built upon a Diamond DA20-A1 fuselage and developed through the effective use of original aircraft components and commercial off-the-shelf components. For this development, emphasis has been placed on the integration of the flight controls and electrical components, and their interface to the virtual environment. Further, a discussion is presented on making efficient use of a small motion base to replicate aircraft motion characteristics using an algorithm known as washout. Identification of the aircraft motion characteristics required the development and performance of a flight testing plan and associated instrumentation interface.

Following completion of the prototype, an assessment of the simulator determined that despite a few deficiencies that could be circumvented, development of a low-cost, type-specific, high-fidelity aircraft simulator for ab-initio flight training is feasible. 
I would like to dedicate my work to my father, the late Clarence James Plumpton, who was my best friend and my hero. He was my number one fan, and I never could have achieved this accomplishment without his support. 


\section{Acknowledgments}

I would like to thank my supervisor, Dr. Robert Langlois, for his guidance and support. Throughout this project you have helped me develop so many skills beyond just the technical skills.

Large contributions, through assistance and support, were provided by the researchers from the Applied Dynamics Laboratory, to whom a great thanks are owed. Further thanks extended to Fred Barrett for his contributions.

Along with my friends from the Applied Dynamics Laboratory, I want to thank all of my friends and family, for providing the emotional support I needed to get through the tough times, and helping me to successfully complete my graduate studies.

Strong support was provided to the project by the Mechanical and Aerospace Engineering Department, especially from the ladies in the office. Within the department machine shop, Alex Proctor and Kevin Sangster were always quick to provide assistance, no matter how difficult the task.

Finally, this project could never have been without the support and insight provided by our industry partners, Ottawa Aviation Services and B-Con Engineering,

along with the financial support of Mitacs and the Ontario Centre for Excellence. I thank you for providing me with this fantastic opportunity. 


\section{Table of Contents}

$\begin{array}{ll}\text { Abstract } & \text { ii }\end{array}$

Acknowledgments $\quad$ iv

Table of Contents $\quad$ v

List of Tables viii

List of Figures $\quad$ ix

List of Acronyms xii

1 Introduction 1

1.1 Flight Simulation and Training . . . . . . . . . . . . . 3

1.1.1 Ab-initio Flight Training . . . . . . . . . . . . . . 5

1.1.2 Motion in Simulation . . . . . . . . . . . . . 7

1.2 Project Motivation and Requirements . . . . . . . . . . . . . . . . . . 10

1.3 Thesis Overview . . . . . . . . . . . . . . . . . 12

2 KatanaSim Development $\quad 14$

2.1 Support Structure . . . . . . . . . . . . . . . . . 15

2.2 Instructor Operator Station f . . . . . . . . . . . . . . 17

2.3 Simulator Subsystems _. . . . . . . . . . . . . . 17 
2.3.1 Flight Controls . . . . . . . . . . . . . . . . . . . . . 19

2.3.2 Instruments and Avionics . . . . . . . . . . . . . 23

2.3.3 Electrical Controls . . . . . . . . . . . . . . . . . 25

2.3.4 Computer Architecture . . . . . . . . . . . . . . . . . 28

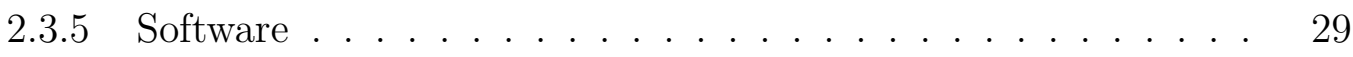

2.3 .6 Visual Cueing . . . . . . . . . . . . . . . . . . . . 33

2.3.7 Audio Cueing . . . . . . . . . . . . . . . . . 38

2.4 KatanaSim Flight Training Device . . . . . . . . . . . . . . . . . . 39

3 Motion Integration $\quad 40$

3.1 Motion Base . . . . . . . . . . . . . . . . . . . . . 40

3.2 Washout Algorithm . . . . . . . . . . . . . . . . 44

3.2.1 Classical Washout. . . . . . . . . . . . . 45

3.2.2 Optimal Control Washout . . . . . . . . . . . . 47

3.2.3 Adaptive Washout . . . . . . . . . . . . . . . . 49

3.3 KatanaSim Motion Tuning . . . . . . . . . . . . . . . . . 50

3.3.1 OverTilt Motion Drive Algorithm . . . . . . . . . . . . . 50

3.3.2 Platform Control . . . . . . . . . . . . . . . . . 52

3.3.3 Platform Optimization . . . . . . . . . . . . . . . . . 54

$4 \quad$ Flight Testing $\quad 59$

4.1 Flight Plan . . . . . . . . . . . . . . . . . . . 60

4.2 Instrumentation . . . . . . . . . . . . . . . . . . . . . 60

4.3 Data Collection Software . . . . . . . . . . . . . . 66

4.4 Equipment Tests . . . . . . . . . . . . . . . . . 66

4.4 .1 Pressure Sensor . . . . . . . . . . . . . . . . 66

4.4 .2 Low Temperatures . . . . . . . . . . . . . . . . 67

4.4 .3 Battery Life . . . . . . . . . . . . . . . 68 
4.5 Flight Permit . . . . . . . . . . . . . . . . . . . . . . . . . . 69

4.6 The Flight Test . . . . . . . . . . . . . . . . . . . . . . 70

4.7 Post-flight Review . . . . . . . . . . . . . . . . . . 71

5 Simulator Assessment $\quad 75$

5.1 Quantitative Evaluation ................... 75

5.1 .1 Data Acquisition . . . . . . . . . . . . . . . 80

5.1 .2 Motion Cueing ................... 81

5.1 .3 Visual Cueing . . . . . . . . . . . . . . . 83

5.2 Qualitative Evaluation . . . . . . . . . . . . . . 86

5.2 .1 Simulator Controls and Inputs . . . . . . . . . . . 87

5.2 .2 Instruments . . . . . . . . . . . . . . . . . . . 88

5.2.3 Motion Cueing ..................... 89

5.2 .4 Visual Cueing . . . . . . . . . . . . . . . 9 90

5.2 .5 Flight Model . . . . . . . . . . . . . . . 91

5.3 Discussion . . . . . . . . . . . . . . . . . . . . . . . . 91

6 Conclusion $\quad 93$

6.1 Contributions . . . . . . . . . . . . . . . . . . . . 95

6.2 Future Work . . . . . . . . . . . . . . . . . 96

$\begin{array}{ll}\text { References } & 97\end{array}$

$\begin{array}{lll}\text { Appendix A Flight Test Data Format } & 101\end{array}$

$\begin{array}{lll}\text { Appendix B Flight Test Permit } & 103\end{array}$

$\begin{array}{ll}\text { Appendix C Sample Flight Test Data } & 106\end{array}$ 


\section{List of Tables}

3.1 Moog 6DOF2000E specifications . . . . . . . . . . . . . . 41

3.2 Katana flight test motion extremes . . . . . . . . . . . . . . . . 44

3.3 Motion tuning parameter test sets . . . . . . . . . . . . . 57

4.1 Proposed manoeuvres for the flight test . . . . . . . . . . . . . . . . 61

4.2 Flight test instrumentation list . . . . . . . . . . . . . . 65

4.3 Revised manoeuvre list from flight test . . . . . . . . . . . . . . . . 70

5.1 Simulator components . . . . . . . . . . . . . . 76

5.2 Visual cueing latency results . . . . . . . . . . . . . . . . . . . 86

5.3 Status of simulated instruments . . . . . . . . . . . . . . . 89

5.4 Selected motion tuning parameters _. . . . . . . . . . . . . . . . 90 


\section{List of Figures}

1.1 Antoinette trainer . . . . . . . . . . . . . . . . . 2

1.2 Link trainer . . . . . . . . . . . . . . . . . . . . 2

1.3 Diamond DA20-A1 'Katana' aircraft . . . . . . . . . . . . . . 12

2.1 Aircraft fuselage . . . . . . . . . . . . . . . . . . . . . 15

2.2 Simulator support structure . . . . . . . . . . . . . . . 16

2.3 Arduino Mega microcontroller board . . . . . . . . . . . . . . . . . . 18

2.4 Original flight controls mounted in the KatanaSim . . . . . . . . . . . 19

2.5 Control stick and rudder pedal signal sources . . . . . . . . . . . . . 20

2.6 Switch for electric trim system . . . . . . . . . . . . . . . . 21

2.7 Flaps controller box . . . . . . . . . . . . . . . . . . . . . . . . 22

2.8 Single-turn potentiometers measuring powerplant inputs . . . . . . . 23

2.9 Simulated components on instrument panel . . . . . . . . . . . . . . 24

2.10 Circuit layout of string potentiometers, standard rotary potentiometers, and switches . . . . . . . . . . . . . . . 26

2.11 Klixon 3SB simulated circuit breaker . . . . . . . . . . . . . . 27

2.12 Power and wiring panel . . . . . . . . . . . . . . . . . 28

2.13 Computer architecture . . . . . . . . . . . . . . . . 29

2.14 Optotrak camera . . . . . . . . . . . . . . . . . 31

2.15 Rudder measurement using Optotrak system . . . . . . . . . . . . . . 31

2.16 Circuit breaker control program . . . . . . . . . . . . . . . 34 
2.17 Projection screen concept . . . . . . . . . . . . . . . . 36

2.18 Projector mount . . . . . . . . . . . . . . . . . . . . 37

2.19 Effect of projector mount deflection on visuals . . . . . . . . . . . 38

2.20 KatanaSim fixed-based flight simulator . . . . . . . . . . . . . . 39

3.1 Body-fixed coordinate system . . . . . . . . . . . . . . . 41

3.2 Support structore interface to motion base . . . . . . . . . . . . . . . 42

3.3 KatanaSim full-flight simulator . . . . . . . . . . . . . . . . 43

3.4 Classical washout algorithm block diagram . . . . . . . . . . . . . 45

3.5 Optimal washout algorithm block diagram . . . . . . . . . . . 48

3.6 Design of optimal control filters . . . . . . . . . . . . . . . . . . 48

3.7 Adaptive washout algorithm block diagram . . . . . . . . . . . . . 49

3.8 Motion control schematic . . . . . . . . . . . . . . . . 52

3.9 Motion control program . . . . . . . . . . . . . 53

3.10 High-pass filter break frequency comparison . . . . . . . . . . . 55

3.11 Motion base response to ramp-to-step input . . . . . . . . . . . 58

4.1 ArduPilot Mega . . . . . . . . . . . . . . . . . . . . 62

4.2 Mediatek GPS . . . . . . . . . . . . . . . 62

4.3 Airspeed pressure sensor . . . . . . . . . . . . . . . . . 62

4.4 Baggage compartment mount . . . . . . . . . . . . . . 64

4.5 Layout of flight test instrumentation . . . . . . . . . . . . . . 65

4.6 U-tube manometer test of pressure sensor . . . . . . . . . . . . . 67

4.7 Results for pitch and roll from the first flight test . . . . . . . . . . 71

4.8 Flight test airspeed results . . . . . . . . . . . . . . . . 73

5.1 Schematic of latency sources . . . . . . . . . . . . . . . . 77

5.2 Flight control input emulator program . . . . . . . . . . . . 78

5.3 Flight control input evaluation wiring diagram . . . . . . . . . . . 79

5.4 RC time constant effects on ripple voltage and settling time $\ldots$. . . 79 
5.5 Schematic of evaluation loop . . . . . . . . . . . . . . . 81

$5.6 \quad$ Flight control input latency evaluation . . . . . . . . . . . . . . . 81

5.7 Motion response to flight testing data . . . . . . . . . . . . . 82

5.8 Orientation effects on surge acceleration f . . . . . . . . . . 83

5.9 Platform response to sinusoidal and step surge acceleration inputs . . 84

5.10 Visual cueing response latency evaluation setup . . . . . . . . . . 85

5.11 Visual cueing response latency evaluation . . . . . . . . . . . . 85 


\section{List of Acronyms}

\begin{tabular}{|c|c|}
\hline Acronyms & Definition \\
\hline $\mathrm{AME}$ & aircraft maintenance engineer \\
\hline $\mathrm{APM}$ & ArduPilot Mega \\
\hline AHRS & attitude and heading reference system \\
\hline CAR & Canadian Aviation Regulations \\
\hline COTS & commercial off-the-shelf \\
\hline DAR & design approval representative \\
\hline DLL & dynamically-linked library \\
\hline FAA & Federal Aviation Administration \\
\hline FEA & finite element analysis \\
\hline FFS & full-flight simulator \\
\hline FTD & flight training device \\
\hline IOS & instructor operator station \\
\hline MDA & motion drive algorithm \\
\hline
\end{tabular}


NTSB

National Transportation Safety Board

OAS

Ottawa Aviation Services

PRM

person responsible for maintenance

PWM

pulse-width modulation

PPL

TC

Transport Canada

TER

transfer effectiveness ratio

UAV

unmanned aerial vehicle

UDP

user datagram protocol

xiii 


\section{Chapter 1}

\section{Introduction}

At the beginning of the twentieth century, early flight training devices were developed to allow pilots to experience the effects of flight controls, as aircraft had not yet stayed airborne for more than a few seconds [1]. Some of these devices made use of wind, such that when turned into the wind, air would flow over the control surfaces and the device would move in response to pilot inputs. Other devices, such as the Antoinette trainer, shown in Figure 1.1, relied on disturbances to be provided by the instructors and would often provide negative training as a result of the poorly-timed disturbances [2].

During the Second World War, the Link trainer, shown in Figure 1.2, was developed to improve pilot experience with flight instruments. Motion was injected into the device by means of pneumatic actuators with instruments driven to resemble the response of the aircraft [1].

Over the next half century, advances in computing, video technology, and mechanical technologies (such as feedback control and hydraulics) have resulted in a mature global simulator industry that provides and maintains very high fidelity simulators for large commercial aircraft (for example, CAE Inc (Canada) [4], Mechtronix 


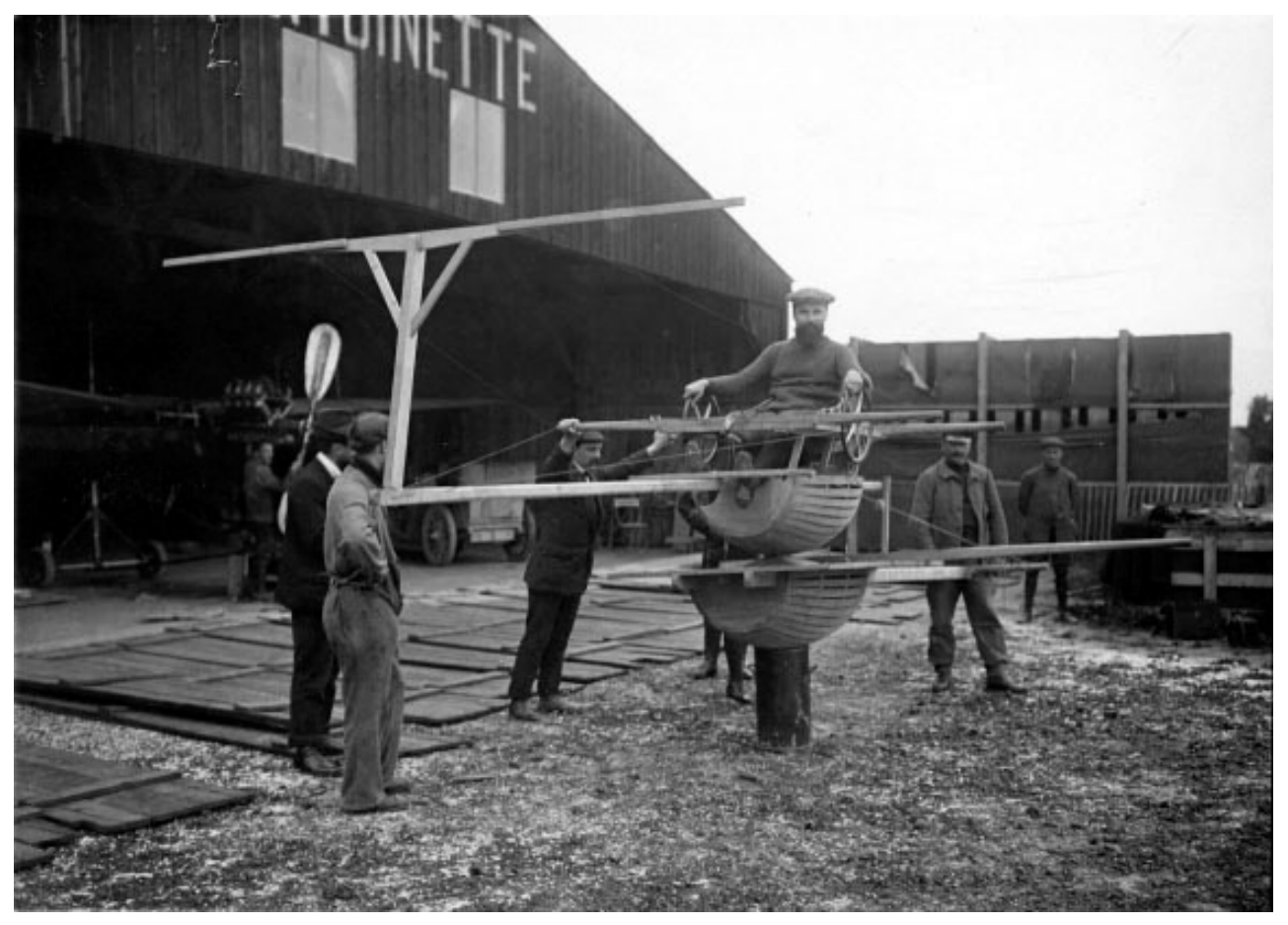

Figure 1.1: Antoinette trainer [1].

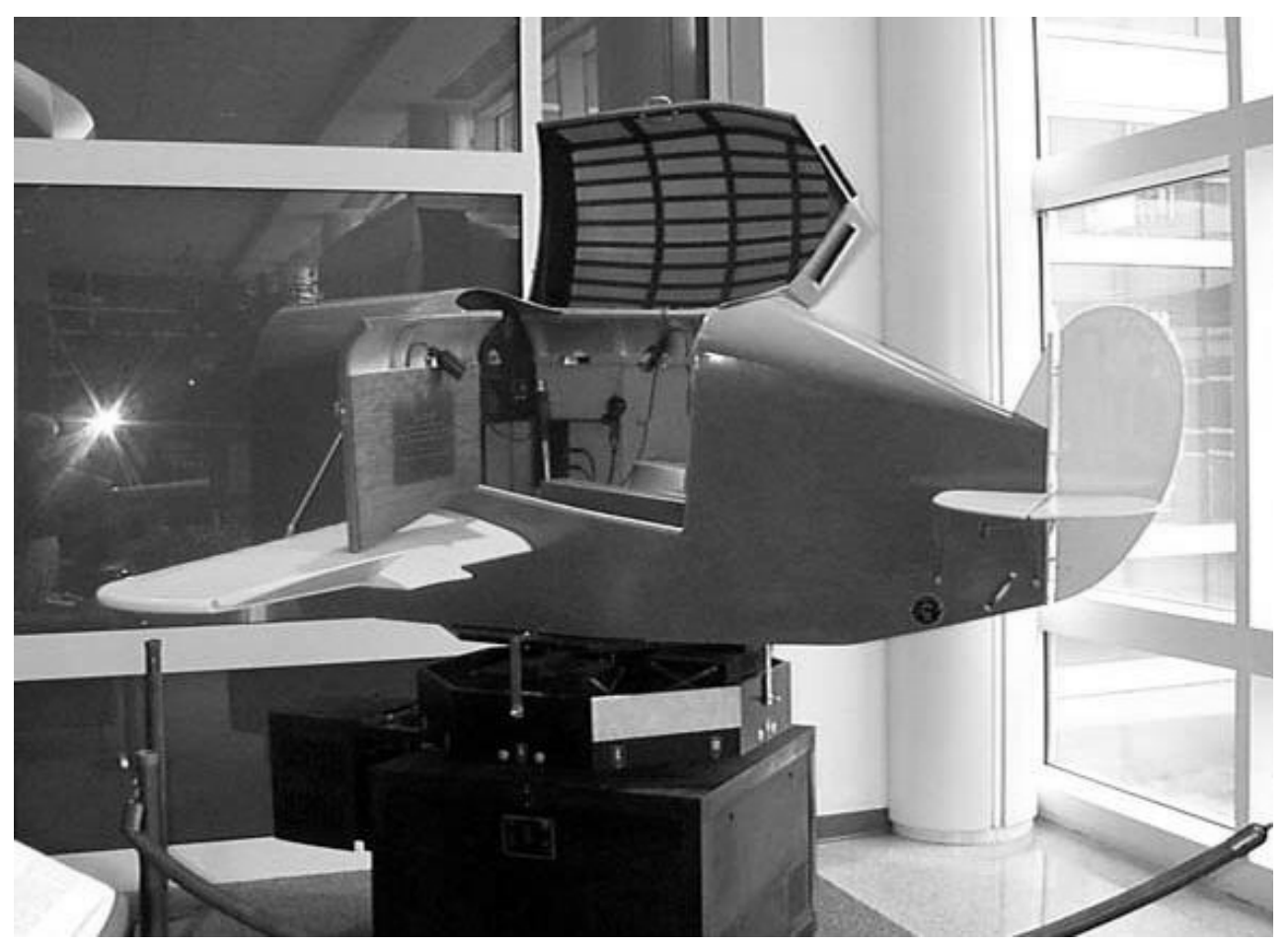

Figure 1.2: Link trainer [3]. 
Systems (Canada) [5], Thales Group (France, UK) [6], and Rockwell Collins (US) [7]).

\subsection{Flight Simulation and Training}

Current flight simulators are built to replicate specific production aircraft with typical customers being commercial airlines. However, the cost of these full-flight simulators (FFSs), often tens of millions of dollars, has generally precluded their use for entry-level pilot training. A lower fidelity (and much less expensive) device known as a flight training device (FTD) is being considered as a more affordable alternative. While FTDs can be helpful for pilot training, regulatory agencies do not consider time spent using them equivalent to time spent in the actual aircraft as is the case with FFSs. A very positive aspect of FTDs is that they have allowed immersive simulation to find its way into flight schools, such as locally-based Ottawa Aviation Services (OAS) Flight Centre. The downside to FTDs is that the aircraft simulators are limited by the fact that they are not generally aircraft specific, do not provide motion cueing, and have more limited field-of-view and lower visual fidelity than ideally required for effective pilot training.

The economic feasibility of FTDs is driven by the rationale that development cost can be reduced by making the devices more generic such that they are applicable to a larger potential market and the high costs of customization to specific aircraft can be avoided. As noted, the downside is that the resulting simulators are not ranked highly by certification agencies, based on their appropriateness for serving as an alternative to flight hours in the actual aircraft. This is why it is typically only type-specific FTDs [8] and FFSs [9] for commercial aircraft that successfully obtain higher levels of certification. Within Canada, flight simulation certification is 
regulated by Transport Canada.

In North America, there are seven levels of FTDs, Levels 1 to 7, where the higher the level, the more specific the cockpit and aerodynamics model. For FFSs, there are four levels, Levels A to D, where all levels require a type-specific cockpit and aerodynamics, and improved visual and motion cueing are required to achieve each higher level.

Despite the sometimes high costs associated with the acquisition and use of flight simulators, the importance of flight simulator training has been well established. First, flight simulator training has been shown to reduce the cost of flight training while improving the effectiveness of the training [1]. Flight simulators typically incur lower operation and maintenance costs; with studies from 1992 finding that simulator operation and maintenance costs were typically $8-20 \%$ lower than the associated aircraft costs, with the margin expected to increase especially as technology costs decrease and fuel costs rise [10]. Second, flight simulation accelerates the rate of acquiring experience as pilots can experience in a short time many different flight scenarios; scenarios they might have otherwise never experienced in the aircraft [2]. In some instances, pilots are fully trained for a particular aircraft in a simulator, with their first experience flying the real aircraft being as co-pilot with fee-paying passengers aboard a scheduled flight [1].

Recent studies [11] have suggested that improved flight simulation, including severe disturbance motions, would likely significantly reduce airline fatalities. A review of National Transportation Safety Board (NTSB) reports on airline accidents involving fatalities that occurred between 2000 and 2010 determined that in $73 \%$ of those reports, the NTSB concluded that the accidents could have been prevented 
with improved simulator training [11]. While flight simulators were initially used for maintaining pilot currency in assorted flight scenarios, flight simulators have found their way into the curriculum of some larger flight schools.

\subsubsection{Ab-initio Flight Training}

The use of flight simulators is currently part of the ab-initio flight training curriculum at several of the larger flight schools. Ab-initio flight training focuses on training students from the beginning, assuming zero previous experience. Embry-Riddle Aeronautical University, where flight training is incorporated into the degrees in Aeronautical Science, introduced FTDs into the flight training curriculum in the Fall of 2002 [12]. This program provided data for a two-year study by Macchiarella et al., in 2005 [13] which suggests that the benefits of flight simulation training do extend to ab-initio pilot training.

In addition to the benefits of reduced operation and maintenance costs, benefits from the use of flight simulators in ab-initio flight training come from improved safety and focused training $[1,12]$. Flight simulators allow instructors to let scenarios continue beyond the critical threshold, a point considered too dangerous in the real aircraft, thereby giving students the conclusive experience of the consequences of their mistakes. One exercise that would benefit from such training is the powerfailure landing, in which the instructor is meant to discontinue the exercise in the real aircraft if it is being performed incorrectly below some safe altitude [12].

Based on current Canadian Aviation Regulations (CAR), ab-initio pilots are limited to five full-flight simulator training hours that can be credited toward the 
minimum 45 hours of flight training required to qualify for the Private Pilot Licence (PPL) [14]. Despite the limited number of hours that can be credited toward licensing requirements, students often take more than the minimum 45 hours of flight training before the chief flight instructor feels they are prepared for the PPL examination. The objective of training performed in the flight simulator is often to reduce the number of flight hours required for a student to meet proficiency expectations. By this consideration, the Transfer Effectiveness Ratio (TER) was conceived to assess the effectiveness of the flight simulator for training needs [2]. This ratio, when applied to certain benchmarks, such as time to first solo or time to licence, is given by

$$
\mathrm{TER}=\frac{A-A_{S}}{S}
$$

where $A$ is aircraft training time when no time is spent in the flight simulator, $A_{S}$ is aircraft training time when time is spent training in the flight simulator, and $S$ is the time spent training in the flight simulator. A TER value greater than one demonstrates that time saved in the aircraft exceeds time spent in the flight simulator, while values between zero and one demonstrate that more time was spent in the flight simulator than was saved in the aircraft [2]. In both cases, the operation and maintenance costs should be factored into the overall effectiveness of the flight simulator. When the TER value falls below zero, negative training is occurring, and consequently, more time has to be spent in the aircraft as a result.

Despite the benefits of flight simulation, the fact is that flight simulators often have capital costs that exceed the capital costs of the aircraft used in flight schools [1]. Notwithstanding low operation and maintenance costs, there are few financial incentives for operating flight simulators, as ab-initio pilots are less inclined to pay high prices for flight training that will not be credited toward their licensing. 
While options do exist for lower-cost flight simulators [15], these systems are typically non-type-specific, and reduce some of the benefits of the flight simulator training. The two leading scenarios that would increase the prevalence of flight simulator use in ab-initio flight training would be: changes in Transport Canada regulations to increase the number of flight simulator hours that count as credit toward licensing; and a decrease in capital costs for type-specific flight simulators that are suitable for ab-initio flight training.

\subsubsection{Motion in Simulation}

To qualify for FFS certification through Transport Canada or the Federal Aviation Administration (FAA) in the United States, a flight simulator faces more stringent standards for visual cueing, and faces a mandatory requirement for motion cueing [16]. As motion cueing adds to the cost of a flight simulator, it is important to understand the purpose of motion cueing.

Systems for developing motion are generally defined by their performance characteristics for each degree-of-freedom produced [2]. The most popular system for producing motion is the Gough-Stewart motion platform, which combines linear and angular motion through independently actuated legs [1]. These motion systems have historically been hydraulically operated, with few exceptions. The main driver of the use of hydraulic actuators has been the larger load capacity associated with hydraulics. However, advances in electrical drive technology over the last decade have led to an increase in the use of electrically-driven motion bases. Despite offering lower performance characteristics, electric motion bases are available at a lower cost and are more environmentally friendly than comparable hydraulic motion bases. Unfortunately all motion bases offer limited motion, typically lower than the totally 
unbounded motion achieved by aircraft.

Despite the often limited motion available in flight simulation, understanding how the human body senses motion provides opportunities to fool the brain into sensing further motions. The main methods of sensing motion used by the human body are visual cues, as sensed by the eyes; tactile cues, as sensed by the skin and muscles; and motion cues, as sensed by the vestibular system [1]. Visual cueing is often the most dominant of the human senses [2]. The goal in motion cueing is to expedite the body's perception of motion. This is similar to how pilots sense motion in the aircraft immediately while instruments in the aircraft often experience lag from the onset of motion to the display [1].

The vestibular system is the non-auditory portion of the inner ear [2] and senses the orientation and dynamic movement of the head [1]. It is comprised of two sensors: the semicircular canals and the otoliths. The vestibular system is used to stabilize the eyes to ensure vision is not blurred.

Each ear has three semicircular canals arranged in three mutually perpendicular planes, which are able to detect angular velocities as low as $2 \mathrm{deg} / \mathrm{s}$ in simulator conditions [1]. This threshold is important in optimizing the limited availability of motion, as it means motion platforms can restore angular positions at angular velocities below $2 \mathrm{deg} / \mathrm{s}$ without being detected by the brain. The otoliths located in each ear are used for detecting translational accelerations from non-gravitational forces acting on the body [2], with thresholds as low as $0.03 \mathrm{~m} / \mathrm{s}^{2}$.

Motion experienced by pilots in aircraft can typically be distinguished between two types of motion: manoeuvre motion and disturbance motion [17]. Manoeuvre 
motion is any motion caused by pilot control inputs. Low-frequency manoeuvre motions are those where the pilot makes small changes and waits a finite time to make corrections, such as gentle turns, gentle climbs, and most speed adjustments. High-frequency manoeuvre motions include those where instant changes are required, such as takeoff and landing. Disturbance motions differ from manoeuvre motions in that disturbance motions are motions not caused by pilot inputs (e.g., turbulence), though they are typically followed immediately by high-frequency manoeuvre motions. As the human body is limited to the threshold and frequency of sensing motion, not all aircraft motion can be sensed through or benefit from motion cues [2]. While motion cueing adds little benefit to low-frequency manoeuvre motions, motion cueing can be beneficial for high-frequency manoeuvre and disturbance motions as they require prompt response from the pilot [18].

Motion bases take advantage of the thresholds on the human body's ability to sense motion. The thresholds provide the opportunity to fool the brain into sensing motion not actually being delivered [1]. This is achieved by slowly reducing the motion and returning the motion base to the neutral position, while relying on visual cueing to maintain the sense of motion. This is achieved through filtering of motion data in a process known as washout (discussed in greater detail in Chapter 3).

In developing motion cueing systems, latency of the motion must be considered, as the latency could have an adverse effect on training [1]. Delays between expected aircraft response and application of motion have minimal effect for delays under $150 \mathrm{~ms}$ [1], while delays in excess of $250 \mathrm{~ms}$ can reduce the quality and transferability of the training completed in the flight simulator [19]. These excess delays can lead to pilots applying a wait and see approach to flying, where they apply an input and wait to see the response of the motion [20]. This wait and see approach would 
constitute negative training as the pilot would then have to relearn the techniques during training in the actual aircraft.

An important aspect of motion cueing is that having no motion is better than incorrect motion, from the perspective of training effectiveness [1]. However, pilots are trained to use their eyes to fly, and not their vestibular senses. If motion can be properly implemented into the flight simulator, the pilots can learn to overcome the distractions associated with motion [19]. An example of how this skill is implemented in training would be Exercise 24 of the Transport Canada approved flight training syllabus [21]. During one stage of the exercise, the flight instructor enters the aircraft into an unusual attitude while the student's eyes are covered. The student is then expected to recover the attitude, ignoring their brain's confused state of their orientation.

The real evaluation of motion is subjective and pilot-specific. While studies have been performed on the benefits of motion $[1,2,18,19]$, no studies have successfully established the overall contributions, be they positive or negative, to training effectiveness. However, motion cueing systems continue to play large roles in full-flight simulators as they are currently required by certification agency regulations.

\subsection{Project Motivation and Requirements}

The goal of the project is to assess the feasibility of developing a viable economical alternative to the currently-available small aircraft flight simulators, thereby providing a supplementary means of training that could be available to small flight schools that train using single-engine, primarily recreational aircraft. The project 
is a collaboration between Carleton University's Applied Dynamics Laboratory and OAS Flight Centre - a local flight school that could potentially benefit from the outcomes of the project.

As most flight schools lack the capital and financial incentive to acquire most high-fidelity commercially-available flight simulators, the focus of the project is to develop a low-cost, type-specific, high-fidelity aircraft simulator [22]. As a means of keeping costs lower while simultaneously maintaining high physical fidelity, original aircraft parts were used, to the extent practical, in the cockpit design. Increases in functional fidelity resulted from ensuring the response of the simulator controls, virtual environment, and flight model mimic the response of the aircraft. Environmental fidelity was improved by improving the quality of the audio, visual, and motion cueing of the simulator.

For this project, a Diamond DA20-A1 'Katana' was selected as the aircraft to be simulated (shown in Figure 1.3). The Katana aircraft is a two-seater trainer aircraft commonly used for ab-initio flight training. Given the selected aircraft, and the nature of the project, the project will commonly be referred to by the name KatanaSim.

The ultimate longer-term goal for the project is development of a certified FFS that could be incorporated into ab-initio training, such as the training obtained at OAS. The current stage of the project saw the development of the FFS with the Transport Canada set of certification standards used as guidelines throughout the design process. 


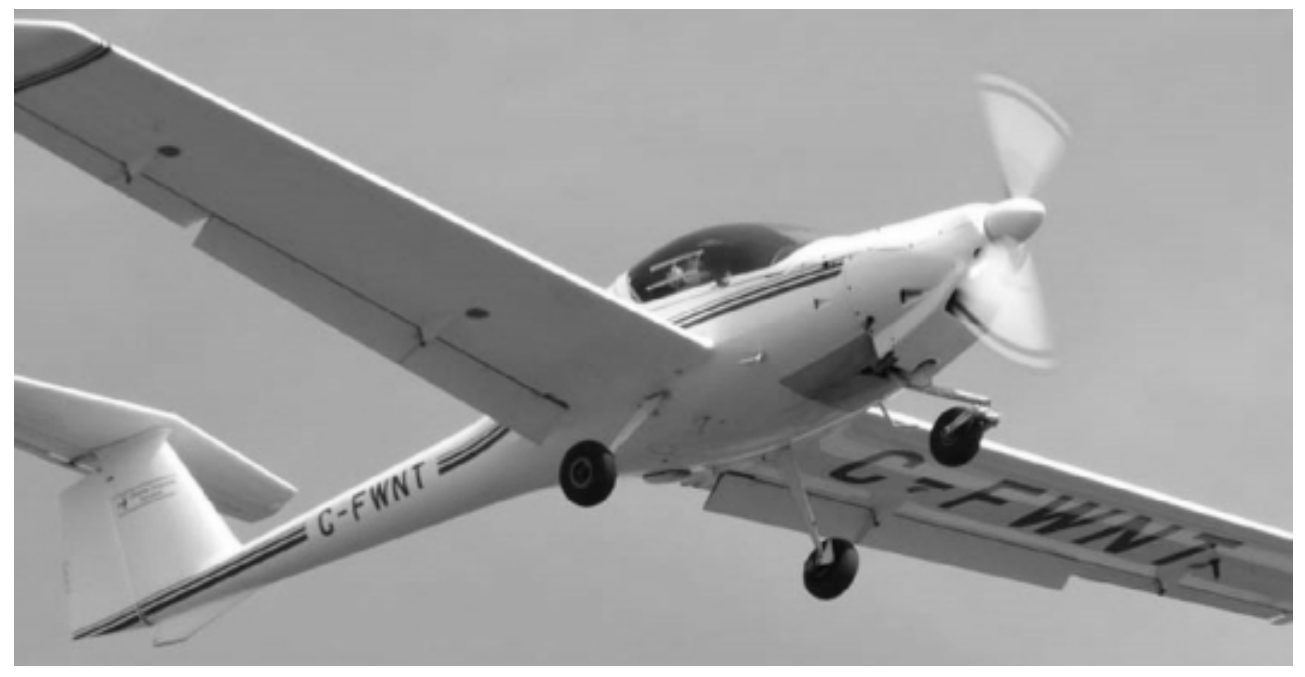

Figure 1.3: Diamond DA20-A1 'Katana' aircraft [23].

\subsection{Thesis Overview}

Development of the flight simulator was mainly divided between two members of the Applied Dynamics Laboratory. Suzanne Swaine [24] took responsibility for the integration of the open-loop control loading of the flight controls, the toe brakes, the flight and powerplant instrumentation, the avionics, the audio cueing, and the flight model. While this thesis provides summaries of these aspects as part of the overall simulator development, it emphasizes the integration of the visual cueing, the flight controls, the electrical components, the interface to the virtual environment, as well as the integration and tuning of the motion cueing.

In Chapter 2 of this thesis, development of the simulator as a fixed-based flight training device will be discussed. The development of the motion cueing for the flight simulator, as required for classification as a full-flight simulator, will then be discussed in Chapter 3. As a means of obtaining the required characteristics of the Katana aircraft, Chapter 4 will discuss flight testing that was undertaken in collaboration with OAS and using a Katana aircraft from the OAS fleet. Finally, Chapter 5 discusses 
quantitative and qualitative assessments of the KatanaSim that evaluated the control inputs, visual cueing, and motion cueing of the simulator, with Chapter 6 providing a discussion of the project and conclusions. 


\section{Chapter 2}

\section{KatanaSim Development}

The development of the KatanaSim occurred in two stages: the development of the simulator as a fixed-base flight training device, followed by the development of motion cueing capacity leading to the full-flight simulator. This chapter will discuss the work completed in developing the flight training device. Specifically, the chapter will look at the development of the mechanical support structure for the simulator, the development and implementation of required hardware, as well as the development and implementation of the software.

To keep the cost of the simulator to a minimum while ensuring that physical fidelity remained high, original Katana components were used where possible in the design. The central structure of the simulator is a Katana fuselage provided by OAS Flight Centre (Figure 2.1). The wings, landing gear, engine, and propeller were removed and the fuselage was stripped of all removable parts. The tail boom was cut off just behind the cabin's baggage compartment to reduce its size while maintaining sufficient structure for proper operation of the canopy. This layout allows for potential future use of the original aircraft canopy as part of the visual cueing system [22]. The use of the fuselage and canopy ensures not only that the interior geometry of the simulator is identical to that of a Katana, but that students will be 


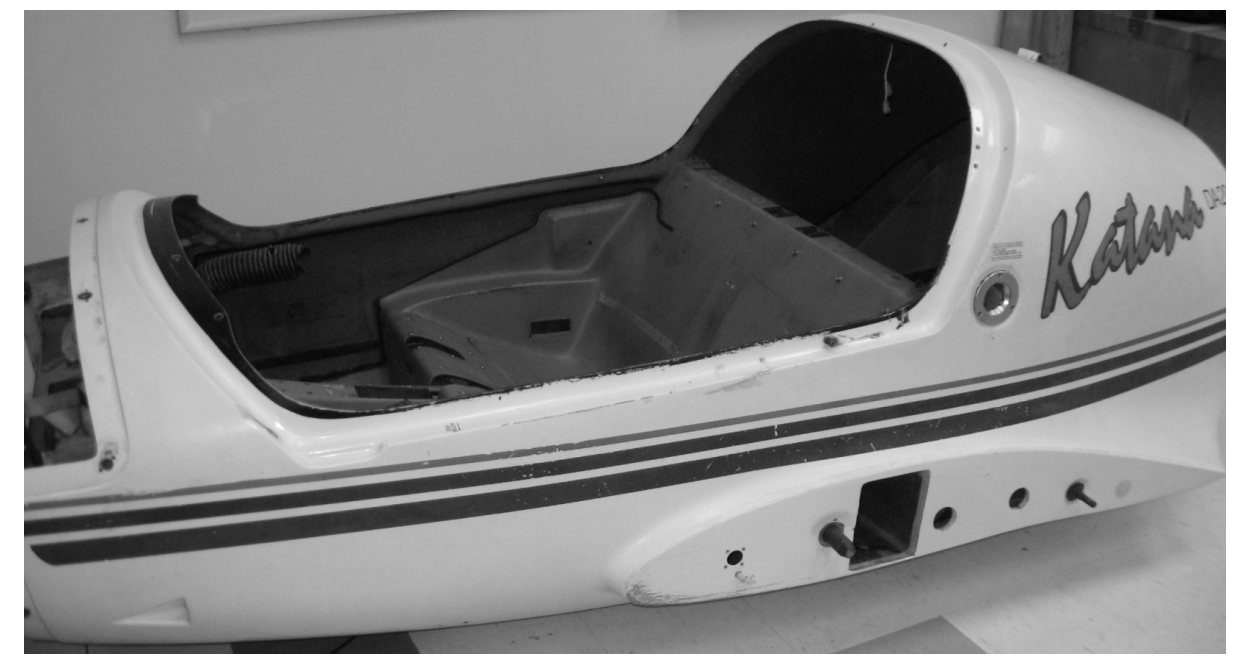

Figure 2.1: Aircraft fuselage.

able to learn and practise safe entry and egress techniques with each simulator session.

\subsection{Support Structure}

As the landing gear had been removed from the Katana, a support structure was required to keep the cockpit and projection system stable and correctly oriented. The structure was designed with minimal modifications to the fuselage and was built to withstand maximum translational accelerations of $0.6 \mathrm{~g}$ in any direction (for compatibility with the motion cueing system described subsequently in Chapter 3). Furthermore, the structure was designed such that it would not interfere with proper entry and egress from the Katana, as well as allowing proper opening and closing of the canopy, should it be installed.

The KatanaSim support structure, designed by Joel Spark and Jamie Léveillé ${ }^{1}$, and shown in Figure 2.2, consists of five primary sub-structures: a base frame, two

\footnotetext{
${ }^{1}$ Research assistants from the Applied Dynamics Laboratory.
} 


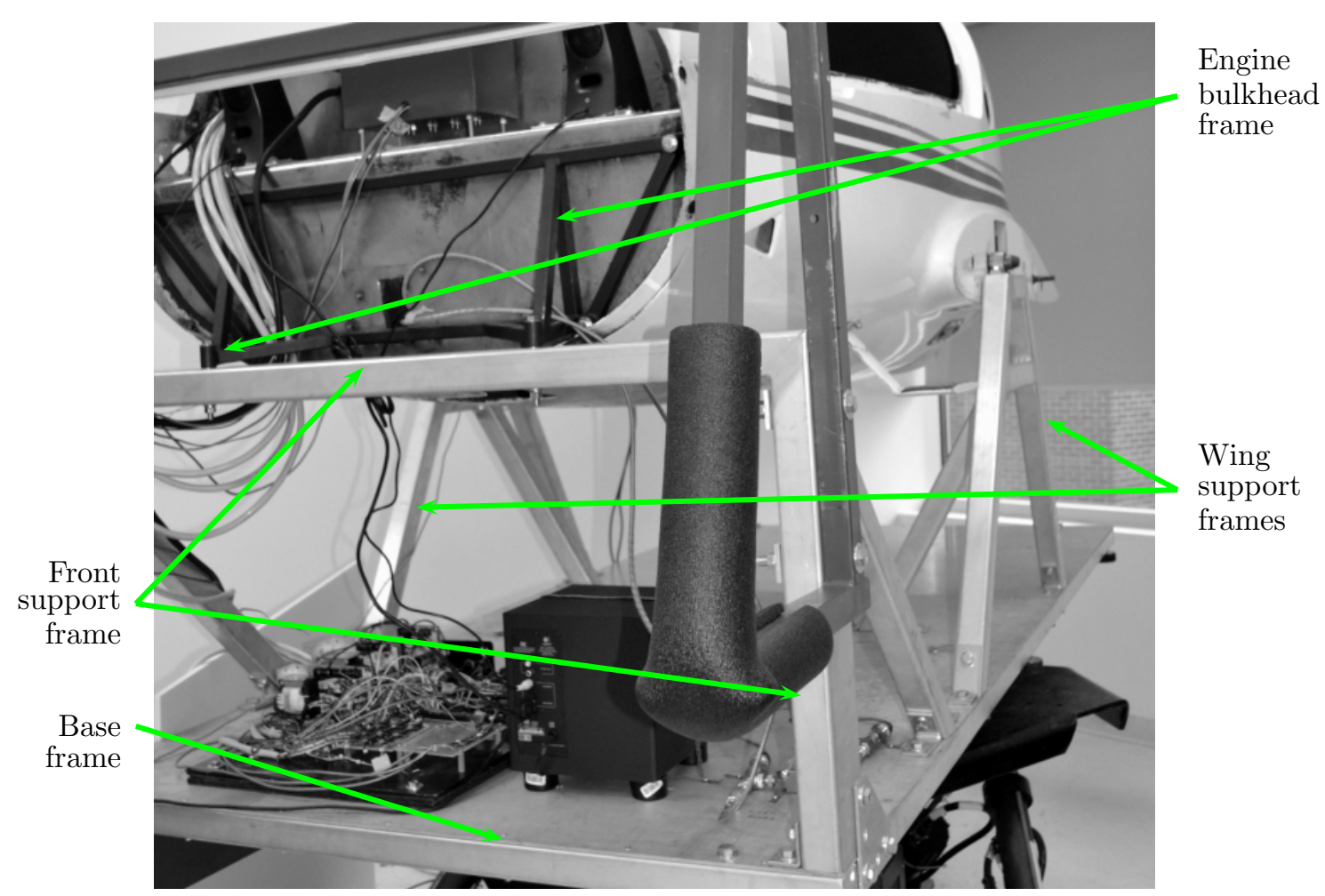

Figure 2.2: Simulator support structure.

wing pin support frames, a front support frame, and an engine bulkhead frame. The base frame provided a single mounting structure onto which the wing pin and front support frames were mounted while also acting as an interface structure for mounting the simulator to a motion platform. Use of the wing pins and engine bulkhead to support the cockpit avoided the need for modifications to the cockpit structure while assuring the attachment points were capable of carrying high loads, as these components are subject to large loads in flight. While a large portion of the design required manufacturing, commercial off-the-shelf brackets were used to secure the wing pin and front support structures to the base frame, in an effort to minimize the total cost of the support structure. The outsourced manufacturing was performed by Bell's Machining, Welding and Hydraulics (Perth, Ontario, Canada) [25]. 


\section{$2.2 \quad$ Instructor Operator Station}

One important element of any flight simulator is the Instructor Operating Station (IOS). The IOS allows an instructor to observe the behaviour of the student while maintaining control over the virtual environment of the simulator. The instructor can use the IOS to modify the location of the virtual aircraft, the weather, and the functionality of the aircraft systems. For certification of an FTD, Transport Canada requires suitable seating for an instructor and a Transport Canada inspector, both with an adequate view of the instrument panel [16].

The KatanaSim currently has an off-platform standalone IOS; however, the simulator base was designed such that with minor modifications to the current design, an additional seat could be installed centred behind the two existing seats. The seat would be accessible from the opening at the rear of the fuselage, and would provide the occupant with an unobstructed view of the instruments and outside visuals. This seat would only be installed if it were deemed necessary when certification is attempted. An alternative offering potential is the use of cameras streamed to the IOS for providing a view of the instrument panel.

\subsection{Simulator Subsystems}

With the physical structure of the simulator established, development of the simulator subsystems began. The use of original components in the simulator further extends within the cockpit to most of the controls, the switches, the levers, and the seat assemblies. The decision to use original components was based on ease of integration and cost comparison to commercial off-the-shelf (COTS) components, as well the 


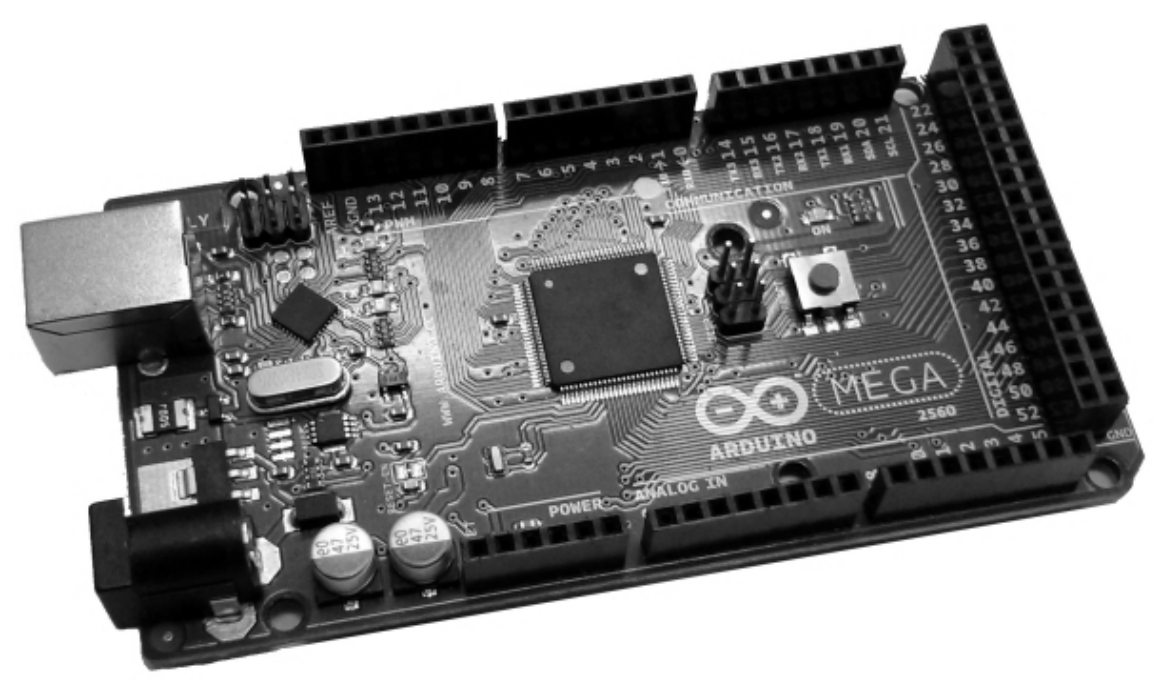

Figure 2.3: Arduino Mega microcontroller board.

greater physical fidelity associated with the original components. For instances where original components could not be utilized, COTS simulated components were selected to provide the best match to the original components. All aspects of the aircraft cockpit had to be properly replicated within the simulator.

The simulator components interfaced to the KatanaSim software either directly by USB or indirectly through an Arduino Mega 2560 microcontroller board (Figure 2.3) [26]. The Arduino is an electronics prototyping board capable of reading direct current analog signals of zero to five volts, reading direct current digital signals of five volts, and outputting zero to five volts of direct current through Pulse-Width Modulation (PWM). The KatanaSim makes use of two Arduinos, referred to as the control Arduino and the instructor Arduino. The Arduinos were programmed for their intended purposes, and connected to the KatanaSim using serial communication. 


\subsubsection{Flight Controls}

All the original controls for the aircraft control surfaces and aircraft powerplant were installed, most of which can be seen in Figure 2.4.

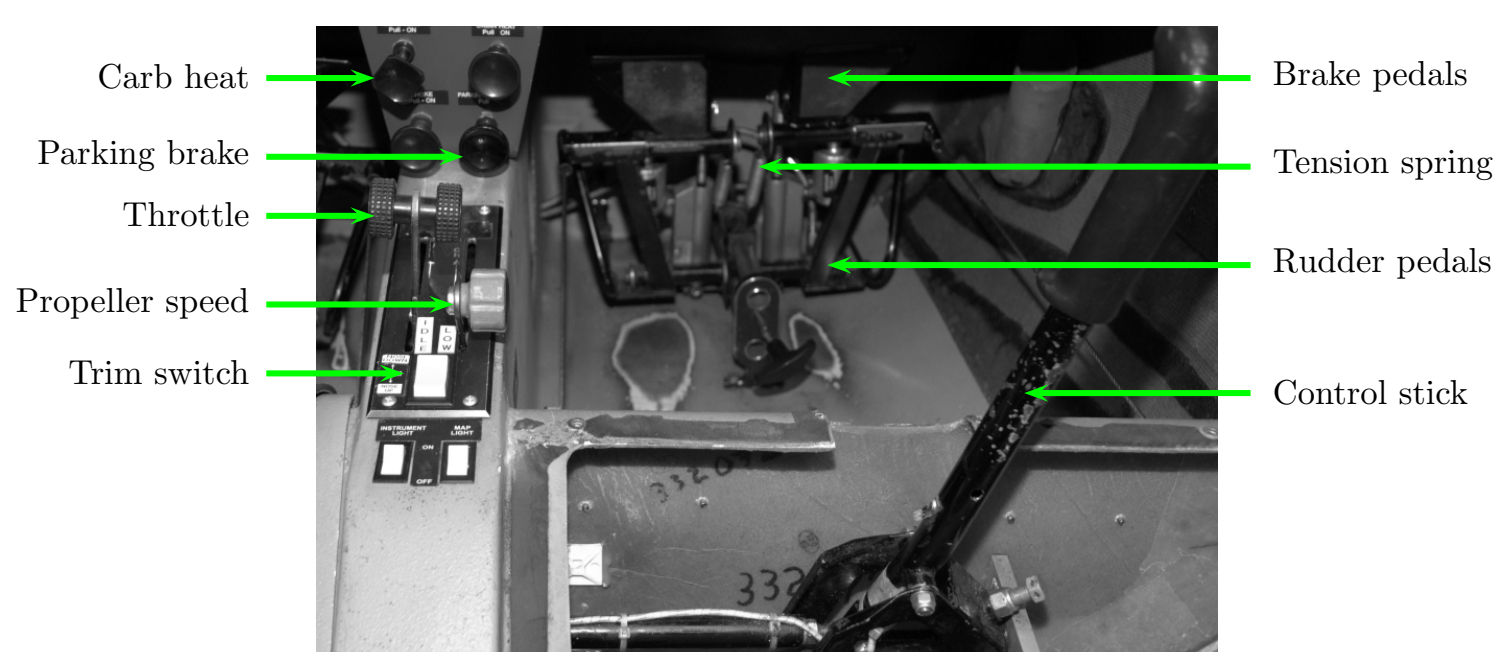

Figure 2.4: Original flight controls mounted in the KatanaSim.

\section{Control Surfaces}

For the control surfaces, components include the control stick, rudder pedals, trim switch, and modified flaps controller box. To ensure proper synchronization between the pilot and co-pilot flight controls, original flight control linkages for both the control stick and rudder pedals had to be installed. The use of these linkages for the flight controls also provided pick-up points for three Celesco SP3 string potentiometers [27] to be attached as a means of sensing the movement of the flight controls in the roll, pitch, and yaw directions, as shown in Figure 2.5. Each string potentiometer can measure a range of 31.75 centimetres (12.5 inches), exceeding the typical range of the flight control linkages of about 5 to 10 centimetres. The string potentiometers require an input voltage of 12 to 32 VDC. This input voltage is internally regulated to produce an output signal of 0 to 10 VDC. As 
the Arduino is only capable of reading up to 5 VDC, a voltage divider was wired for each string potentiometer output signal such that the control Arduino could read and interpret the inputs, then communicate the results to the simulator software.

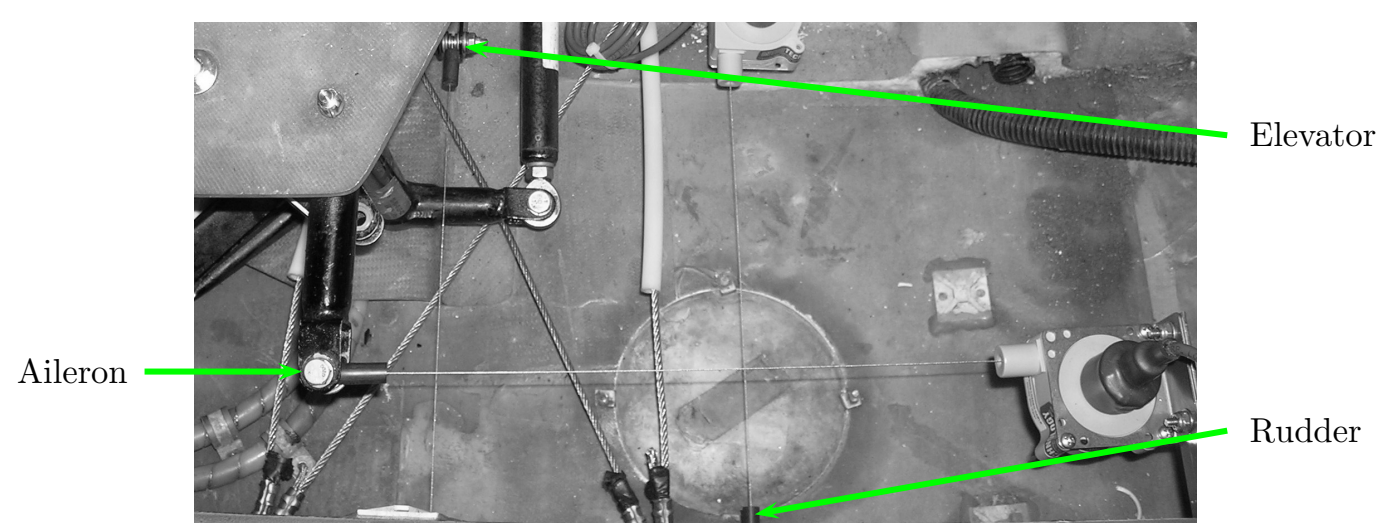

Figure 2.5: Control stick and rudder pedal signal sources.

As an interim solution, until active force feedback on controls is ultimately implemented, a passive control loading system for the control stick has been developed and implemented by Suzanne Swaine [24]. It consists of tunable nonlinear springs such that the controls return to the neutral position when released and exert forces representative of nominal flight conditions when deflected. No passive control loading system was developed for the rudder pedals as tension springs are already in place to centre the pedals.

The Katana aircraft is not equipped with the typical adjustable trim tab on the elevator [28]. Instead, the aircraft possesses an electric trim system which balances the elevator forces for the desired configuration, simplifying the pilot's task of maintaining the desired flight path. This is achieved by a double throw switch on the centre console (Figure 2.6), which actuates a motor to adjust forces on the elevator in the desired direction. For the KatanaSim, replicating this control is enabled, in part, by connecting the trim switch to the control Arduino, as will be discussed in 


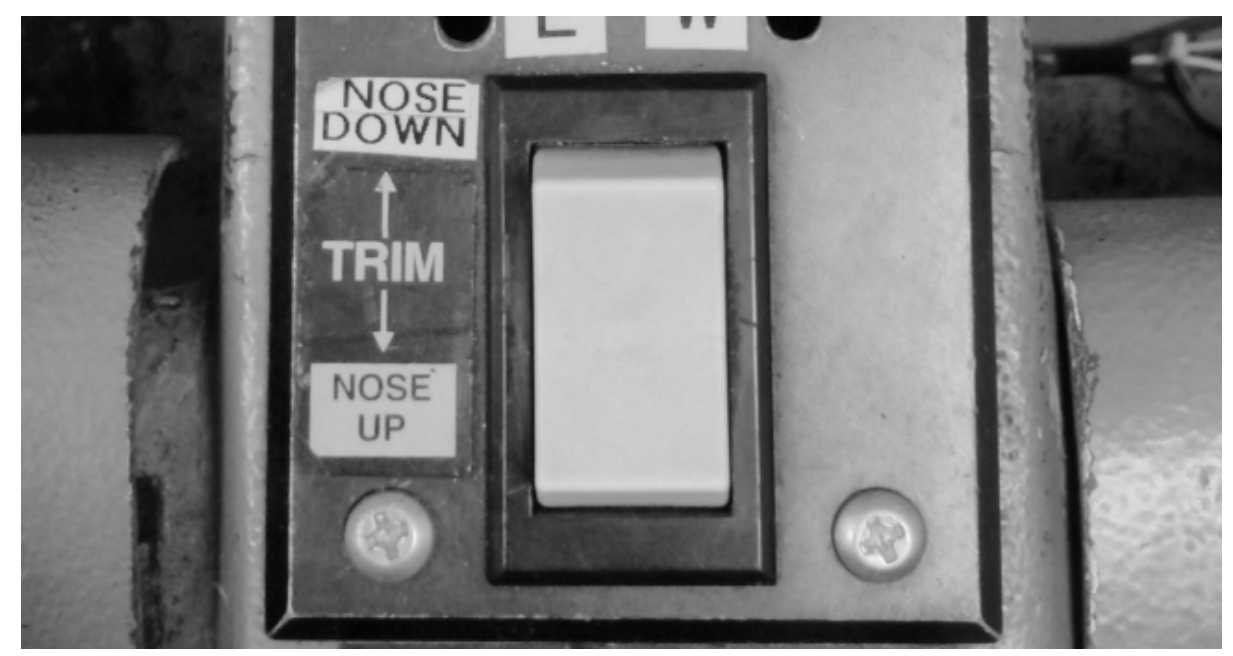

Figure 2.6: Switch for electric trim system.

Section 2.3.3.

For the control of the flaps, the Katana aircraft contains a flaps controller box, shown in Figure 2.7. The flaps controller box contains a three-position switch which corresponds to the three configurations of flaps available to the aircraft: clean/no flap configuration, takeoff flap configuration, and full flap configuration. The flaps controller box connects to the flap motor which actuates the flaps by adjusting the position of a control rod. The position of the control rod is measured by use of contact switches within the actuation system which allow for both proper positioning of the flaps as well as feedback to the LEDs located on the flaps controller box which indicate the position of the flaps. To replicate this setup in the simulator, the flaps controller box was connected directly to the control Arduino for sensing the position of the switch and controlling the LEDs. 


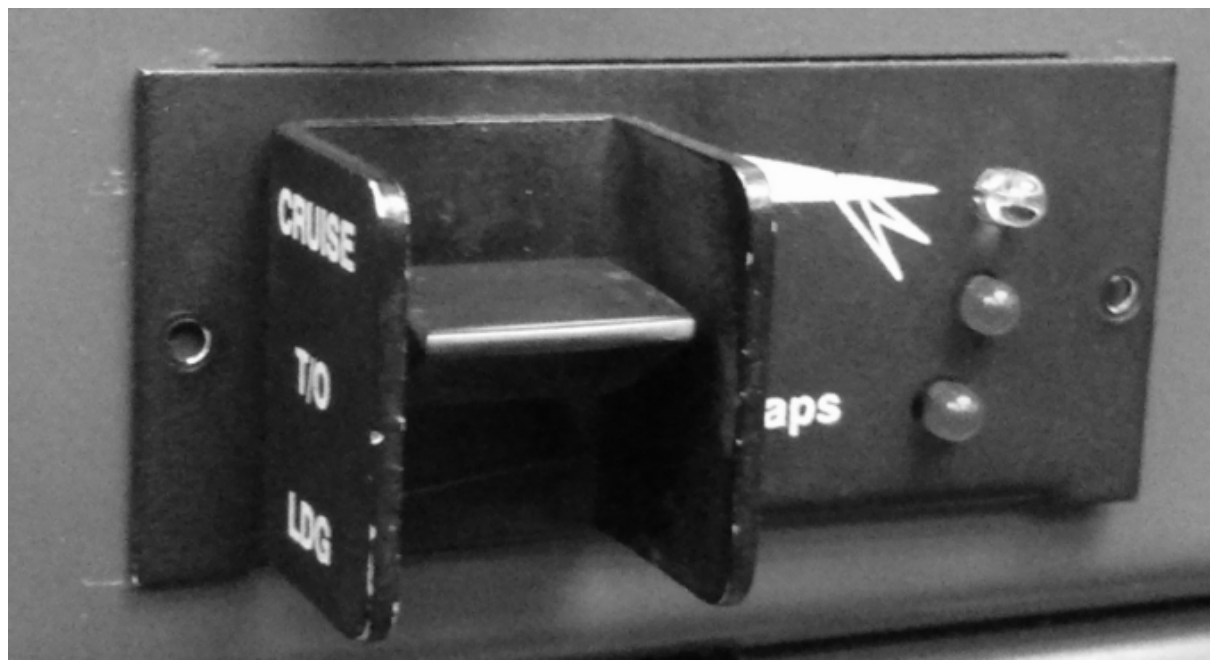

Figure 2.7: Flaps controller box.

\section{Powerplant}

Control of the throttle, propeller speed, carburetor heat, choke, cabin heat, and parking brake are achieved through cables that run from controls in the cabin, through the firewall, and to the respective devices in the powerplant. To maintain the authentic feel of the controls in the KatanaSim, the cables were maintained from inside the cabin, through the firewall to where they connect to a standard single-turn $10 \mathrm{k} \Omega$ linear rotary potentiometers with custom extension arms, as shown in Figure 2.8. The cables typically use roughly 60 to 70 degrees of potentiometer range. These potentiometers have an input voltage of $5 \mathrm{VDC}$, and thus output a 0 to 5 VDC analog signal that can be read by the control Arduino.

\section{Brakes}

In planning the brakes, it was decided that the original brake pedals, reservoir, and lines would be used along with aircraft grade brake fluid to provide the KatanaSim with realistic feeling brakes. As the Katana has independent left and right toe 


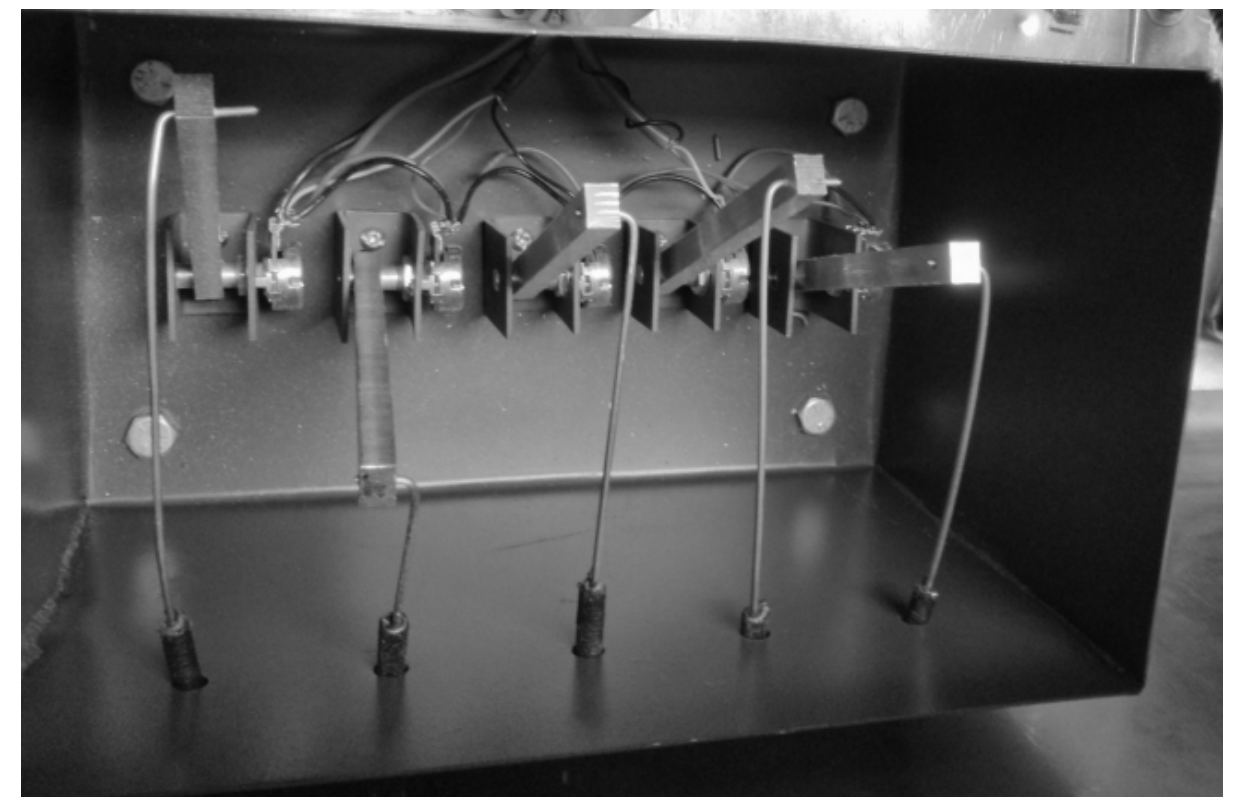

Figure 2.8: Single-turn potentiometers measuring powerplant inputs.

brakes, two independent setups were required. The system, implemented by Suzanne Swaine [24], involved a pressure transducer connected to each brake line. The two pressure transducers, which output 0 to $5 \mathrm{VDC}$ analog signals, were then wired to the control Arduino.

\subsubsection{Instruments and Avionics}

As with most general aviation aircraft, the flight instruments in the Katana operate by sensing stagnation pressure, dynamic pressure, or gyroscopic motion. In order to use original instruments, the KatanaSim would need to stimulate the instruments by actively controlling the pressure within each instrument, as well as utilize some means of stimulating the gyroscopic instruments including the artificial horizon, turn coordinator, and heading indicator. Unfortunately this was not feasible within the constraints of the project; instead, commercially-available simulated instruments were purchased. The practice of simulated instrument is more consistent with other 
simulator developers.

Suzanne Swaine led a process to find commercially-available simulated instruments that best match the Katana specific instruments [24]. As a result, the instruments for monitoring the status of the powerplant were acquired from Simkits [29], while the navigation instruments and the flight avionics were acquired from Flight Illusion [30]. This selection is shown in Figure 2.9.

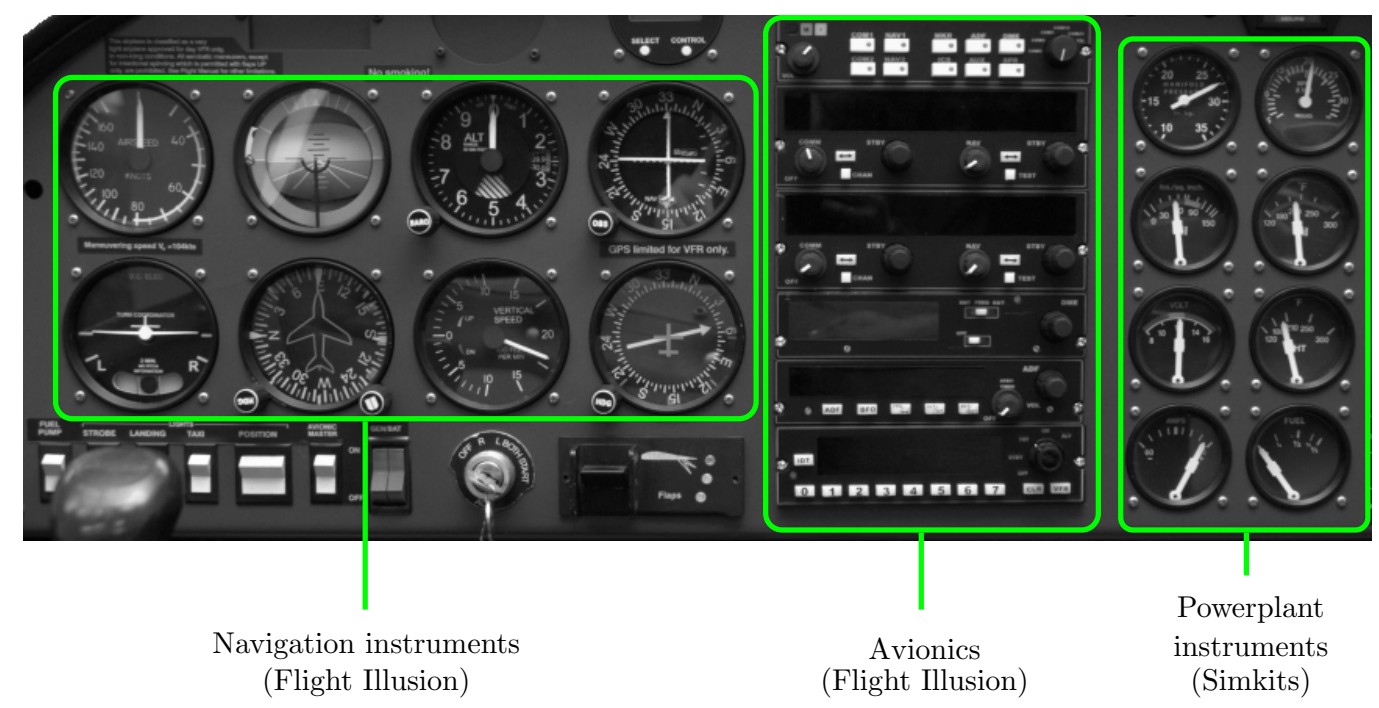

Figure 2.9: Simulated components on instrument panel.

The Simkits instruments connect directly to the computers by USB, which provides power and signals to each device. The Flight Illusion instruments each connect to a central interface by ribbon cable. This central interface connects the devices to the computers by USB, but is externally powered by both a 12 VDC and 5 VDC input. 


\subsubsection{Electrical Controls}

The original electrical components, including the ignition switch, the instrument panel switches, and the annunciator lights were used and connected to the control Arduino. The exception to the use of original electrical components is the circuit breakers.

\section{Circuit Breakers}

The original circuit breakers trip at amperage levels that range from $1 \mathrm{~A}$ to $40 \mathrm{~A}$. As a means of avoiding such high amperage levels, simulated circuit breakers were acquired. The Klixon 3SB series simulator circuit breakers [31] offer the look and feel of aircraft circuit breakers while offering fast trip response with low current draw at 24 VDC. These circuit breakers also have auxiliary terminals for sensing when the circuit breakers have been tripped, thereby allowing the circuit breakers to be tripped at one voltage, while the state is tested at another voltage. This configuration is shown in Figure 2.11.

As previously noted, the Arduino is only capable of outputting 5 VDC. To achieve the voltage required for tripping the circuit breakers, an electrical interface was developed by Fred Barrett ${ }^{2}$. To trip the circuit breakers from the instructor Arduino, a reed relay was connected to both an output signal from the Arduino and a 24 VDC power source, and then connected to the terminal screws on the circuit breaker. When the Arduino outputs 5 VDC, the reed relay closes an internal switch which allows the 24 VDC to pass through the circuit breaker, causing the circuit breaker to trip. The internal switch remains closed until the Arduino stops the 5 VDC input to the reed relay.

\footnotetext{
${ }^{2}$ Electrical engineer who supported the development of the instrumentation interface panel.
} 

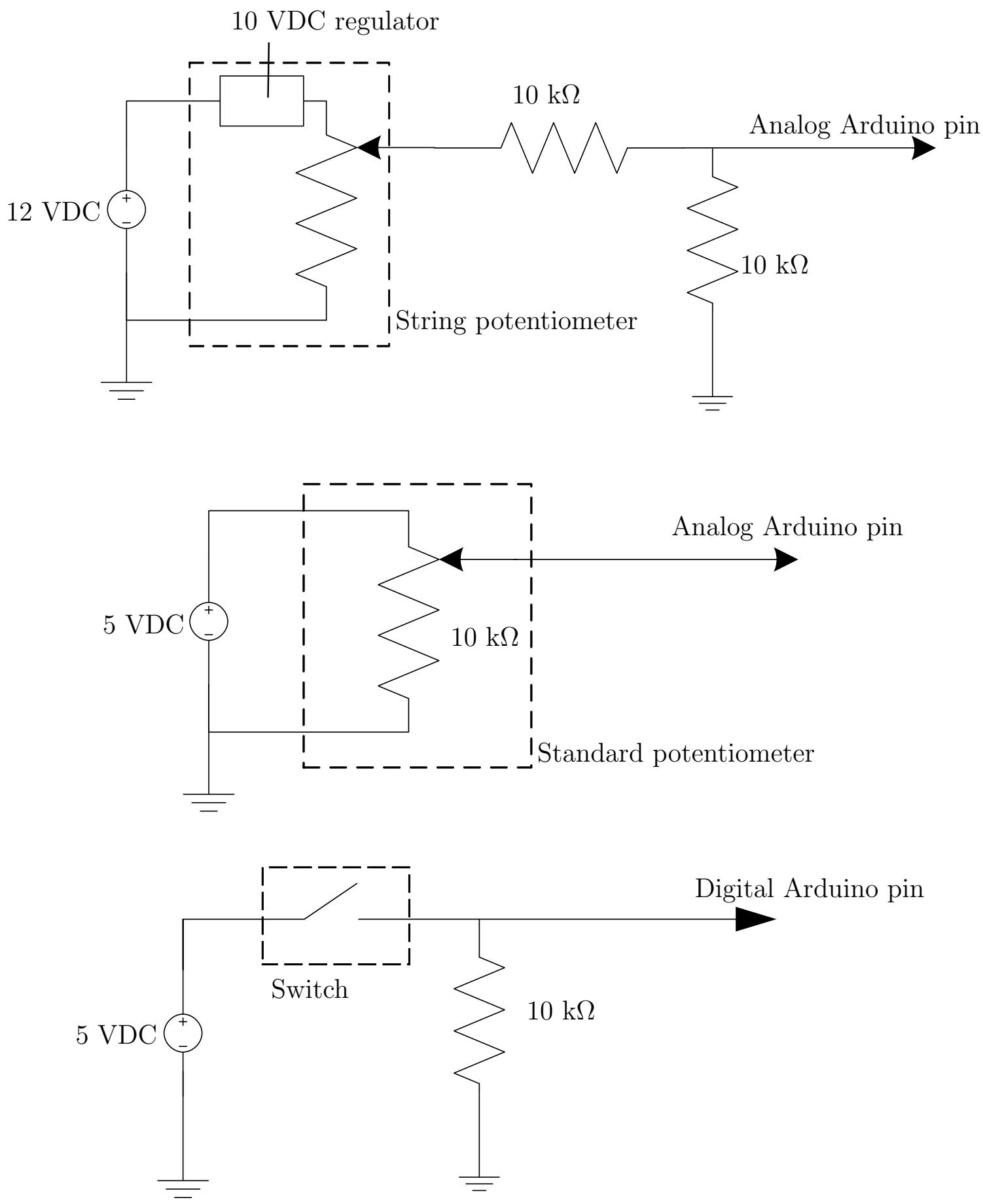

Figure 2.10: Circuit layout of string potentiometers (upper), standard rotary potentiometers (middle), and switches (lower). 


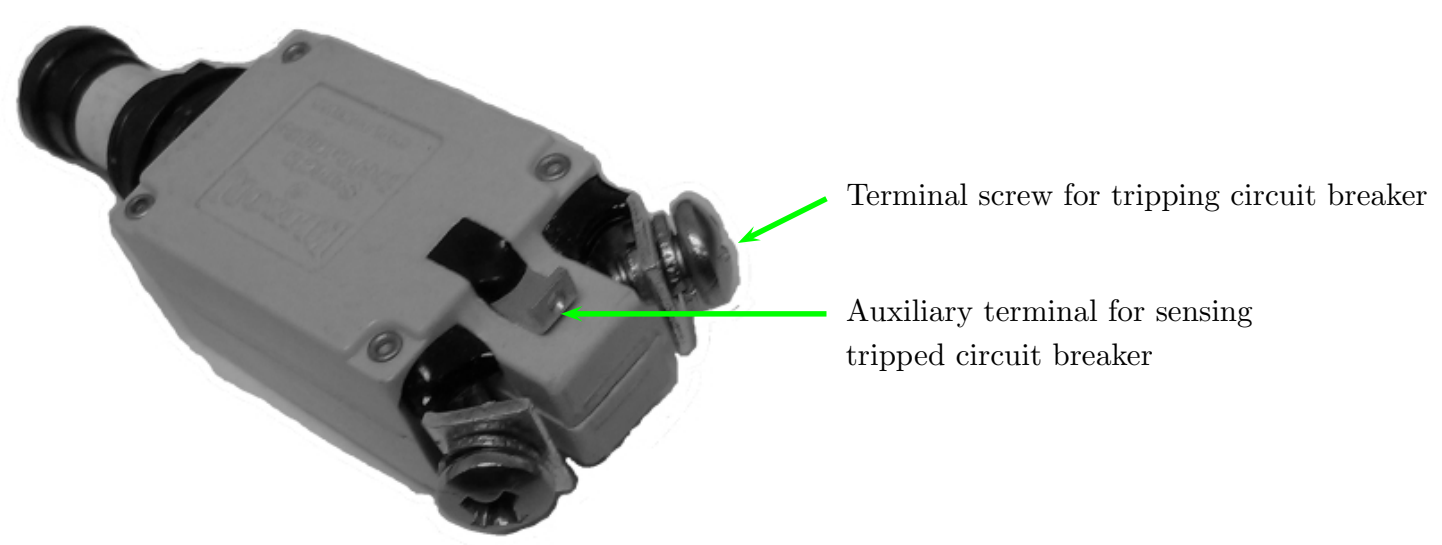

Figure 2.11: Klixon 3SB simulated circuit breaker.

When the circuit breaker is tripped, either by the instructor Arduino or pulled by the pilot, the control Arduino reads this new status and passes the status to the virtual environment, resulting in the appropriate simulated failure.

\section{Annunciator Lights}

The instrument panel in the Katana contains three annunciator lights: fuel pressure warning light, generator warning light, and canopy warning light. These lights are illuminated by 24 VDC. As the KatanaSim does not currently use the canopy, the mechanism is not in place to display the canopy as closed; thus only the fuel pressure and generator warning lights have been activated. These are connected to the control Arduino using the reed relays as described above for the circuit breakers.

\section{Power and Wiring}

To provide power to all of the components that were previously discussed, a panel was put together by Fred Barrett to provide three power supplies: 5 VDC, 12 VDC, 
and 24 VDC. The panel, shown in Figure 2.12, houses the three power supplies, each with its own power switch, as well as the reed relays, the voltage dividers, and two Arduinos - one for measuring the analog and digital inputs, and the other for tripping the circuit breakers.

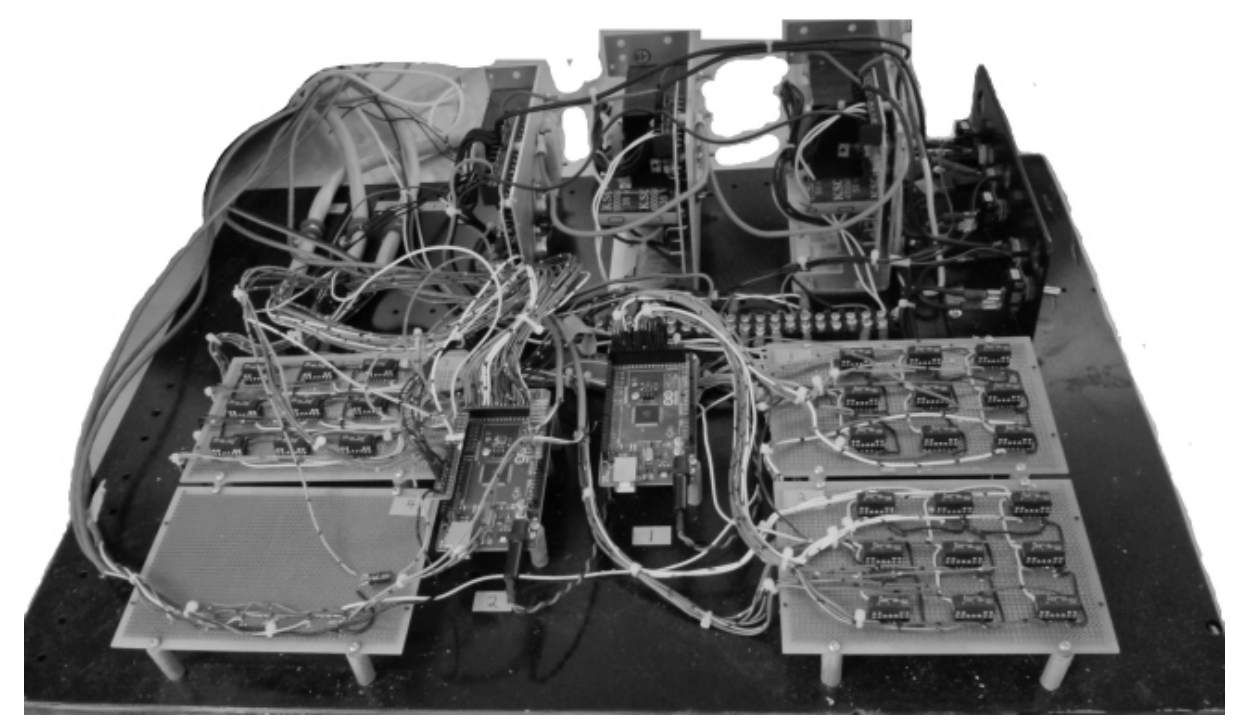

Figure 2.12: Power and wiring panel.

\subsubsection{Computer Architecture}

For the KatanaSim flight simulator, it was decided that four computers would be utilized. This computer architecture, depicted in Figure 2.13, would allow the resources of each computer to focus on separate needs. The first computer is the main computer which is essentially the brain of the simulator. This first computer is responsible for receiving user inputs from the control Arduino, and calculating the flight model. The second computer is responsible for the accessory components, to relieve some of the processing burden from the main computer; this second computer handles communications with the simulated instruments and avionics. The sole purpose of the third computer is to provide the visual cueing for the flight model 
calculated by the first computer; as will be discussed further in Section 2.3.6. Finally, the fourth computer, the IOS, is used for controlling flight scenarios, for tripping the circuit breakers at the instructor's discretion, and for controlling the motion base.

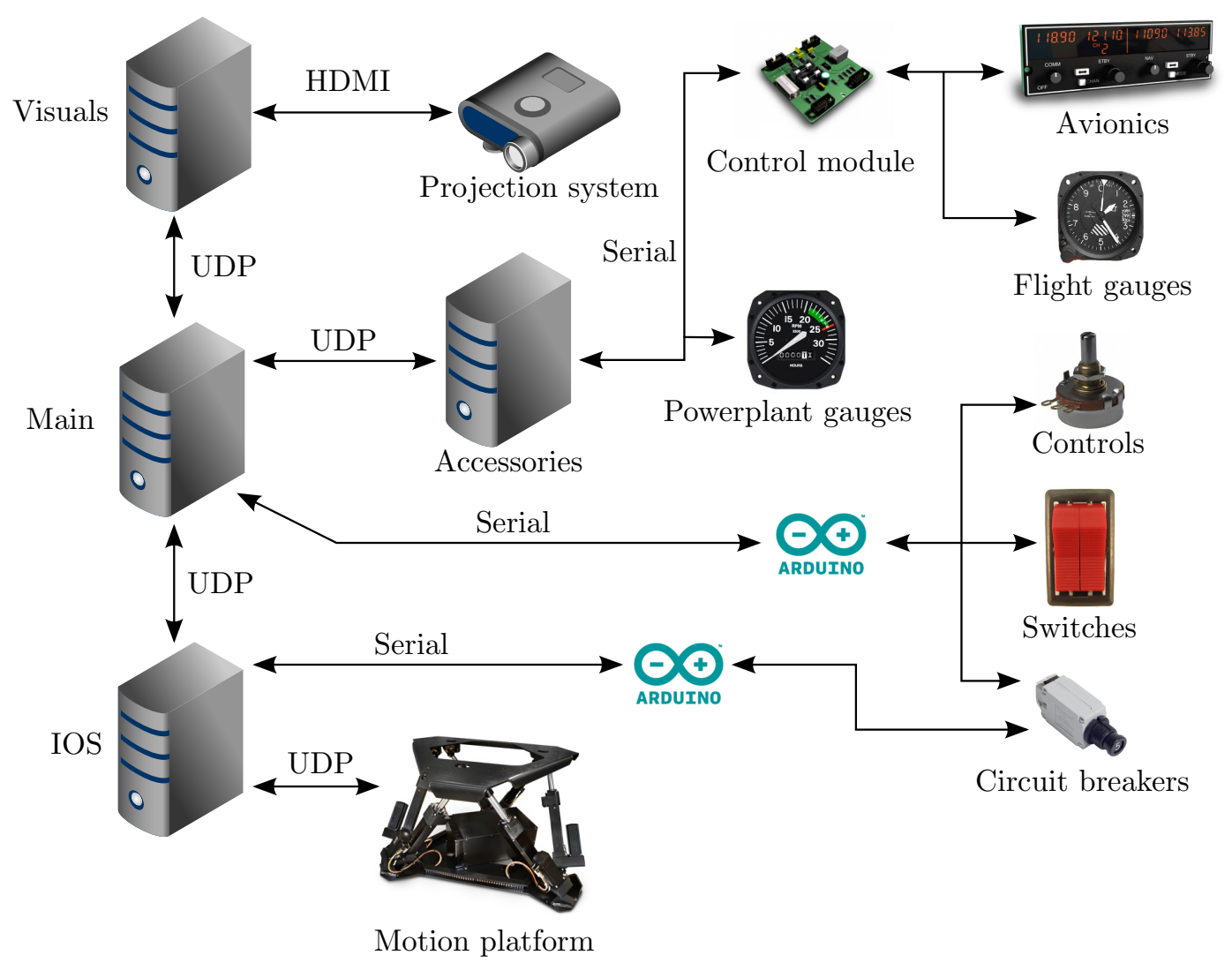

Figure 2.13: Computer architecture.

\subsubsection{Software}

The KatanaSim operates using three main types of software: the flight simulation environment, which calculates the flight model and develops the visuals; software for interfacing the instruments and avionics [24]; and software developed in-house specifically for the KatanaSim. The software developed in-house includes an interface 
for communication between X-Plane and the Arduino, a tool for calibrating the analog control inputs, a tool for tripping individual circuit breakers on command, and a tool for operating the motion base (to be discussed further in Chapter 3).

\section{Simulation Environment}

In an attempt to develop the simulator using COTS components, it was decided that the flight simulation environment should be selected from commercially-available flight simulation software. The two leading products available are Microsoft Flight Simulator (MFS) and X-Plane by Laminar Research. While both products offer exceptional virtual environments, it was determined that X-Plane was the more suitable choice due to the software allowing for open-source development for flight models and software add-ons, the large community of developers available to provide

assistance, and a more accurate means of calculating the flight model [32]. Flight models in MFS make use of lookup tables to determine how the flight model should perform under different conditions. This method requires large quantities of data, and leads to inaccuracies for conditions outside of those tables, as interpolation or extrapolation are applied. On the other hand, X-Plane uses blade element theory, which separates each part of the plane into smaller sections, then combines calculations performed on each small section to get the behaviour of the flight model as a whole. As a result, X-Plane provides a more accurate flight model in unusual flight conditions.

\section{Flight Model}

Development of the flight model was initiated by Suzanne Swaine [24]. Flight model development began with sourcing data from Diamond Aircraft documentation such as the Pilot Operation Handbook, the Illustrated Parts Catalogue, and the Aircraft 


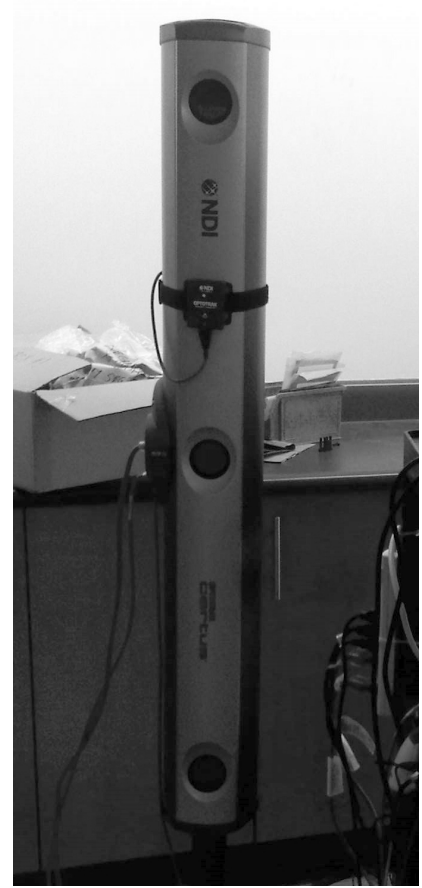

Figure 2.14: Optotrak camera.

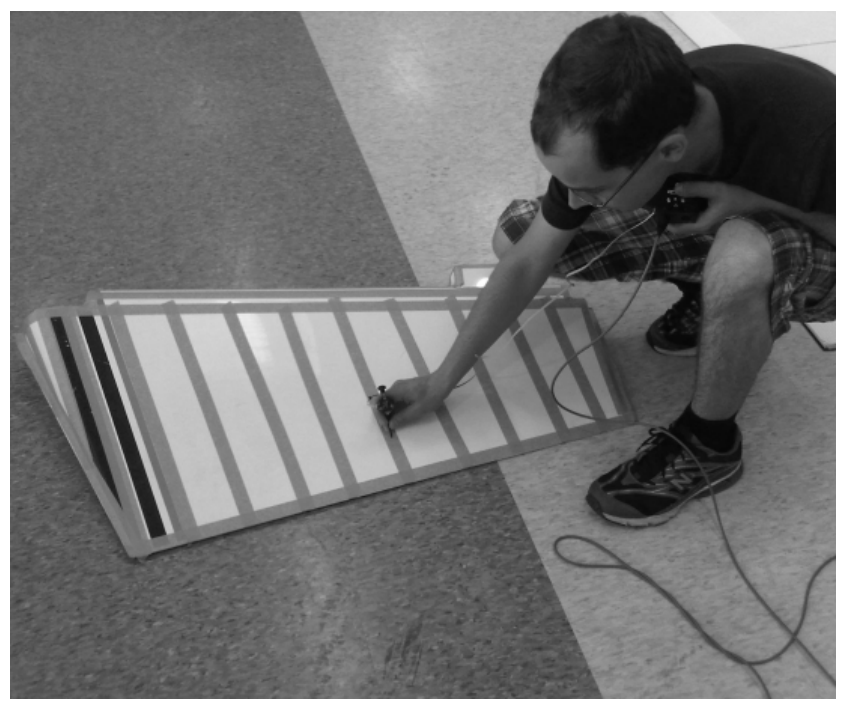

Figure 2.15: Rudder measurement using Optotrak system.

Maintenance Manual. As X-Plane uses blade element theory, a vital component of the flight model is accurate modelling of the aircraft geometry. Aircraft geometry was obtained using an Optotrak Certus motion capture system. The Optotrak system uses a three-lens IR camera (Figure 2.14) in combination with a three-marker digitizing probe to obtain 3D coordinates for the tip of the probe. The Optotrak system was used to map coordinates on the control surfaces and canopy. Figure 2.15 demonstrates the use of the probe in mapping coordinates on the surface of the rudder.

Due to difficulties in matching the performance of the Katana aircraft, development of the flight model is currently incomplete [24]. The simulator currently uses a Katana flight model developed by an X-Plane hobbyist from the X-Plane forums [33]. 


\section{X-Plane - Arduino Interface}

Having selected X-Plane as the flight simulation environment, software was then developed for interfacing X-Plane to the control Arduino. X-Plane provides a Software Development Kit (SDK) to allow developers to access memory locations within X-Plane for reading and writing parameters used for calculating the flight model. Using this SDK, a dynamic-linked library (DLL) was developed in C++ to read serial inputs from the control Arduino, interpret the inputs, and change the corresponding X-Plane parameter. Furthermore, the DLL monitored the state of certain properties within X-Plane to provide the control Arduino with regular updates to flap position, tripped position, annunicator warning states, and airspeed.

The DLL interpretation of inputs varied by whether the input was digital or analog. All the switches as well as the status of the auxiliary terminals of the circuit breakers were measured digitally. On every call to the DLL from X-Plane, the DLL checks to see if any of the digital inputs have encountered a change in state, and applies the change(s) accordingly.

The string potentiometers, standard potentiometers, and pressure transducers all provided analog inputs, and thus had to be calibrated for proper measurement. The Arduino reads 0 to 5 VDC input as integers between 0 and 1023. As the full range of each component was not utilized, a tool was developed for calibrating these analog control inputs. The tool asked the user to move through the entire accessible range for each control input, and then saved the corresponding minimum and maximum integer values for each control input to a configuration file that the DLL utilizes. The DLL then applies interpolation within the range to find the corresponding input for X-Plane, typically a ratio between 0 and 1 , or between -1 and 1 . 
For the control Arduino, $\mathrm{C}++$ code was developed to read the digital and analog inputs, then send the data as a packet of integers through the serial port. The control Arduino simultaneously monitors the receive buffer for updates from the DLL. These updates are then output through digital ports either through PWM signals for the trim and flaps displays, or a direct 5 VDC for the reed relays to the annunciator lights.

\section{IOS Circuit Breaker Control}

Software was developed for the IOS such that the instructor can trip any individual circuit breaker. This tool, developed in C\# and shown in Figure 2.16, responds to the user clicking on a particular circuit breaker by sending a command via serial communication to the instructor Arduino. The instructor Arduino reads in these commands and then sends a 5 VDC signal through the reed relay corresponding to the selected circuit breaker. This results in the circuit breaker getting tripped after a maximum delay of just under 3 seconds, as specified by the manufacturer. The instructor Arduino resets the signal after a period of roughly 5 seconds, though the circuit breaker itself has to be reset manually.

\subsubsection{Visual Cueing}

At the project definition stage, Ottawa-based B-Con Engineering Inc. [34], a company that specializes in the design and manufacture of advanced optical components, committed to developing an innovative projection system for use with the KatanaSim. The concept was to use a custom-designed projection lens fitted to a standard data projector and a mirror such that outside visuals could be back-projected onto the original Katana canopy that would be treated with 


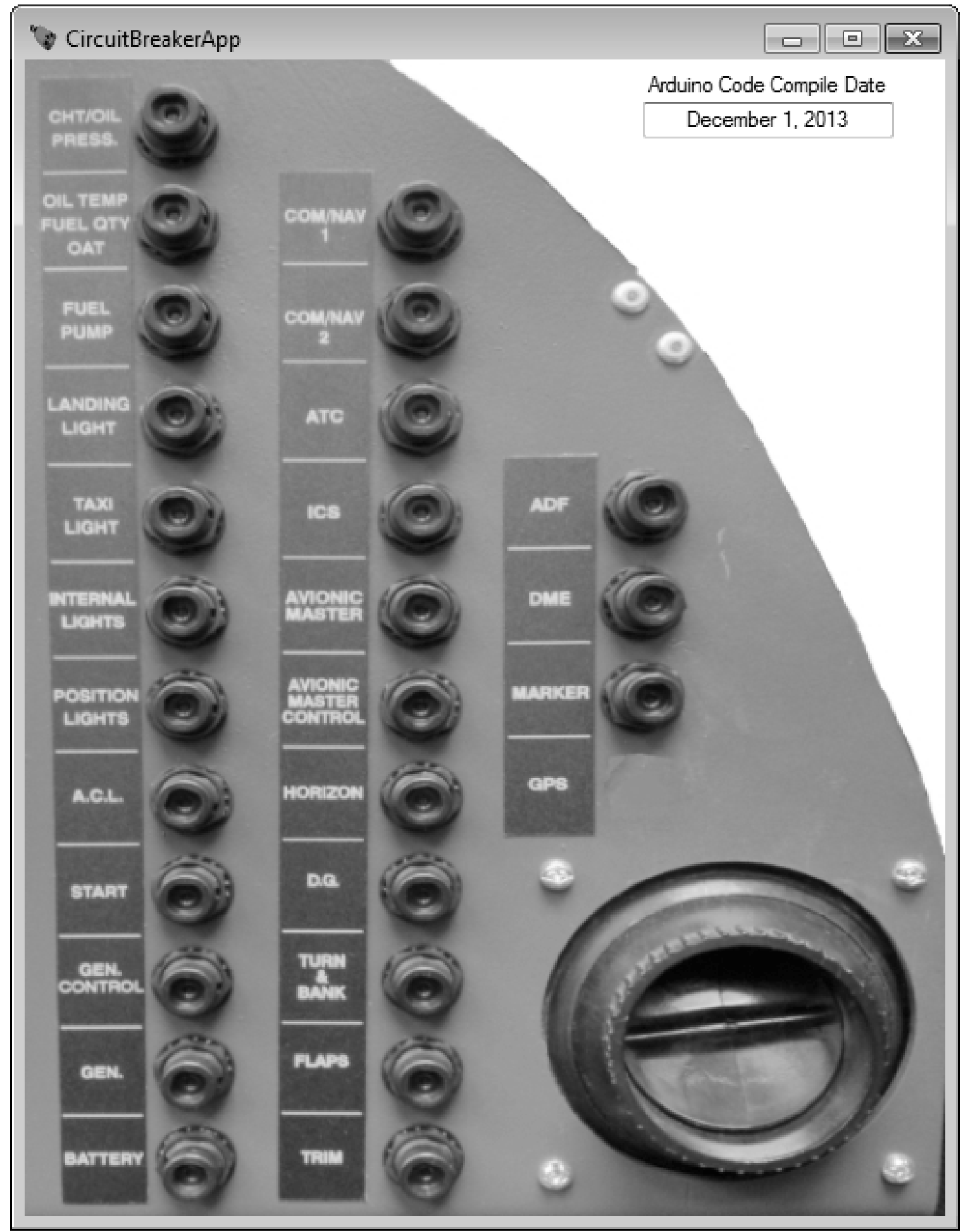

Figure 2.16: Circuit breaker control program. 
an opaque coating. The attractive feature of this was that it had the potential to create a fully-immersive environment where the trainee in the cockpit would experience almost the same field of view that would be available in the actual aircraft.

However, midway through the project, when it became apparent that B-Con Engineering Inc. was not going to provide the visual system, an alternative method for providing visual cues had to be developed. Several conventional options, including an arrangement of multiple digital displays as well as flat and curved multi-projector systems, were considered. However, since the development of a projection system was beyond the scope of the original project, a relatively-simple system that would satisfy the immediate objectives of the KatanaSim project, without over-taxing available resources, was selected. This solution comprised of a screen mounted in front of the cockpit, as shown in Figure 2.17, with a projector mounted behind and above the cockpit.

For the screen, white foam board was selected due to a combination of reflectivity, rigidity, weight, size availability, and cost. The design called for the screen to be secured to two crossbeams that would be secured to two side frames mounted to the front support frame of the simulator. As large vibrations of the screen would negatively impact the visual cueing, the frame supporting the screen was designed to experience minimal deflections when the platform was subjected to the maximum translational accelerations. It was decided that for worst-case translational acceleration of $0.6 \mathrm{~g}$, with a safety factor of 2 , the screen should undergo a deflection at the top of the screen of less than $5 \mathrm{~mm}$, with respect to the base support structure. Studies have shown a tendency for increased motion sickness as deflection in the visuals exceed $5 \mathrm{~mm}$ [35]. It should be noted that the safety factor is actually larger than 2 as in actual operation the platform will be limited to significantly less than 


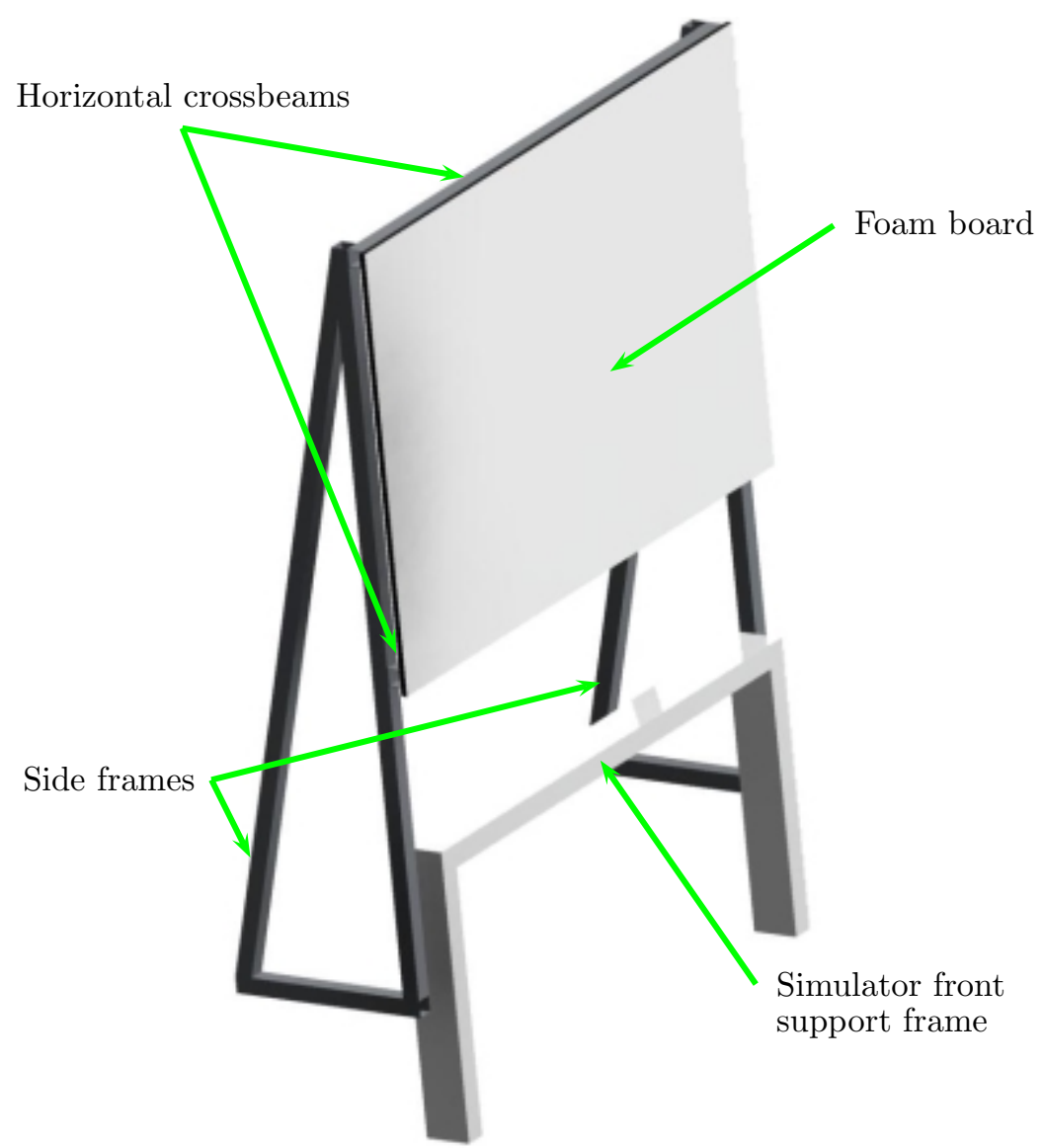

Figure 2.17: Projection screen concept.

$0.6 \mathrm{~g}$ of translational acceleration, as will be discussed in Chapter 3.

Using finite element analysis (FEA), it was determined that supporting the screen with two vertical beams would result in a maximum displacement of $8.12 \mathrm{~mm}$. As this resulted in a larger-than-desired displacement, the structure was redesigned to provide more rigidity perpendicular to the screen. This was accomplished by welding two lengths of tubing to each of the vertical beams to create a triangular structure, resisting deflection perpendicular to the screen. The result of FEA performed on this new design was a maximum displacement of $2.89 \mathrm{~mm}$, thereby meeting the design criterion. 
The projector used for the KatanaSim was an Epson PowerLite Home Cinema 3010 1080p 3LCD Projector, and was provided by B-Con. In order for the visuals to be properly projected on the screen, the projector needed to be mounted so that it had an appropriate combination of height and angle for the visuals to clear all obstacles (such as the instrument panel and cover, and the wet compass mounted on top), and that the mount would resist large vibrations. The projector required a sufficiently-rigid mount that would conform to the shape of the rear of the aircraft, to which it would be secured. The selected design comprised of sheets of 11 gauge hot rolled steel welded together to provide a secure base for the projector. This design is shown in Figure 2.18.

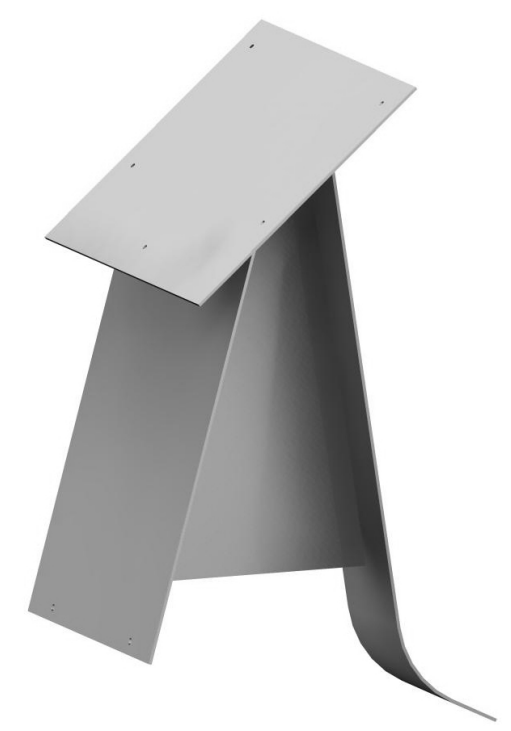

Figure 2.18: Projector mount.

For worst-case translational accelerations of $0.6 \mathrm{~g}$, with a safety factor of 2 , the maximum deflection in the projector should result in less than $0.5 \mathrm{~mm}$ of displacement of the visuals on the screen. Based on the schematic provided in Figure 2.19, the displacement $b$ of the visuals is related to the deflection $a$ of the projector by the 
throw distance $L$ of the projector and the distance $l$ between the front and rear mounting screws of the projector. Through similar triangles, the displacement of the visuals can be found as follows:

$$
b=\frac{L}{l} \cdot a
$$

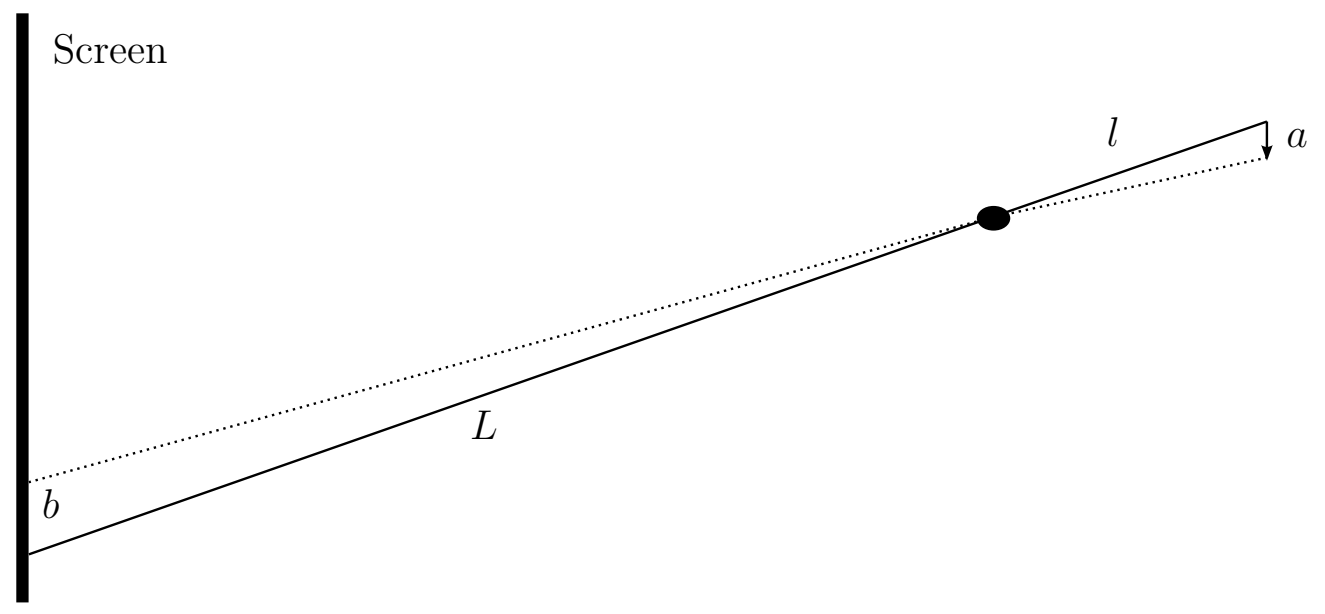

Figure 2.19: Effect of projector mount deflection on visuals.

For the KatanaSim, the projector has a throw distance of $1.8 \mathrm{~m}$, with the mounting screws located $230 \mathrm{~mm}$ apart. Therefore the rear of the projector can sustain a maximum displacement of approximately $0.064 \mathrm{~mm}$ in order to keep the displacement of the visuals under $0.5 \mathrm{~mm}$. From the FEA performed on the current design under extreme conditions, the projector mount would encounter a maximum displacement of $0.05 \mathrm{~mm}$.

\subsubsection{Audio Cueing}

The final component of the fixed-base flight training device is the audio. For certification as an FTD, Transport Canada requires the simulator to demonstrate "significant cockpit sounds which result from pilot actions corresponding to those of the 
airplane" [16]. To meet this requirement with the KatanaSim, the Z523 Speaker System by Logitech [36] was selected as it offers a 2.1 speaker system including a subwoofer at an economical price. The two speakers were securely fastened to the outside of the firewall at the front of the aircraft, and the subwoofer was fastened to the top plate of the support structure [24]. The audio system is connected to the main computer discussed in Section 2.3.4 and uses the sound effects from X-Plane.

\subsection{KatanaSim Flight Training Device}

The combination of these physical structures and simulator subsystems form the KatanaSim fixed-base FTD. The assembled simulator is shown in Figure 2.20.

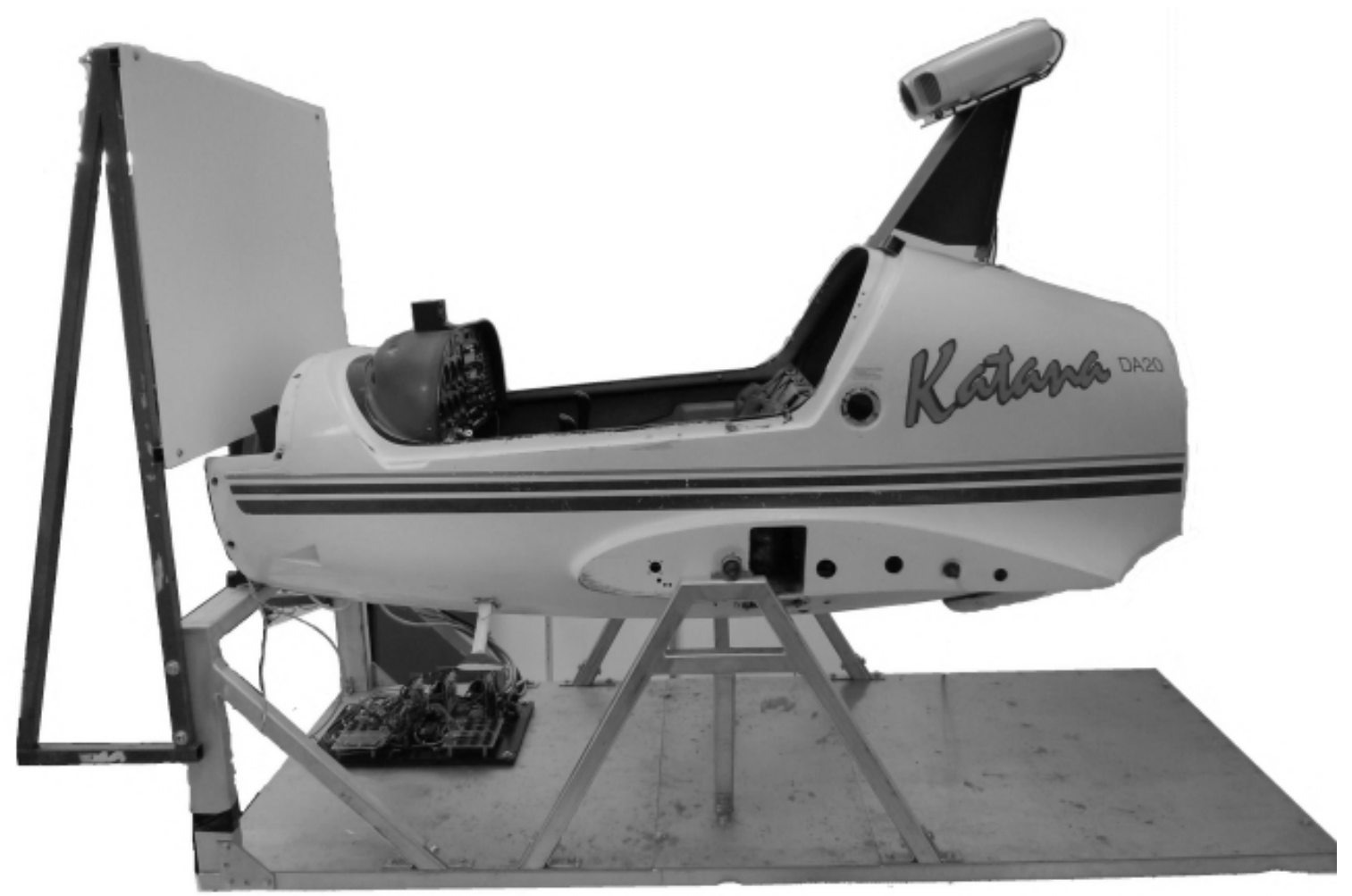

Figure 2.20: KatanaSim fixed-based flight simulator. 


\section{Chapter 3}

\section{Motion Integration}

For a flight simulator to be certified as a full-flight simulator, motion cueing must be present. This chapter will focus on development and implementation of motion cueing for the KatanaSim. Specifically the focus is on making efficient use of the limited motion of a small motion base to most effectively replicate motion characteristics of the Katana aircraft. This motion is obtained by mounting the KatanaSim on a commercial motion base and then tuning the motion drive algorithm specifically for the flight characteristics of the Katana.

\subsection{Motion Base}

The motion for the KatanaSim is provided by a Moog 6DOF2000E motion base [37] located in the Carleton University Applied Dynamics Laboratory. The motion base is a Gough-Stewart platform capable of handling $1160 \mathrm{~kg}$ of gross moving mass and is capable of achieving the kinematic amplitudes listed in Table 3.1. The motion base uses the body-fixed coordinate system shown in Figure 3.1, where $x$ is positive in the forward (or surge) direction, $y$ is positive to the right in the sway direction, and $z$ is positive downwards in the heave direction. The orientation is defined by the $z-y-x$ Euler angle convention, or yaw-pitch-roll; this is the same convention 
Table 3.1: Moog 6DOF2000E specifications [37].

\begin{tabular}{|l|c|c|c|}
\hline Motion & Maximum Excursion & Maximum Velocity & Maximum Acceleration \\
\hline \hline Surge $(x)$ & $0.25 \mathrm{~m}$ & $0.50 \mathrm{~m} / \mathrm{s}$ & $6 \mathrm{~m} / \mathrm{s}^{2}$ \\
Sway $(y)$ & $0.25 \mathrm{~m}$ & $0.50 \mathrm{~m} / \mathrm{s}$ & $6 \mathrm{~m} / \mathrm{s}^{2}$ \\
Heave $(z)$ & $0.18 \mathrm{~m}$ & $0.30 \mathrm{~m} / \mathrm{s}$ & $5 \mathrm{~m} / \mathrm{s}^{2}$ \\
Roll $(p)$ & $21 \mathrm{deg}$ & $30 \mathrm{deg} / \mathrm{s}$ & $500 \mathrm{deg} / \mathrm{s}^{2}$ \\
Pitch $(q)$ & $22 \mathrm{deg}$ & $30 \mathrm{deg} / \mathrm{s}$ & $500 \mathrm{deg} / \mathrm{s}^{2}$ \\
Yaw $(r)$ & $22 \mathrm{deg}$ & $40 \mathrm{deg} / \mathrm{s}$ & $400 \mathrm{deg} / \mathrm{s}^{2}$ \\
\hline
\end{tabular}

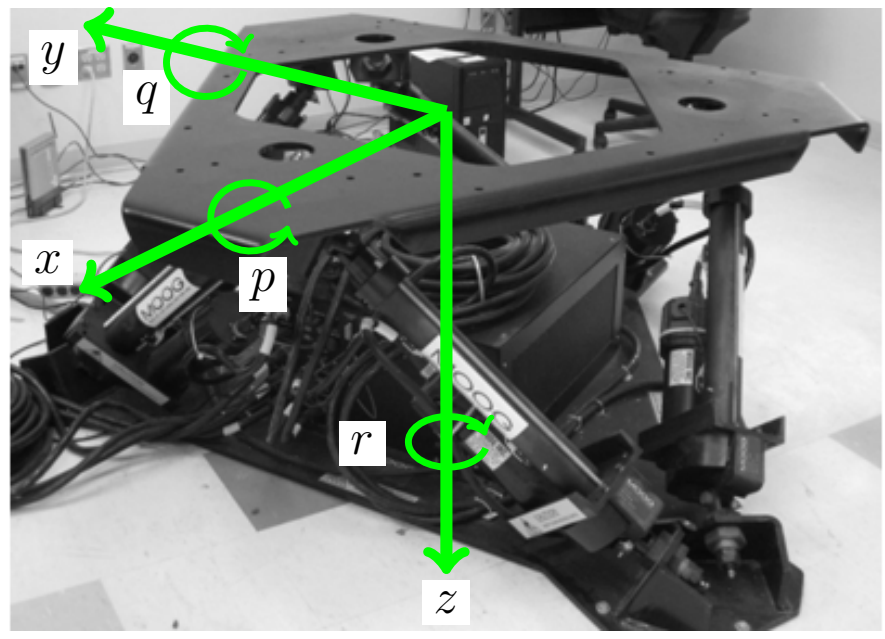

Figure 3.1: Body-fixed coordinate system on Moog motion base.

used for aircraft principal axes.

As mentioned in Section 2.1, the KatanaSim support structure was designed for the highest inertial loads the motion base could induce. While the base frame on the support structure was designed to be secured to the custom flying frame found on the Moog motion base in the Applied Dynamics Laboratory, the final simulator design called for the use of the original Moog flying frame. The Moog flying frame provides a set number of mounting points in fixed positions. These mounting points did not provide adequate mounting locations for the base frame of the support 
structure, thus a series of structural support c-channels were mounted to the flying frame, allowing for full support of the KatanaSim base frame, as shown in Figure 3.2. The fully-assembled structure can be seen in Figure 3.3.

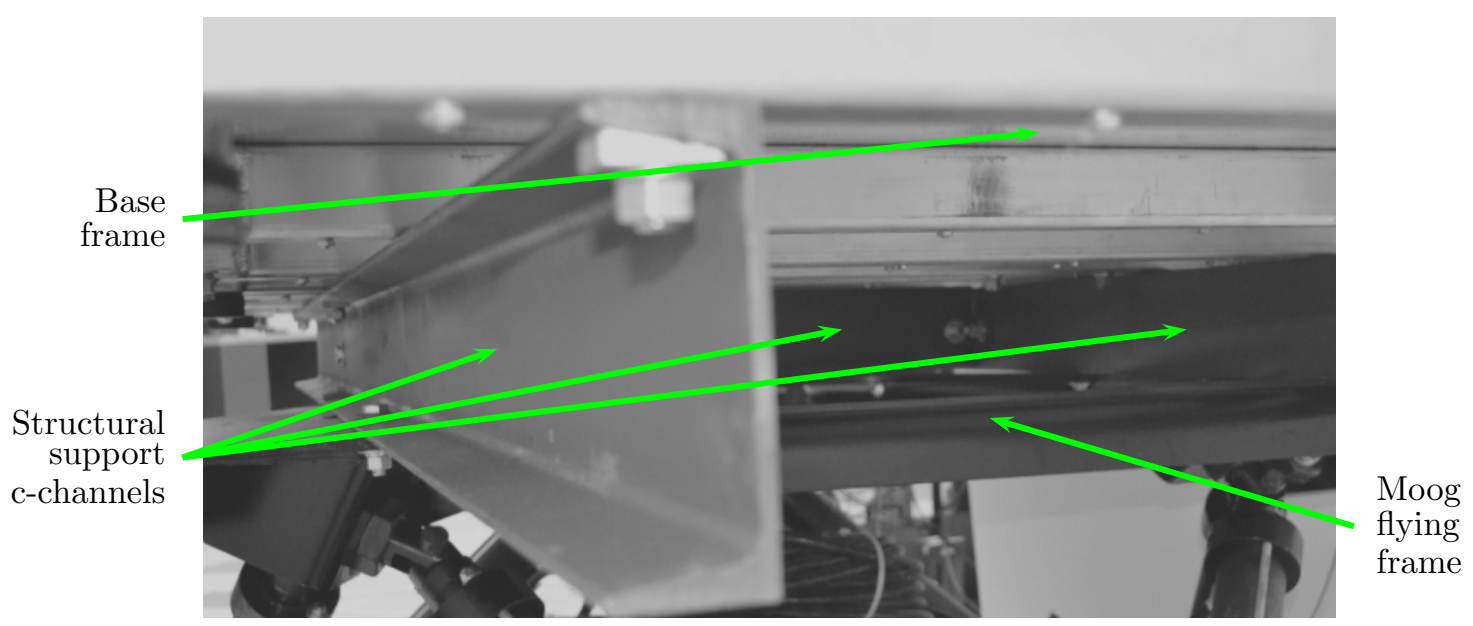

Figure 3.2: Support structore interface to motion base.

Control of the motion base is accomplished by network communication through the user datagram protocol (UDP) to the motion control computer. The motion control computer requires communication from the host computer at $60 \mathrm{~Hz}$ and runs in one of three possible modes: degree-of-freedom (DOF) input (platform angles and positions), actuator length input, and motion drive algorithm (MDA) input. The DOF and actuator length input modes apply the unfiltered input and go to the desired state, or the closest extreme, at the fastest rate possible, leading to potentially jerky or hazardous motions. The MDA mode takes in the inputted data and filters the data, in a process referred to as washout, to ensure smooth and attainable motion. 


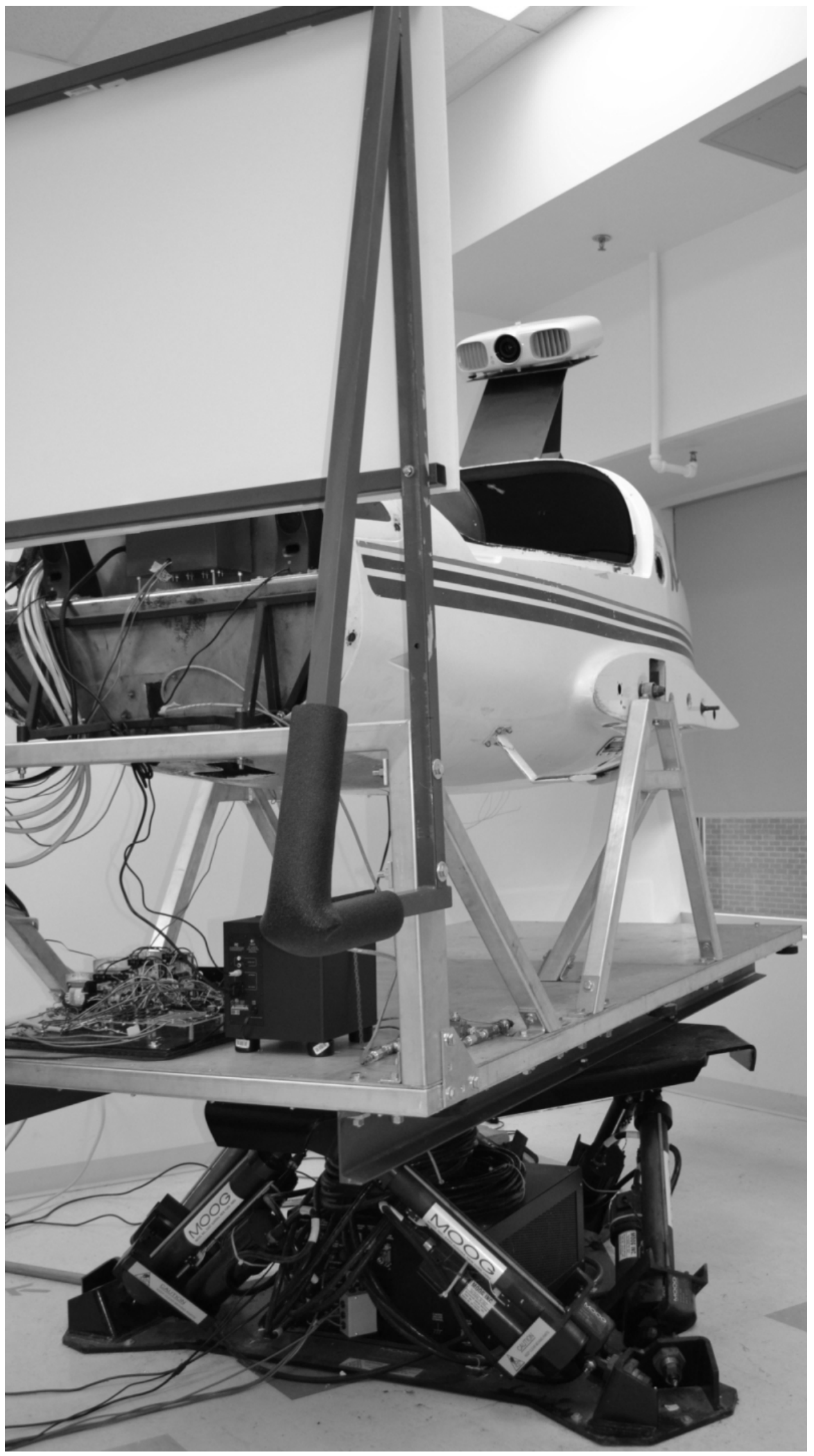

Figure 3.3: KatanaSim full-flight simulator. 
Table 3.2: Katana flight test motion extremes.

\begin{tabular}{|l|c|c|c|}
\hline Motion & Maximum Excursion & Maximum Velocity & Maximum Acceleration \\
\hline \hline Surge & - & - & $3.72 \mathrm{~m} / \mathrm{s}^{2}$ \\
Sway & - & - & $4.64 \mathrm{~m} / \mathrm{s}^{2}$ \\
Heave & - & - & $28.52 \mathrm{~m} / \mathrm{s}^{2}$ \\
Roll & $172.86 \mathrm{deg}$ & $156.70 \mathrm{deg} / \mathrm{s}$ & $152.53 \mathrm{deg} / \mathrm{s}^{2}$ \\
Pitch $^{*}$ & $82.72 \mathrm{deg}$ & $40.31 \mathrm{deg} / \mathrm{s}$ & $80.00 \mathrm{deg} / \mathrm{s}^{2}$ \\
Yaw $^{*}$ & - & $65.82 \mathrm{deg} / \mathrm{s}$ & $77.66 \mathrm{deg} / \mathrm{s}^{2}$ \\
\hline
\end{tabular}

* Orientation provided using $z-y-x$ Euler angle convention.

\subsection{Washout Algorithm}

As is almost always the case, the motion offered through the Moog motion base is significantly more limited than the motion available in the Katana aircraft, with typical aircraft motion extremes shown in Table 3.2. While the motion base can achieve peak surge and sway translational accelerations that exceed those typically experienced in the aircraft, the aircraft is capable of large translations and rotations which the platform is unable to reproduce.

In the simulator, both translational and rotational aircraft motions must be washed out through filters in order to fool the brain into sensing motions that are only partially sustained. This use of filters is a process known as washout. Typical washout filtering is achieved through linear filtering through the classical washout algorithm. Some advanced algorithms that are commonly implemented are the optimal control algorithm, utilizing a vestibular model to reduce pilot motion sensation error; and the adaptive algorithm with non-linear filters with variable parameters calculated in real time at each time step [38]. 


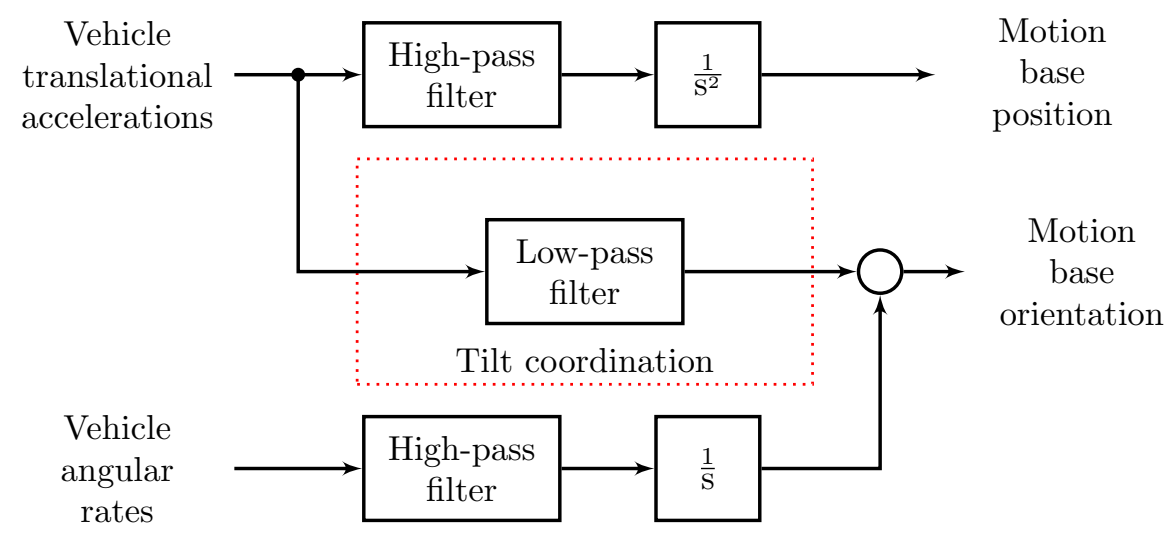

Figure 3.4: Classical washout algorithm block diagram.

\subsubsection{Classical Washout}

Classical washout is the most common approach and has been around the longest. A simplified schematic of the algorithm is shown in Figure 3.4. The classical washout algorithm takes the vehicle translational accelerations and angular rates and uses this information to adjust the motion base position and orientation. The angular rates are passed through a first-order high-pass filter which generates the onset cues, with the angular displacements getting filtered out before reaching platform limits [1]. These first-order high-pass filters are typically implemented in the following form:

$$
T_{H P_{\theta}}=\frac{s}{s+\omega_{\theta}},
$$

where the break frequency $\omega_{\theta}$ is determined from the maximum angular velocity $\Omega_{\max }$ and maximum angular displacement $\theta_{\max }$, as given by

$$
\omega_{\theta}=\frac{\Omega_{\max }}{\theta_{\max }}
$$

For translational accelerations, second-order high-pass filters are typically implemented, which generate the onset motion cues, and then these cues are washed out 
before reaching platform displacement limits [1]. These high-pass filters are given in the following form:

$$
T_{H P_{x}}=\frac{s^{2}}{s^{2}+2 \zeta_{x} \omega_{x} s+\omega_{x}^{2}},
$$

where the break frequency $\omega_{x}$ is given by

$$
\omega_{x}^{2}=\frac{a_{\max }}{x_{\max }}
$$

and the viscous damping is given by

$$
2 \zeta_{x} \omega_{x}=\frac{a_{\max }}{v_{\max }}
$$

While these high-pass filters apply motion cues for sudden changes, the platform displacement limits make sustained motions difficult [1]. As accurate motion cueing in the translational direction often requires more than the onset motion cues, sustained motion can be obtained by tilting the platform with respect to the gravity vector to provide a sense of sustained acceleration; this process is highlighted as tilt coordination in Figure 3.4. This is achieved through the implementation of a second-order low-pass filter on the translational acceleration to obtain the sustained accelerations, and then calculation of the associated rotation. This low-pass filter takes the following form:

$$
T_{L P_{x}}=\frac{w_{l p}^{2}}{s^{2}+2 \zeta_{l p} \omega_{l p} s+\omega_{l p}^{2}} .
$$

Unlike the high-pass filters, there are no direct formulas for obtaining the feedback coefficients. The break frequency and viscous damping for this low-pass filter must be selected such that the pilot does not receive false motion cues. These feedback coefficients should be tuned such that the tilt angular rate does not exceed 
$2 \mathrm{deg} / \mathrm{s}$, while any false translational accelerations caused by angular accelerations do not exceed $0.03 \mathrm{~m} / \mathrm{s}^{2}[39]$.

The classical washout algorithm is mathematically and computationally simple, as it requires very few differential equations [38]. Furthermore, selection and tuning of the algorithm parameters does not require complex modelling, allowing for simple adjustments to be made based on pilot feedback obtained during tuning. Limitations of the classical washout algorithm are that parameters are necessarily selected for worst-case manoeuvres, and limitations related to the use of linear filters to develop motion cues to deceive the nonlinear human perception mechanisms.

\subsubsection{Optimal Control Washout}

Much like the classical washout algorithm, the optimal control washout algorithm is programmed with predetermined parameters [38]. Unlike the classical washout algorithm, the optimal control washout algorithm is fed in vehicle Euler angles instead of the vehicle angular rates, and filter parameters are selected through the application of a vestibular system model.

The filters used in the optimal control washout are generally numerous and of higher order than those used in the classical washout [38]. From Figure 3.5, which demonstrates a typical arrangement of the optimal control washout, it can be observed that the optimal washout algorithm requires a greater number of calculations in determining the simulated motion. Furthermore, determination of the washout filters, demonstrated in Figure 3.6, requires development of precise models of the vestibular system, which can vary significantly from pilot to pilot [40]. With an accurate model of a pilot's vestibular system, determination of the optimal 


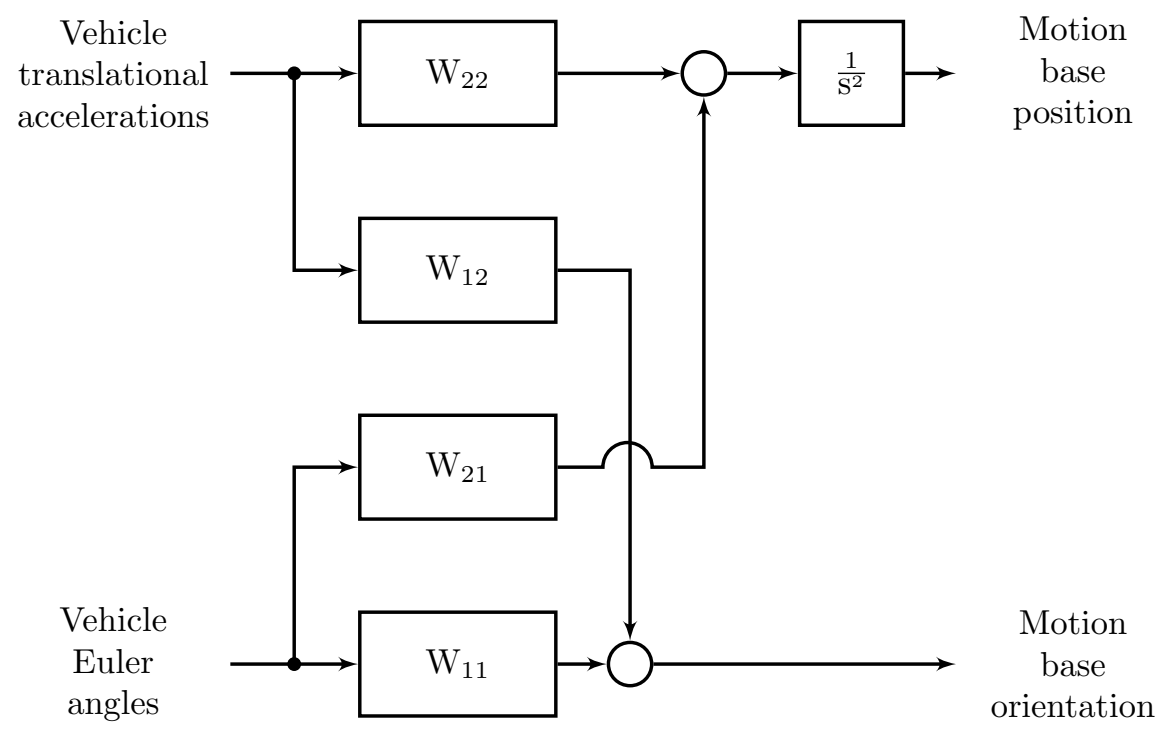

Figure 3.5: Optimal washout algorithm block diagram.

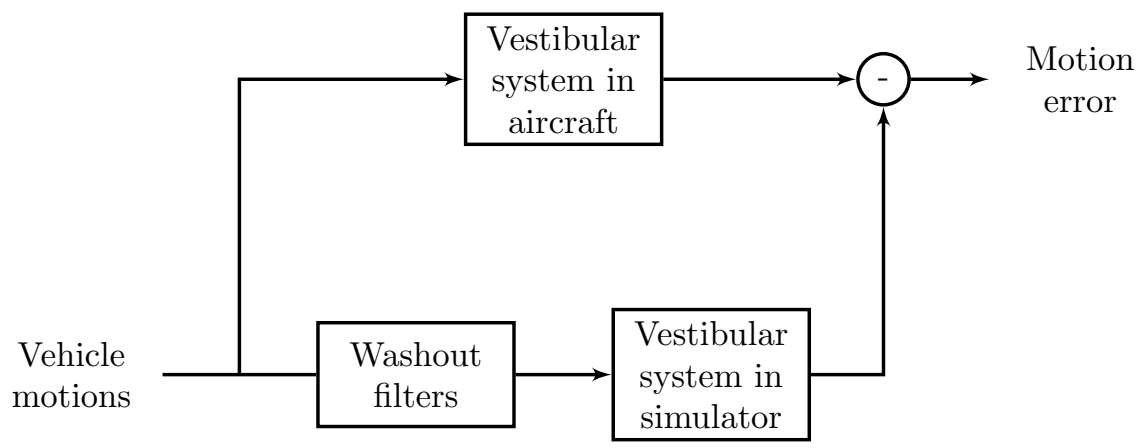

Figure 3.6: Design of optimal control filters.

control filters then becomes a cost-optimization problem, to reduce the error between motion sensed in the real aircraft and the simulated environment.

Due to the inclusion of the vestibular model, adjustment of filters in the optimal control washout algorithm is often difficult and not very intuitive [38]. As a result, the optimal control washout algorithm is not desirable in settings where pilots are changed frequently. 


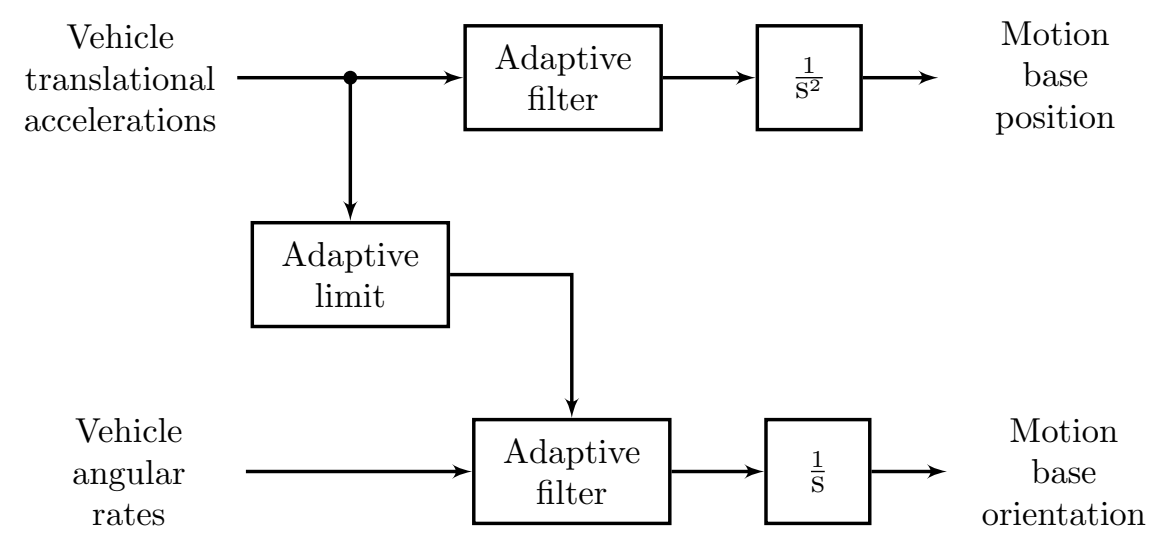

Figure 3.7: Adaptive washout algorithm block diagram.

\subsubsection{Adaptive Washout}

Unlike both the classical and optimal control washout algorithms, the adaptive washout algorithm allows for variation of the filter coefficients in real time [41]. Similar in layout to the classical washout, the adaptive washout, shown in Figure 3.7, uses a defined cost function to vary the gain of the filters in real time, to reduce errors between aircraft motion and simulator motion.

There is flexibility in the selection of the cost function, such that vestibular models or varying penalty functions could be implemented, depending on the application. These extra functions result in a greater number of calculations to be made in real time; exceeding the number of calculations required for both the classical and optimal control washout algorithms [41]. Furthermore, due to the flexible nature of the adaptive washout response, quantitative evaluation of the motion is relatively difficult. As a result, behaviour of the adaptive filters can be less predictable than the classical washout filters. 


\subsection{KatanaSim Motion Tuning}

Given that flight schools typically have a high number of students going through training in a short period, the selected washout algorithm needed to be an effective balance between the flexible tuning of the classical washout algorithm, and the motion quality provided by the adaptive washout algorithm. Given this requirement, a modified version of the classical washout was selected as the washout algorithm for the KatanaSim as it could be easily fine-tuned once the algorithm was fully implemented and the parameters selected. Furthermore, the Moog motion base provides software in the motion base computer that implements a modified version of the classical washout algorithm, and that can be tuned. The use of the commercial washout is also in line with the project objectives.

\subsubsection{OverTilt Motion Drive Algorithm}

The Moog motion base implements the OverTilt MDA for washout filtering of motion [42]. The OverTilt MDA implements a pseudo-adaptive algorithm for developing surge and sway translational acceleration cueing. OverTilt assists the motion base in providing more accurate and adaptive translational cueing without having to develop and implement the cost functions typically associated with adaptive washout algorithms. OverTilt is tuned by providing surge and sway translational acceleration limits, translational displacement limits, and angular tilt rate limits in the pitch and roll directions for tilt coordination. OverTilt uses these parameters to implement pseudo-adaptive high-pass filters for onset translational cueing. As translational limits are approached, the motion of sustained cueing is filtered through pseudo-adaptive low-pass filters associated with tilt coordination. 
For the heave translational accelerations and all three angular velocities, the filters associated with the classical washout algorithm are implemented. These filters are tuned based on selection of the parameters in the generic filter:

$$
T=\frac{A_{0} s^{2}+A_{1} s+A_{2}}{B_{0} s^{2}+B_{1} s+B_{2}}
$$

where $A_{i}$ and $B_{i}$ are the coefficients of the numerator and denominator parametric equations. Overtilt requires $B_{0}$ to be non-zero.

For the KatanaSim motion, these parameters were tuned based on the literature, as described in Section 3.2.1. This implementation matches the manufacturerrecommended methods. This means the use of a first order high-pass filter for the angular velocities:

$$
T_{H P_{\theta}}=\frac{s^{2}}{s^{2}+\omega_{\theta} s}=\frac{s}{s+\omega_{\theta}}
$$

and use of a second order high-pass filter for the heave translational accelerations:

$$
T_{H P_{z}} \frac{s^{2}}{s^{2}+2 \zeta_{z} \omega_{z} s+\omega_{z}^{2}}
$$

For tuning of the 6DOF2000E motion base, Moog suggests a range of 0.5 to $1.2 \mathrm{~m} / \mathrm{s}^{2}$ for translational acceleration limits, and the following recommended starting values for displacement limits of each degree-of-freedom:

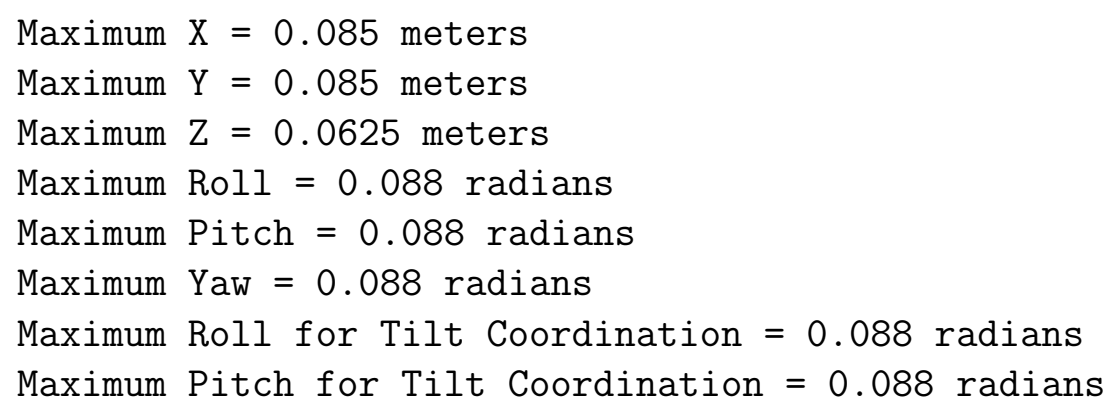




\subsubsection{Platform Control}

For controlling the platform, a DLL plugin was developed for X-Plane that extracts motion data and communicates this data to an intermediate software program via

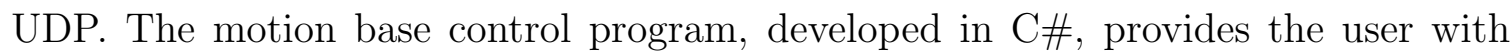
control over the state of the motion base, the source of the motion data, and the tuning parameters to be used for the washout algorithm. The program then sends the commanded data to the motion base computer. A schematic of this process is shown in Figure 3.8. It should be noted that while possible to send the commanded data directly from X-Plane to the motion base computer, the intermediate software ensures that control of the platform remains with the user and not X-Plane.

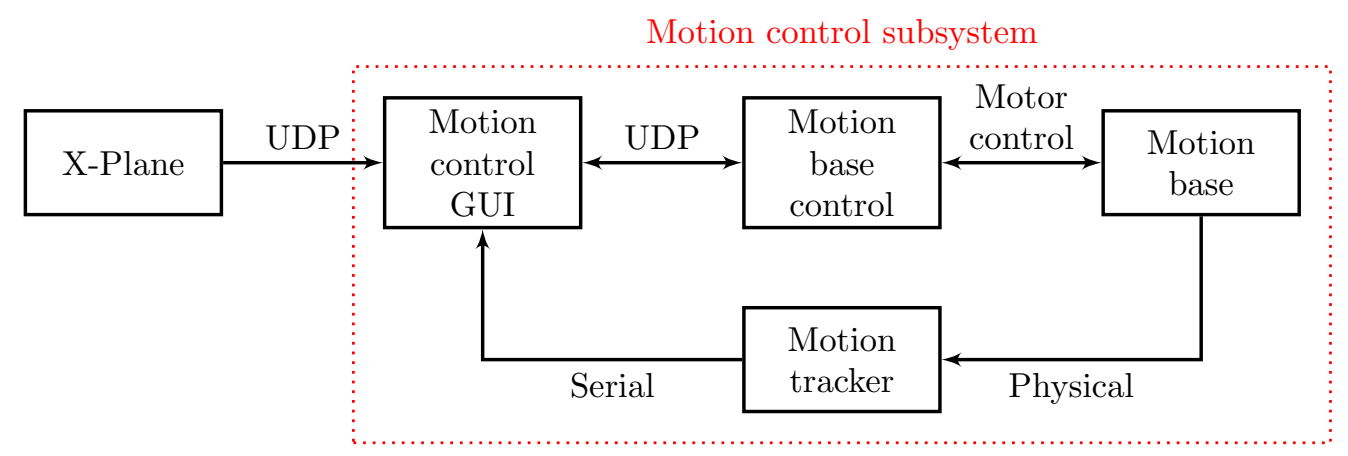

Figure 3.8: Motion control schematic.

The motion base will not begin receiving motion data until the user commands the motion base to engage, and then run. The user can also end motion cueing at any time by commanding the motion base to park, or for immediate termination by hitting one of the emergency stop buttons located in the vicinity of the simulator.

The motion base control program will typically use X-Plane motion data as the input; however, the GUI offers the ability to use prescribed motions for each degree-of-freedom. Those prescribed motions are currently limited to sinusoidal 
motions with prescribed amplitude and frequency. These prescribed motions are mostly for motion cueing assessment, as will be discussed in Chapter 5 .

The motion base control program also monitors and displays the current state of the motion base, as well as the current input motion data. While the motion base provides feedback for faults and current position, an Xsens MTi motion tracker [43] was implemented to provide feedback motion data. The Xsens MTi is an Attitude and Heading Reference System (AHRS) capable of high rates of $120 \mathrm{~Hz}$. Input and feedback data can then be recorded for post-run analysis and motion evaluation. As with the motion platform, the XSens MTi outputs orientation using the $z-y-x$ Euler angle convention.

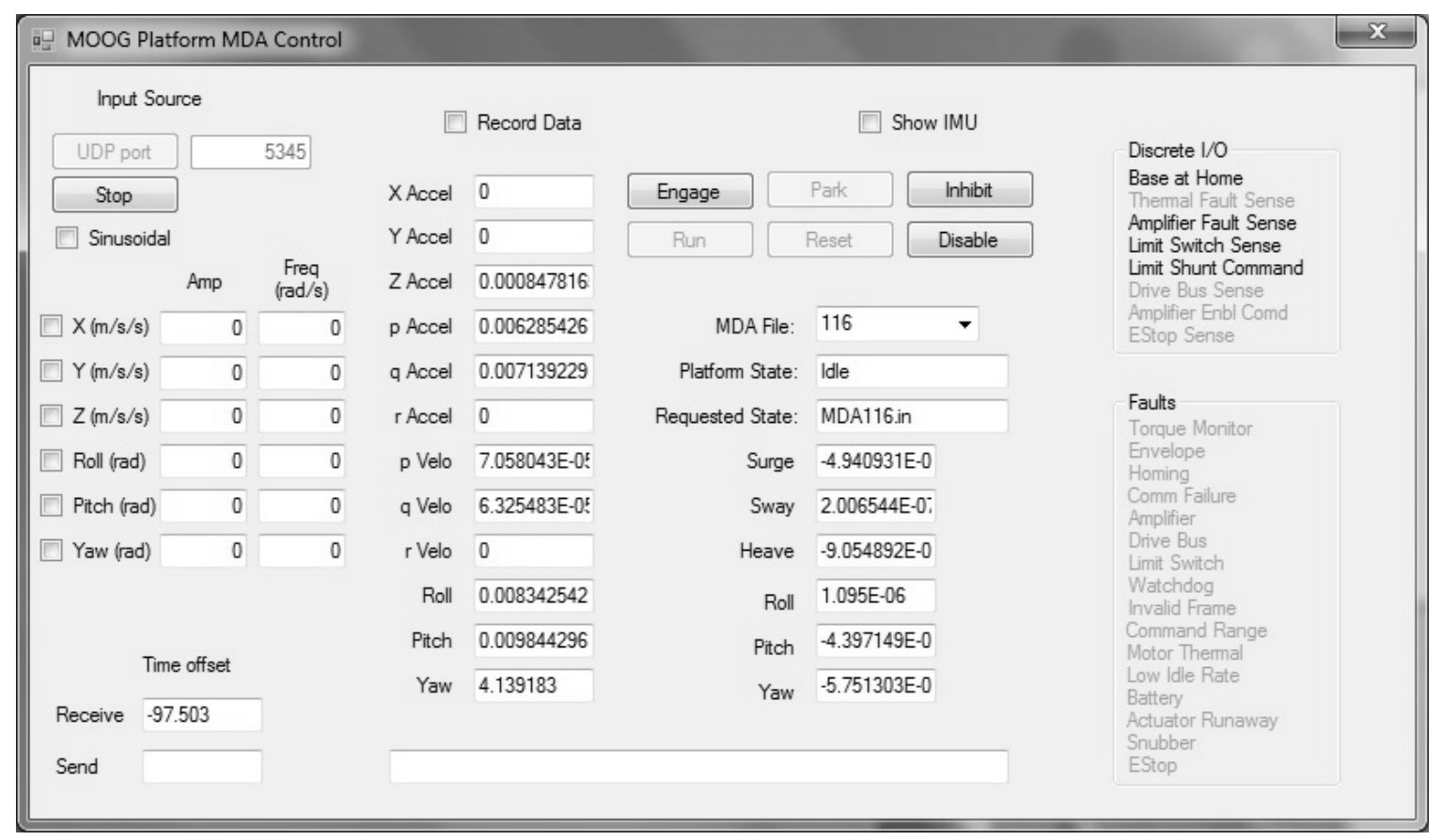

Figure 3.9: Motion control program. 


\subsubsection{Platform Optimization}

From Chapter 1, it was determined that high-frequency manoeuvre motions are the most critical motions to consider when developing motion cueing for flight simulation. For smaller general aviation aircraft, such as those used in ab-initio flight training, these high-frequency manoeuvre motions most often occur as a result of turbulence, or during one of the following flight exercises: takeoff, approach, landing, slow-flight, stalls, spins, and spiral dives [21]. To determine the typical performance characteristics associated with these exercises, flight testing was undertaken. The flight testing is described in Chapter 4.

From the flight testing, the aircraft had the typical maximum values presented in Table 3.2. It should be noted that these results do not demonstrate the extremes of the aircraft, just motions encountered during typical flight training.

Using the Moog-suggested starting values, the motion response to prescribed motion was assessed for different translational acceleration limits, along with associated calculations for gain and break frequency. As per literature recommendations, the same value of gain was used for all degrees of freedom. The response to a sinusoidal surge acceleration, shown in Figure 3.10, demonstrates that for the KatanaSim motions, the larger translational acceleration limits result in a larger break frequency, and consequently, a larger delay in motion response. These results match a study by White and Rodchenko which recommends low break frequencies for higher physical fidelity [39]. However, to achieve the desired typical motions without missing any cues, lower gains have to be applied when lower translational acceleration limits are used. This means the aggressiveness of the washout can be applied toward lower break frequencies, larger gains, or a favourable compromise between the two. 


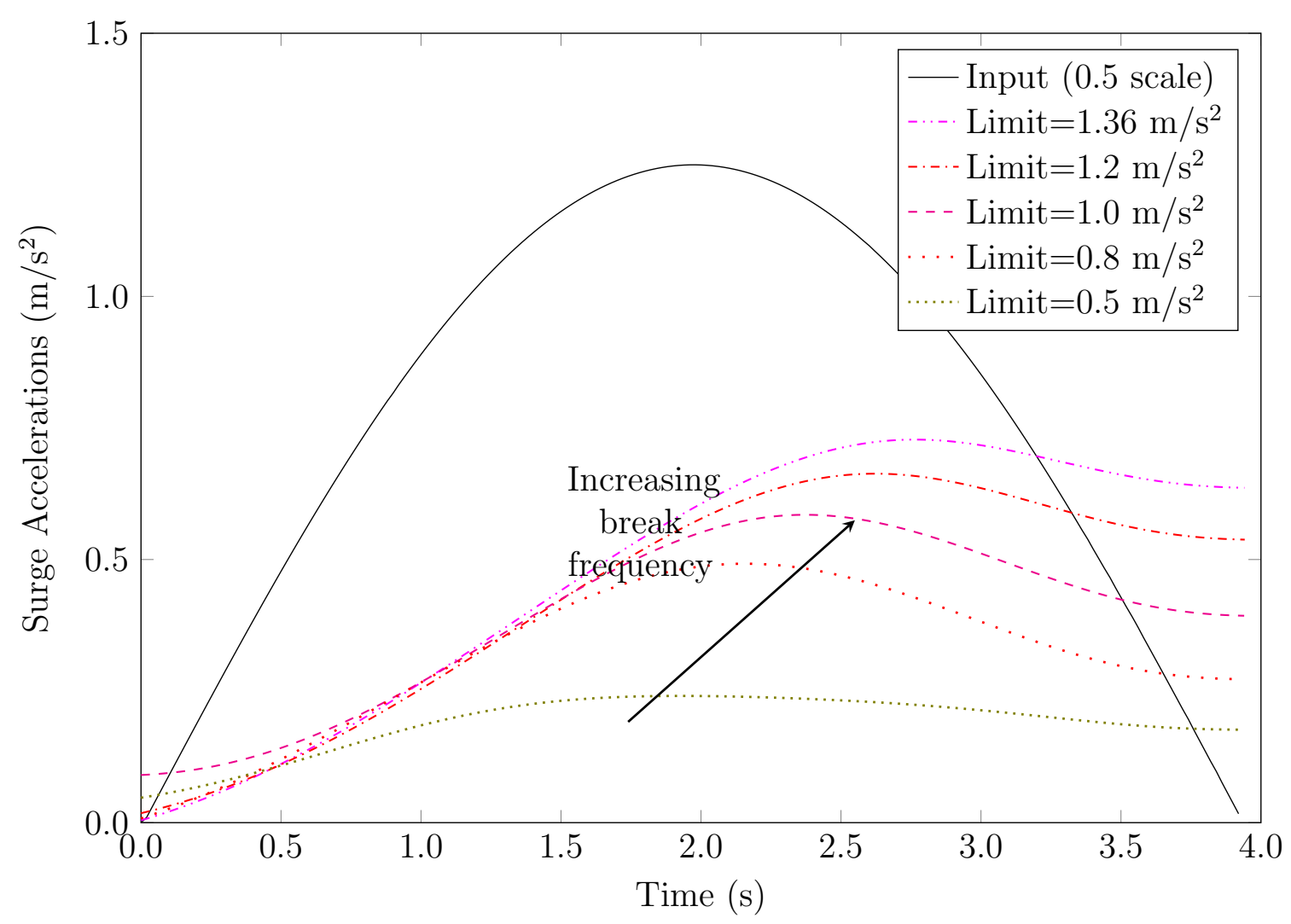

Figure 3.10: Break frequency comparison for onset surge acceleration.

One method of lowering the break frequency, while achieving larger translational acceleration limits, is through Equation 3.4. To have minimal effect on the break frequency, an increase in the translational acceleration limits must be matched with a similar increase in platform translational displacement limits. This approach to tuning must be applied cautiously, since there will be a reduced availability of motion in the remaining directions as a displacement limit is approached. This would likely result in missed cues for certain phases of flight.

When tuning the tilt coordination of the washout algorithm, it is typically desired to perform the tilt coordination about a point close to the pilot's head. 
Due to project requirements for support structure design (discussed in Chapter 2), performing tilt coordination about a point close to the pilot's head would require translational motion of the platform exceeding platform thresholds. For the KatanaSim, tilt coordination is performed below the pilot, such that when large angular accelerations are applied to the platform during tilting, the actual gravity vector becomes misaligned and an additional translational acceleration is required to correct for the error. This additional translational acceleration is referred to as a false cue.

In order to minimize false cues, proper angular rates must be implemented, such that false translational acceleration cues are not felt during rotations, and such that false angular cues are not felt during tilt coordination. A typical means of comparing simulator response to aircraft motion is through the use of a step input of aircraft motion [44]. Figure 3.11 demonstrates the simulator response to a step input of surge acceleration of $1 \mathrm{~m} / \mathrm{s}^{2}$ applied at a rate of $3 \mathrm{~m} / \mathrm{s}^{3}$. Along with the results for surge acceleration, Figure 3.11 shows the effects of tilt coordination on motion response, through the addition of pitch as the surge acceleration is sustained. While higher gain leads to higher angular rates achieved in tilt coordination, Figure 3.11 demonstrates that the angular rates remain below $0.034 \mathrm{deg} / \mathrm{s}(0.0006 \mathrm{rad} / \mathrm{s}), \mathrm{much}$ below the desired $2 \mathrm{deg} / \mathrm{s}$. Much like with the response to prescribed sinusoidal surge accelerations, the larger translational acceleration limits result in greater latency in achieving the peak acceleration.

The KatanaSim was tuned to maximize the gain while keeping the break frequency sufficiently low to meet latency requirements. Based on the aforementioned effects of translational acceleration limits and gain, $0.5 \mathrm{~m} / \mathrm{s}^{2}$ was selected as the specific force limit, with the translational displacement limits and gain increased 
to just below the value that resulted in missed cues. Table 3.3 shows the set of tuning parameters that were attempted during tuning of the motion base. The final selection of tuning parameters was performed during the evaluation, which will be discussed further in Chapter 5.

Table 3.3: Motion tuning parameter test sets.

\begin{tabular}{|c|c|c|c|c|c|}
\hline $\begin{array}{c}\text { Test } \\
\text { No. }\end{array}$ & $\begin{array}{c}\text { Translational } \\
\text { Acceleration } \\
\text { Limit } \\
\left(\mathrm{m} / \mathrm{s}^{2}\right)\end{array}$ & $\begin{array}{c}\text { Translation } \\
\text { High-pass Break } \\
\text { Frequency } \\
(\mathrm{rad} / \mathrm{s})\end{array}$ & $\begin{array}{c}\text { Translational } \\
\text { Displacement } \\
\text { Limits }(\mathrm{m})\end{array}$ & Gain & $\begin{array}{c}\text { Damping } \\
\text { Ratio }\end{array}$ \\
\hline \hline 1 & 1.36 & 4.000 & 0.085 & 0.40 & 1.0 \\
2 & 1.20 & 3.757 & 0.085 & 0.35 & 1.0 \\
3 & 0.75 & 3.068 & 0.085 & 0.30 & 1.0 \\
4 & 0.50 & 2.425 & 0.085 & 0.25 & 1.0 \\
5 & 0.50 & 2.425 & 0.085 & 0.25 & 1.2 \\
6 & 0.50 & 2.425 & 0.085 & 0.25 & 1.4 \\
7 & 0.50 & 2.425 & 0.085 & 0.25 & 1.5 \\
8 & 0.50 & 2.132 & 0.110 & 0.25 & 1.2 \\
9 & 0.50 & 2.132 & 0.110 & 0.25 & 1.4 \\
10 & 0.50 & 2.132 & 0.110 & 0.25 & 1.5 \\
11 & 0.75 & 2.611 & 0.110 & 0.30 & 1.0 \\
12 & 0.75 & 2.611 & 0.110 & 0.30 & 1.2 \\
13 & 1.20 & 3.303 & 0.110 & 0.35 & 1.0 \\
14 & 1.20 & 3.303 & 0.110 & 0.35 & 1.2 \\
\hline
\end{tabular}



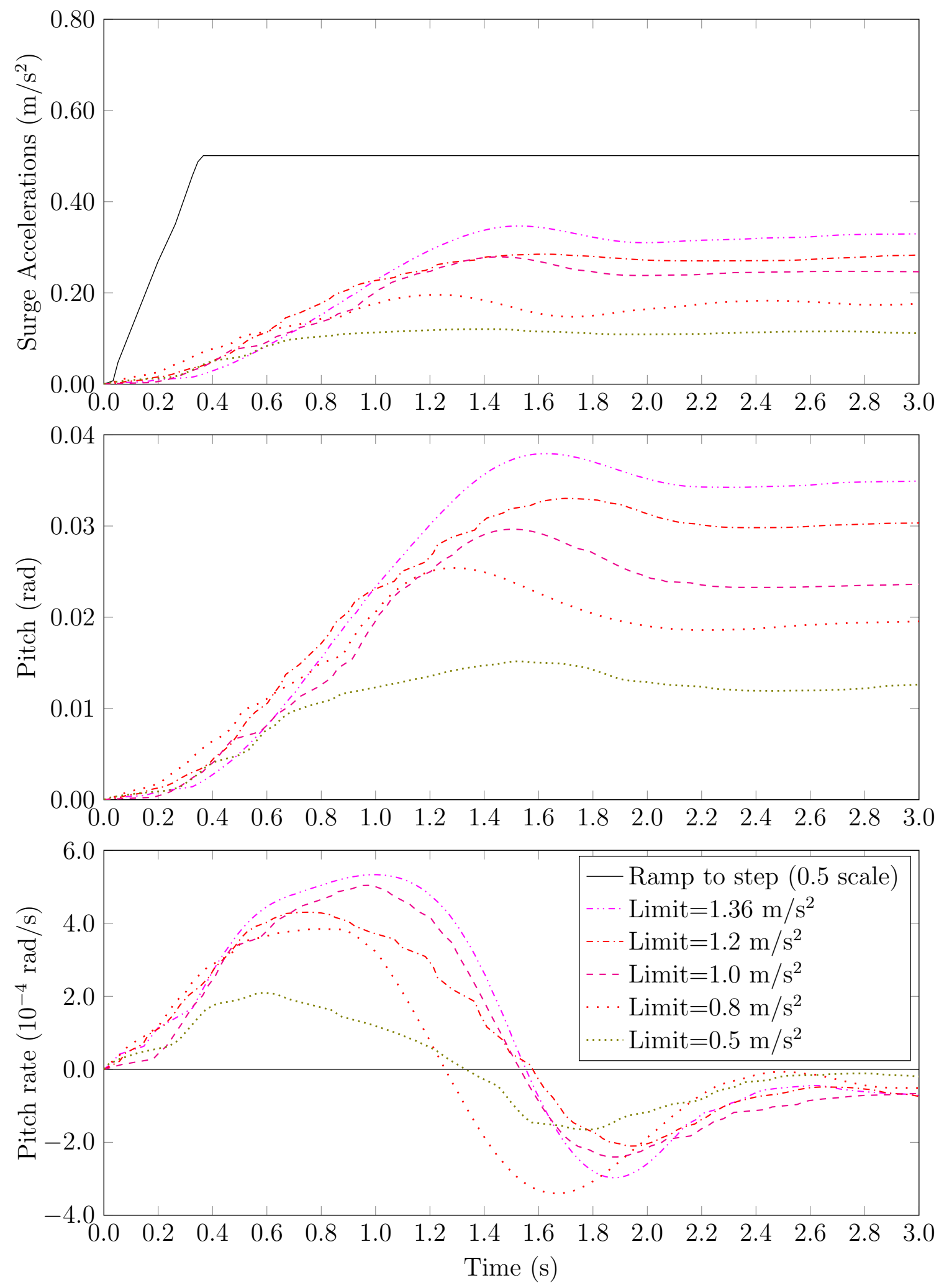

Figure 3.11: Motion base response to ramp-to-step input surge acceleration. 


\section{Chapter 4}

\section{Flight Testing}

Flight testing was undertaken as a collaboration between the Department of Mechanical and Aerospace Engineering [45], and Ottawa Aviation Services (OAS). The flight test involved equipping a Katana aircraft from OAS with instrumentation, and then proceeding to fly typical manoeuvres from Transport Canada's Flight Training Manual [21]. To ensure the proposed flight test plan was in compliance with Transport Canada regulations, a flight permit was acquired from Transport Canada. This process is discussed in Section 4.5.

For the KatanaSim project, the results from the flight testing were used for tuning of the motion cueing, previously discussed in Chapter 3, as well as a benchmark for comparison in the quantitative evaluation of the response of the control inputs, visual cueing, and motion cueing of the simulator (to be discussed in Chapter 5).

For this portion of the KatanaSim project, this thesis emphasizes the interfacing of all the instrumentation used during the flight test. Specifically, selection of how the individual instruments are incorporated into the full setup, and development of the software. 


\subsection{Flight Plan}

The flight plan was developed through the use of flight testing literature [46], OAS standard operating procedures, the pilot operating handbook, the Transport Canada Flight Training Manual, and consultation with the Chief Flight Instructor at OAS. In order to execute all the required manoeuvres without exhausting the pilot, it was decided that the flights should ideally be under two hours. The plan called for three flights, with the list of manoeuvres and their estimated time for execution shown in Table 4.1. Full descriptions of each manoeuvre can be found in the Carleton University Katana Flight Test Plan [45].

\subsection{Instrumentation}

Having established the manoeuvres, a list of critical data was defined to determine the required instrumentation. To properly analyze the manoeuvres, it was determined that aircraft flight control inputs, aircraft motion (airspeed, translational accelerations, and angular velocities), aircraft orientation (roll, pitch, and yaw), aircraft position (latitude, longitude, and altitude) would be required.

The instrumentation designed and programmed for the flight test centred on an ArduPilot Mega (APM) open source autopilot system [47], shown in Figure 4.1, that for the flight test was set exclusively for data acquisition. The compact size, open source software, and ability to add auxiliary sensors make the APM a practical choice for the desired flight test. Integrated into the APM are a three-axis gyro, triaxial accelerometer, magnetometer, and a high-precision barometer for measuring the aircraft motion at about $20 \mathrm{~Hz}$. A $10 \mathrm{~Hz}$ GPS module is attached to the APM to 
Table 4.1: Proposed manoeuvres for the flight test.

\begin{tabular}{|c|c||c|c||c|c|}
\hline \multicolumn{2}{|c||}{ Flight 1} & \multicolumn{2}{|c||}{ Flight 2} & \multicolumn{2}{c|}{ Flight 3 } \\
\hline $\begin{array}{c}\text { Time } \\
(\text { mins })\end{array}$ & Task & $\begin{array}{c}\text { Time } \\
(\text { mins })\end{array}$ & Task & $\begin{array}{c}\text { Time } \\
(\text { mins })\end{array}$ & Task \\
\hline \hline 10 & Start \& T/O & 10 & Start \& T/O & 10 & Start \& T/O \\
\hline 10 & Transit & 10 & Transit & 10 & Transit \\
\hline 5 & High Alt Level & 5 & Low Alt Level & 3 & Flight Stability \\
\hline 12 & Phugoid & 10 & Climb & 12 & Phugoid \\
\hline 3 & Flight Stability & 3 & Flight Stability & 6 & Short Period \\
\hline 6 & Short Period & 12 & Phugoid & 5 & Slips \\
\hline 10 & Stall & 6 & Short Period & 25 & Circuits \\
(CYRP)
\end{tabular}




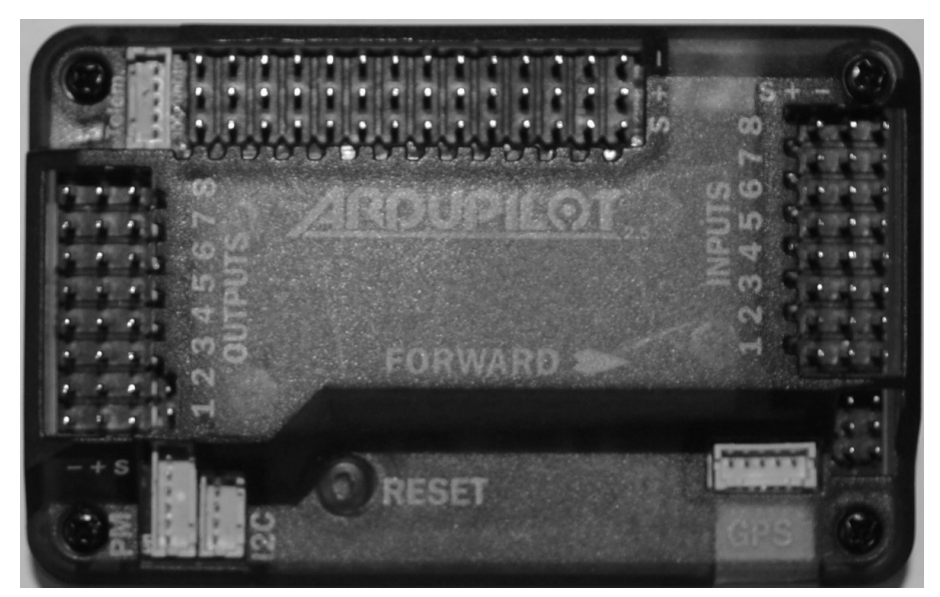

Figure 4.1: ArduPilot Mega.

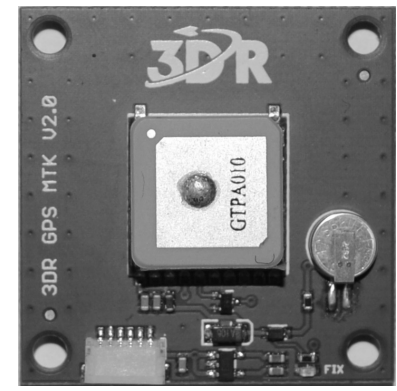

Figure 4.2: Mediatek GPS.

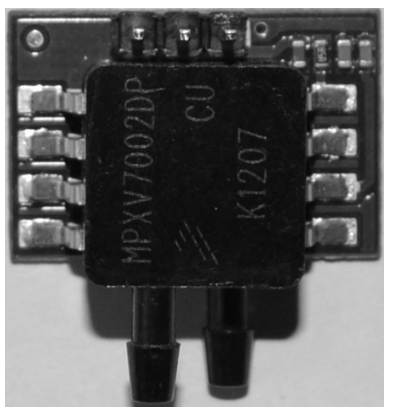

Figure 4.3: Airspeed sensor.

provide current location and groundspeed (Figure 4.2). In order to provide accurate airspeed, a pressure sensor was connected to the APM (Figure 4.3) which senses differential pressure from the pitot-static system of the aircraft. The existing static and pitot lines running into the aircraft's airspeed indicator were teed to allow a connection to the airspeed sensor. This installation was performed by maintenance staff at OAS.

As a means of obtaining redundant, but higher-frequency motion data, the Xsens MTi motion tracker described in Chapter 3 was implemented into the flight test. The Xsens motion tracker was configured for an update rate of $100 \mathrm{~Hz}$, allowing for data to be collected at a rate higher than the limit of the APM. 
The movements of the control column and rudder pedals during flight were measured using string potentiometers. These string potentiometers, installed on the co-pilot's side of the cockpit, were connected to an Arduino UNO microcontroller board and recorded at $50 \mathrm{~Hz}$. One string potentiometer was connected to the rudder pedals to record yaw inputs, while two string potentiometers were connected to the control column to record relative motion of the control column. Trilateration was then applied with the relative motion, along with known fixed points on the control column, to determine the corresponding roll and pitch inputs, using a method implemented by Suzanne Swaine [24]. Power for the string potentiometers was provided by an 18 VDC Li-ion battery. The battery was securely housed in a sheet metal container to prevent exposure of the battery to other devices, and was connected to components by a fuse and a master power switch, easily accessible from the co-pilot seat.

The APM, the Xsens MTi, and the Arduino UNO were all connected to a computer housed in the baggage compartment of the Katana. The computer was a 15.4 inch Compaq Presario C700 personal laptop running customized software (to be discussed in Section 4.3). As the laptop offered limited battery power, power was supplemented by an Anker Astro Pro2 20000mAh Multi-Voltage External Battery [48].

During flight, the computer was inaccessible as it was securely mounted in the baggage compartment; however, the co-pilot was given a custom LED-switch combination which allowed markers to be recorded in the data, while the LED turned on and off in a heartbeat rhythm as a means of ensuring connectivity of the components, as well as status of the software and data acquisition system. 


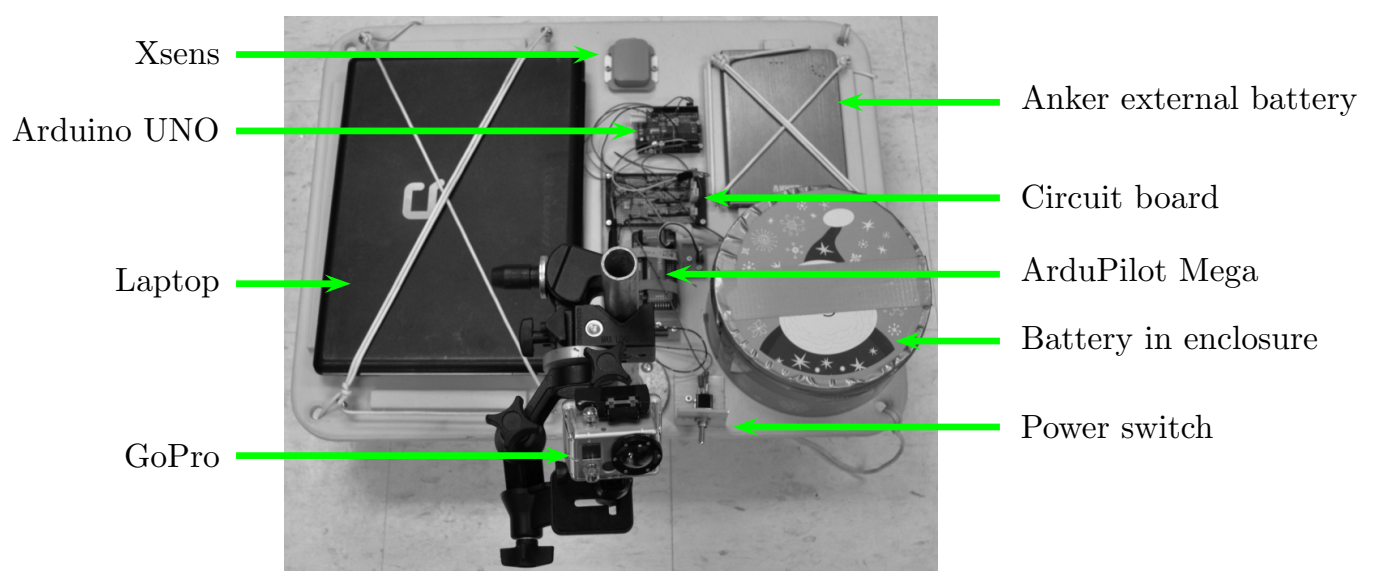

Figure 4.4: Baggage compartment mount.

As a means of maintaining a video log of the instrument panel, a GoPro HERO2 camera was mounted in the cockpit, secured in the baggage compartment. The GoPro camera is a high-definition, portable video camera often used in dynamic environments.

Aside from the string potentiometers, the GPS receiver, and the pressure sensor, all the equipment was securely mounted to a $610 \mathrm{~mm}$ by $480 \mathrm{~mm}$ piece of $25 \mathrm{~mm}$ thick plywood, as shown in Figure 4.4. This mount was strapped down to the base of the baggage compartment by attaching D-rings to the mounting screws of the baggage compartment panel which were then attached to four corner holes of the mount with 550 parachute cord. Zip ties were used as a redundant securing system. The underside of the board had four $12 \mathrm{~cm}$ lag bolts, with rubber end caps, acting as feet for the board. These lag bolts increased the height at which the board sat in the baggage compartment and allowed the parachute cord to be pulled tight.

The overall layout of the flight test instrumentation can be seen in Figure 4.5. Table 4.2 provides a list of the instruments used during the flight test along with a summary of their intended purpose. 


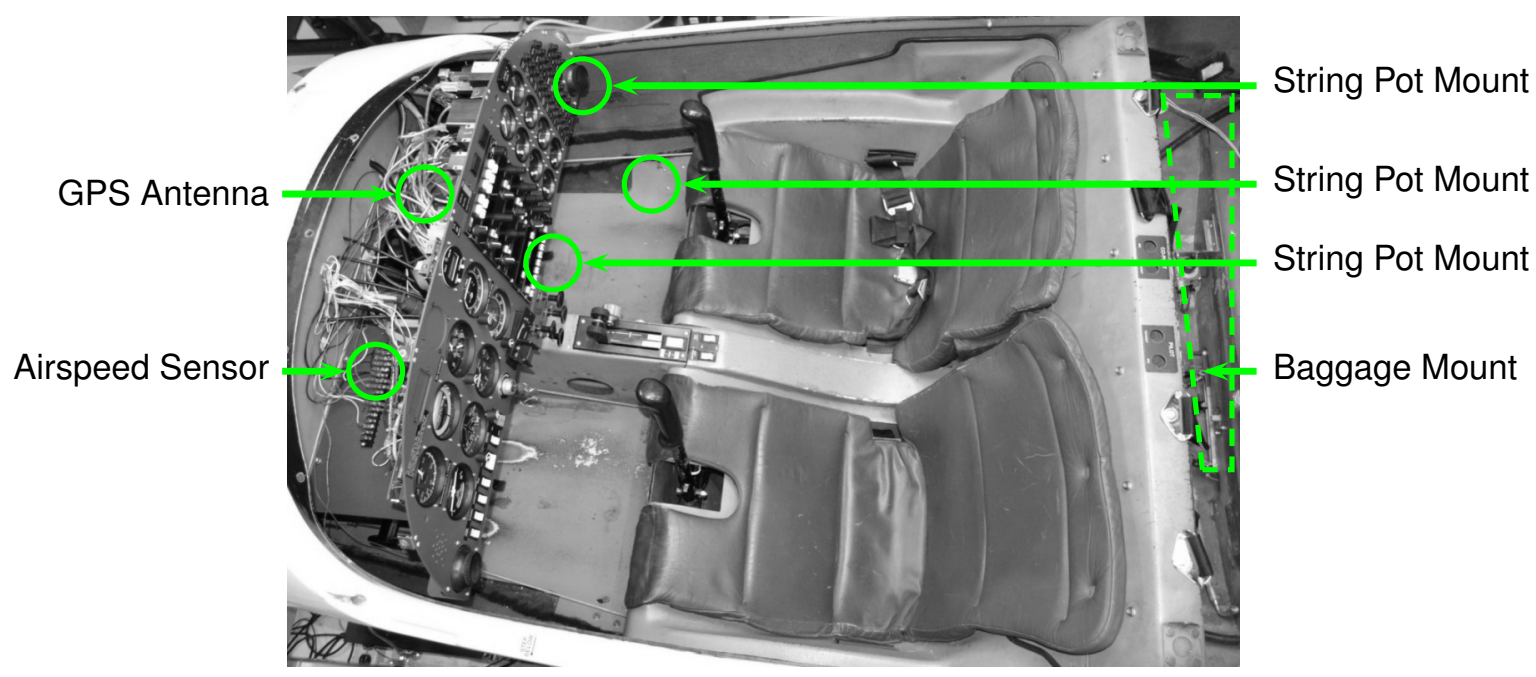

Figure 4.5: Layout of flight test instrumentation.

Table 4.2: Flight test instrumentation list.

\begin{tabular}{|l|l|}
\hline Instrument & Purpose \\
\hline \hline XSens motion tracker & Motion data \\
\hline ArduPilot Mega & Motion data \\
\hline GPS receiver & Position data \\
\hline Pressure sensor & Airspeed \\
\hline String potentiometers & Control input ratios \\
\hline LED-switch & Switch to insert markers combined with heartbeat LED \\
\hline Arduino UNO & Communication to string pots and LED-switch \\
\hline Laptop & Data recording \\
\hline GoPro camera & Video and audio logging \\
\hline
\end{tabular}




\subsection{Data Collection Software}

Instrumentation control and data collection were accomplished using a customized version of software called Mission Planner [49]. Mission planner is a piece of open source software developed for configuring and monitoring the APM. The customized additions provide access to the Xsens motion tracker and to the Arduino UNO. Mission Planner has also been implemented to provide real-time display and recording of the flight test data. The data was output to a comma-separated values data file with the format shown in Appendix A.

\subsection{Equipment Tests}

Prior to approval of the flight permit and flight testing, a few basic tests of the equipment were performed, to reduce the probability of equipment failure in the flight environment.

\subsubsection{Pressure Sensor}

According to the pilot operating handbook [28], the Katana aircraft has an average cruise speed of 95 knots $(48.88 \mathrm{~m} / \mathrm{s})$. As the selected pressure sensor is typically intended for hobby-level Unmanned Aerial Vehicles (UAVs), the pressure sensor was tested for accuracy at higher differential pressures (corresponding to higher airspeeds) than those typically encountered by these UAVs. For this test, the static pressure port of the pressure sensor was open to the atmosphere, while the dynamic pressure port of the pressure sensor was connected to a water-filled U-tube manometer. While manometers are typically used for measuring the pressure of a system, the 
manometer used in this test was the source of the pressure difference. The test began with the water at the same level in both columns, such that the pressure difference was zero. Water was then added to the open side of the manometer, with the applied pressure difference compared to the displayed pressure from the pressure sensor. The results from this test, plotted in Figure 4.6, showed that the pressure sensor measured the pressure with about 1\% accuracy, and maintained this accuracy above $58 \mathrm{~m} / \mathrm{s}$, well above the aircraft cruise speed.

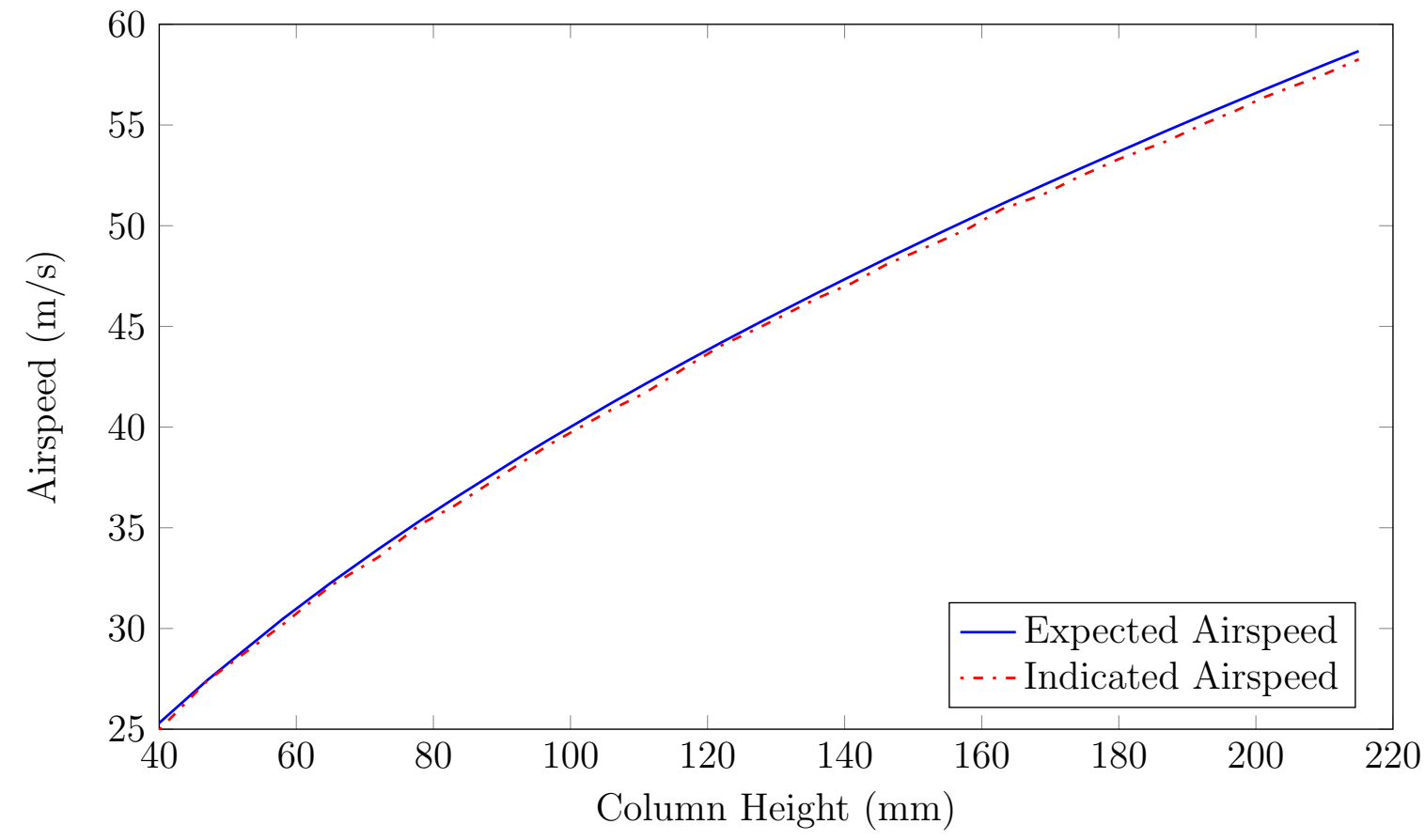

Figure 4.6: U-tube manometer test of pressure sensor.

\subsubsection{Low Temperatures}

As the flight testing was scheduled for the winter season, there were concerns over the potential of having to operate the flight test equipment at low temperatures. It was therefore decided to test the flight test equipment reliability at low temperatures. As 
Ottawa Aviation Services has a policy of not flying when the ground temperature is below $-20^{\circ} \mathrm{C}$, it was determined that the test could be performed for any temperature below this cutoff temperature. Given the climate in Ottawa, natural test conditions were provided on the selected test day with an outside temperature of $-21^{\circ} \mathrm{C}$ (any temperature below $-20^{\circ} \mathrm{C}$ was deemed sufficient for the testing). The enclosed cockpit is unlikely to to dip below this temperature.

As all of the planned flights were estimated to take less than two hours, it was decided that the equipment should be tested by operating all the equipment, outdoors, for two and a half hours. At the end of the test period, all the equipment was still functional and responsive, and the sensors continued to provide reasonable results. No equipment failed as a result of the low temperatures.

The only remaining temperature-related concerns were those of condensation. After the two-and-a-half hours of outdoor operation, the equipment was brought into the warm laboratory, where the equipment continued to function without issue.

\subsubsection{Battery Life}

With all three flight tests scheduled to be flown on the same day, concerns were raised about the length of time required between flights to charge batteries to ensure sufficient battery life for each flight. Following the test described in Section 4.4.2, which simulates a long and cold flight, all batteries were charged for 70 minutes, to simulate an 80 minute down time between flights. All equipment was then turned on and set to record. The equipment had sufficient power for another two-and-a-half hours, at which time the equipment powered off. 
From this test, it was determined that the time between each flight would be dependent on the length of time the equipment ran for the previous flight. A minimum of one hour of charge was suggested, with a minimum charge time of 90 minutes suggested for flights exceeding two hours.

\subsection{Flight Permit}

As the flight testing required equipment to be physically attached to the flight controls (the string potentiometers) and modifications to the pitot-static system (the pressure sensor), Transport Canada approval was required and sought prior to flying. This process was initiated through discussions with Ashraf Othman, a Transport Canada Design Approval Representative (DAR) based in Ottawa.

Under the guidance of the DAR, the flight test plan was developed and submitted by OAS to the Aircraft Certification Branch of Transport Canada for review and acceptance. Following the review, George East, the Transport Canada safety inspector responsible for OAS inspections, was given approval to issue the flight permit. The conditions of the flight permit stipulated that all modifications to the aircraft were to be overseen by Chris Adams, the Person Responsible for Maintenance (PRM) at OAS, or delegated to one of the Aircraft Maintenance Engineers (AMEs). The flight permit, shown in Appendix B, was issued December 23, 2013 and was valid for sixty days. It was subsequently extended to March 31, 2014. 
Table 4.3: Revised manoeuvre list from flight test.

\begin{tabular}{|c||c|}
\hline Flight 1 Tasks & Flight 2 Tasks \\
\hline \hline Start \& T/O & Start \& T/O \\
\hline Transit & Transit \\
\hline High Alt Level & Low Alt Level \\
\hline Phugoid & Phugoid \\
\hline Flight Stability & Short Period \\
\hline Short Period & Turns \\
\hline Stall & Slips \\
\hline Spin & Climb \\
\hline Slow Flight & Flight Stability \\
\hline Spiral Dive & Circuits (CYRP) \\
\hline Slips & Transit \\
\hline Transit & Landing \\
\hline Landing & \\
\hline
\end{tabular}

\subsection{The Flight Test}

The flight test took place on March 8, 2014. The instrumentation was installed as previously described the morning of flight testing under the supervision of an OAS AME. Due to low clouds in the morning, the first flight departed shortly after 12 PM. As a result, the flight plan was altered to reduce the flight testing to two flights, in order to best take advantage of daylight hours. The manoeuvres that were removed from the end of the day were repeated manoeuvres, and thus no important aspects of the flight test were omitted. This revised flight plan is shown in Table 4.3. 

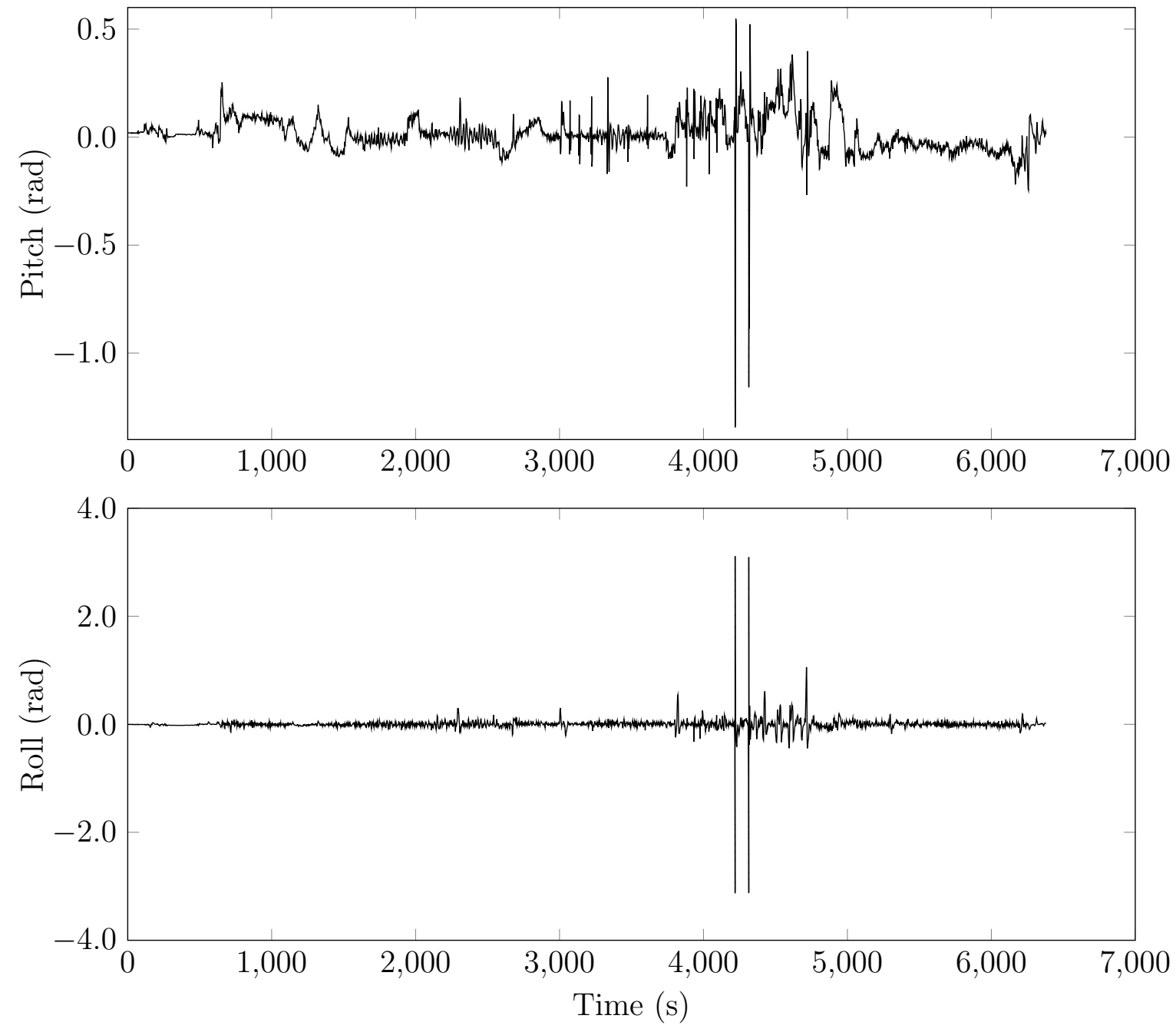

Figure 4.7: Results for pitch and roll from the first flight test.

\subsection{Post-flight Review}

Following the flight test, a review of the flight data showed promising results for the Xsens flight data; the most critical data for the tuning of the motion cueing. Appendix $\mathrm{C}$ shows a sample of data that was recorded during the second flight. Figure 4.7 shows the pitch and roll results from the first flight. The large pitch and roll displacements associated with the spins can be clearly identified around the 5000 second mark. 
That same review of the flight data showed that some of the equipment did not function as expected, despite previous tests. While a quick review of the data occurred between flights, some of the issues were sufficiently subtle that they were not observed until a full review of the data was performed.

\title{
GPS Position
}

While the GPS receiver showed a GPS fix for the entirety of the flight, the data from the first flight showed GPS position data that erroneously indicated that the aircraft did not move. However, for the second flight, no GPS issues were present. As this issue had not been present before, and could not be repeated after that first flight, no clear cause could be determined. The problem was deemed to be a reliability issue.

\begin{abstract}
Airspeed
Despite having tested the pressure sensor prior to flight testing, the pressure sensor experienced an undetermined malfunction the day of flight testing. The trouble is that when stationary or at low speeds, the calculated airspeed from the pressure sensor appeared accurate, and then a problem was not observed during the quick review of the data. Upon further review, the results, shown in Figure 4.8, erroneously indicated that the aircraft never exceeded $5 \mathrm{~m} / \mathrm{s}$ for either flight. Given the Katana aircraft requires a speed of $29.3 \mathrm{~m} / \mathrm{s}$ (57 knots) for takeoff, it is clear that the results are inaccurate.
\end{abstract}

Initial thoughts were that the installation of the airspeed sensor into the aircraft may have damaged the system. In particular, teeing into the existing pitot-static system meant that the AME had to perform a test of the pitot-static system, 

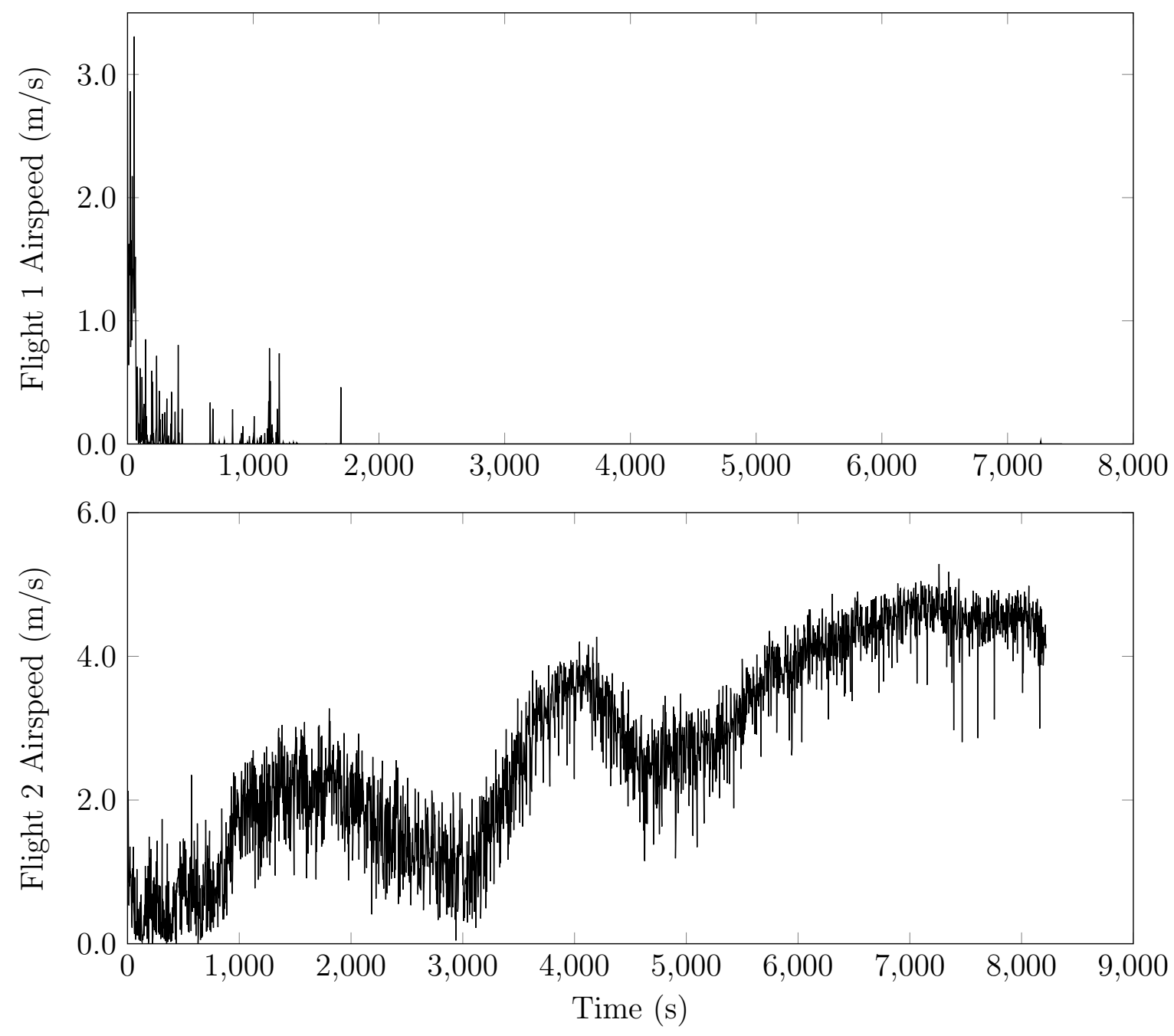

Figure 4.8: Flight test airspeed results.

to verify the accuracy of the aircraft flight instruments. The AME test involves connecting the pitot-static system to a machine that simulates the aircraft flying at an airspeed of $82.3 \mathrm{~m} / \mathrm{s}$ (160 knots). It was speculated that the associated high pressure may have damaged the sensor.

This hypothesis proved to be false, as a post-flight repetition of the test presented in Section 4.4.1 established that not only was the pressure sensor still functional, but while the system could not read values above $60 \mathrm{~m} / \mathrm{s}$, the system maintained similar 
accuracy to the initial tests. This accuracy was maintained even after exceeding $82 \mathrm{~m} / \mathrm{s}$ and then immediately reperforming the test.

As the issue could not be replicated in laboratory conditions, the pressure measurements were deemed to have reliability issues, that should be resolved prior to any future flights.

\section{Flight Controls}

The final problem was found in the flight control inputs that resulted from the trilateration algorithm [24]. The algorithm that was employed resulted in flight control ratios that did not appear appropriate given the aircraft orientation and motion. For instance, during an extended straight-and-level flight condition, the algorithm would suggest that the aircraft was being flown with a $10 \%$ left roll input. This input would typically result in the aircraft also rolling left.

Further investigation into the collected data and the algorithm is required to determine the source of the errors. As the data collected was the raw string potentiometer data, the unprocessed data could still be used in the event that errors are found in the algorithm or the calibration. 


\section{Chapter 5}

\section{Simulator Assessment}

Having developed both the fixed-base flight training device and motion cueing capabilities for the full-flight simulator, an assessment of the simulator was performed to determine the extent to which the simulator met the project requirements. While certification requirements were considered during the assessment, the goal of the assessment was to determine if the simulator would be suitable for ab-initio flight training. This assessment involved quantitatively and qualitatively evaluating the performance characteristics of the simulator and discussing the potential effectiveness of the simulator.

Table 5.1 summarizes the major components of the simulator, as well as their status and how they were assessed. The following sections will discuss these features in further detail.

\subsection{Quantitative Evaluation}

The main means of quantitatively evaluating the KatanaSim is through comparison with flight test data, as performed through the testing described in Chapter 4 . This 
Table 5.1: Simulator components.

\begin{tabular}{|c|c|c|}
\hline Component & Status & Assessment Type \\
\hline Data acquisition & Complete & Latency \\
\hline Flight controls & Complete & General use \\
\hline $\begin{array}{l}\text { Tactile cueing }{ }^{*} \\
(\text { force feedback) }\end{array}$ & $\begin{array}{l}\text { Interim passive } \\
\text { Installation complete } \\
\text { Require tuning }\end{array}$ & $\begin{array}{l}\text { Fish scale force; subjective } \\
\text { feel }\end{array}$ \\
\hline Brakes ${ }^{*}$ & $\begin{array}{l}\text { Installation complete } \\
\text { Require tuning }\end{array}$ & General use \\
\hline Switches & Complete & General use \\
\hline Circuit breakers & Complete & General use \\
\hline Warning lights & Complete & General use \\
\hline $\begin{array}{l}\text { Status lights (trim } \\
\text { and flap) }\end{array}$ & Complete & General use \\
\hline Flight instruments ${ }^{*}$ & Reliability issues & General use \\
\hline Ventilation & Incomplete & No mechanics in place \\
\hline $\begin{array}{l}\text { Powerplant } \\
\text { instruments }\end{array}$ & Reliability issues & General use \\
\hline Avionics ${ }^{*}$ & $\begin{array}{l}\text { Installation complete } \\
\text { Not tested }\end{array}$ & $\begin{array}{l}\text { Functionality not fully } \\
\text { tested }\end{array}$ \\
\hline Visual cueing & $\begin{array}{l}\text { Interim flat display } \\
\text { Limited field of view } \\
\text { Potential latency issues }\end{array}$ & $\begin{array}{l}\text { Latency; subjective scenery } \\
\text { quality }\end{array}$ \\
\hline Motion cueing & Complete & $\begin{array}{l}\text { Latency and missed cues; } \\
\text { subjective feel }\end{array}$ \\
\hline Audio cueing* ${ }^{*}$ & Complete & Subjective sound quality \\
\hline Flight model ${ }^{*}$ & $\begin{array}{l}\text { Incomplete } \\
\text { Interim flight model } \\
\text { used }\end{array}$ & $\begin{array}{l}\text { Flight performance point } \\
\text { comparison to flight testing }\end{array}$ \\
\hline
\end{tabular}

*Work undertaken by Suzanne Swaine [24]. 
evaluation, focused on the work directly related to the content of this thesis, will compare time delays within the simulator, as well as look at the performance of the motion cueing.

Latency can be described as "inevitable delays occurring in real-time simulation" [1]. While latency is inherent in all simulators, when the latency becomes too large, the performance and feel of the simulator become intolerable. Figure 5.1 shows the primary sources of latency within the simulator. The first contribution to latency results from data acquisition, as a finite time is required for the Arduino to read the inputs, transmit them by serial communication, and have them interpreted by X-Plane. Once these inputs are received by X-Plane, a latency can be introduced through calculation of the aircraft flight model such that the aircraft dynamics can be transmitted to both the motion and visual systems. Each of these systems will then introduce further latency as time is required for developing the motion and projecting the visuals.

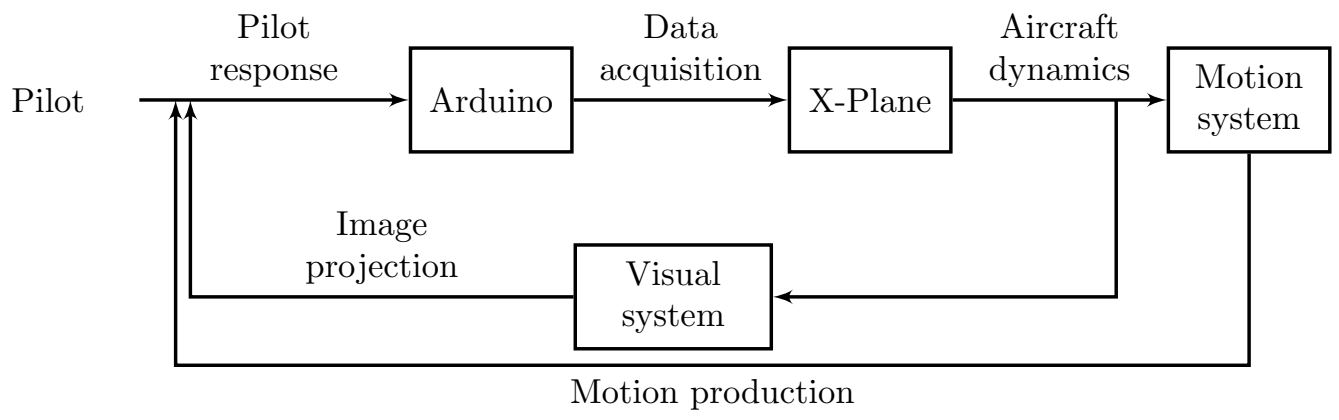

Figure 5.1: Schematic of latency sources.

The latency portion of the evaluation will investigate the latency associated with data acquisition, visual projection, and motion production. A flight control input emulator tool (shown in Figure 5.2) was developed to communicate desired control 


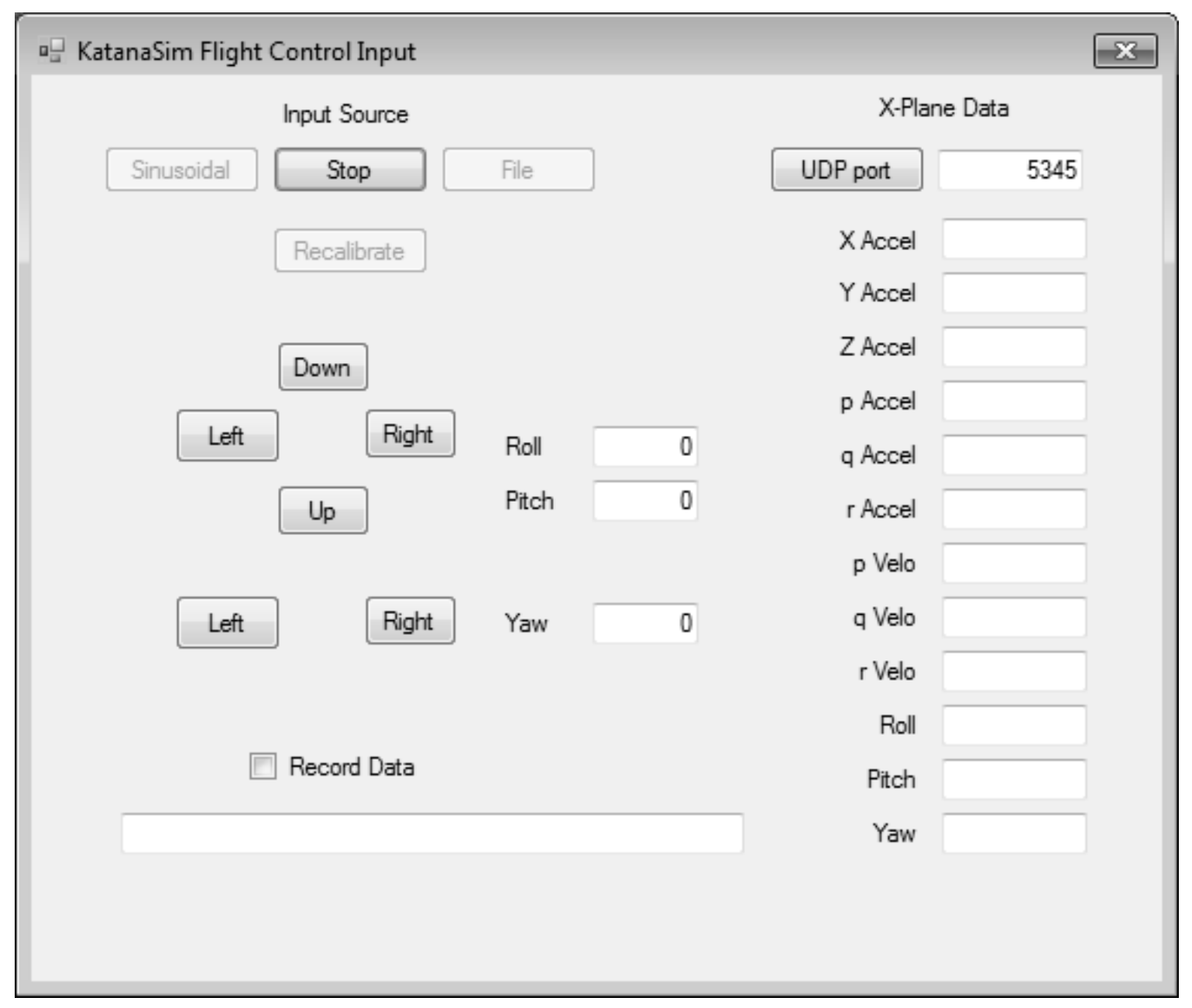

Figure 5.2: Flight control input emulator program.

inputs to an Arduino. The Arduino then makes use of pulse width modulation to output analog signals which take the place of the physical potentiometer signals to the control Arduino described in Chapter 2. As the developed PWM signal is a digital signal, the signal had to be passed through a low-pass filter to be properly read as an analog signal. This is implemented through a resistor-capacitor circuit, for which the schematic is shown in Figure 5.3. Selection of the resistance and capacitance used in the circuit affects the noise and response time of the filter, with a reduction in signal noise coming at the expense of the response time. This relationship is shown in Figure 5.4, based on a PWM simulation developed by Okawa 


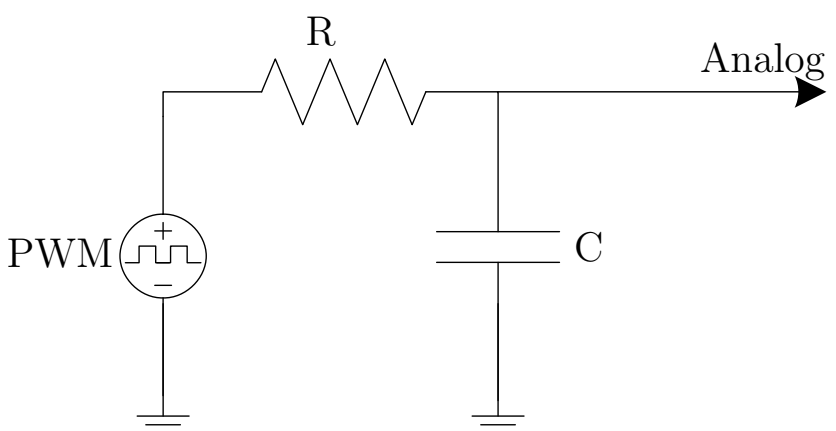

Figure 5.3: Flight control input evaluation wiring diagram.

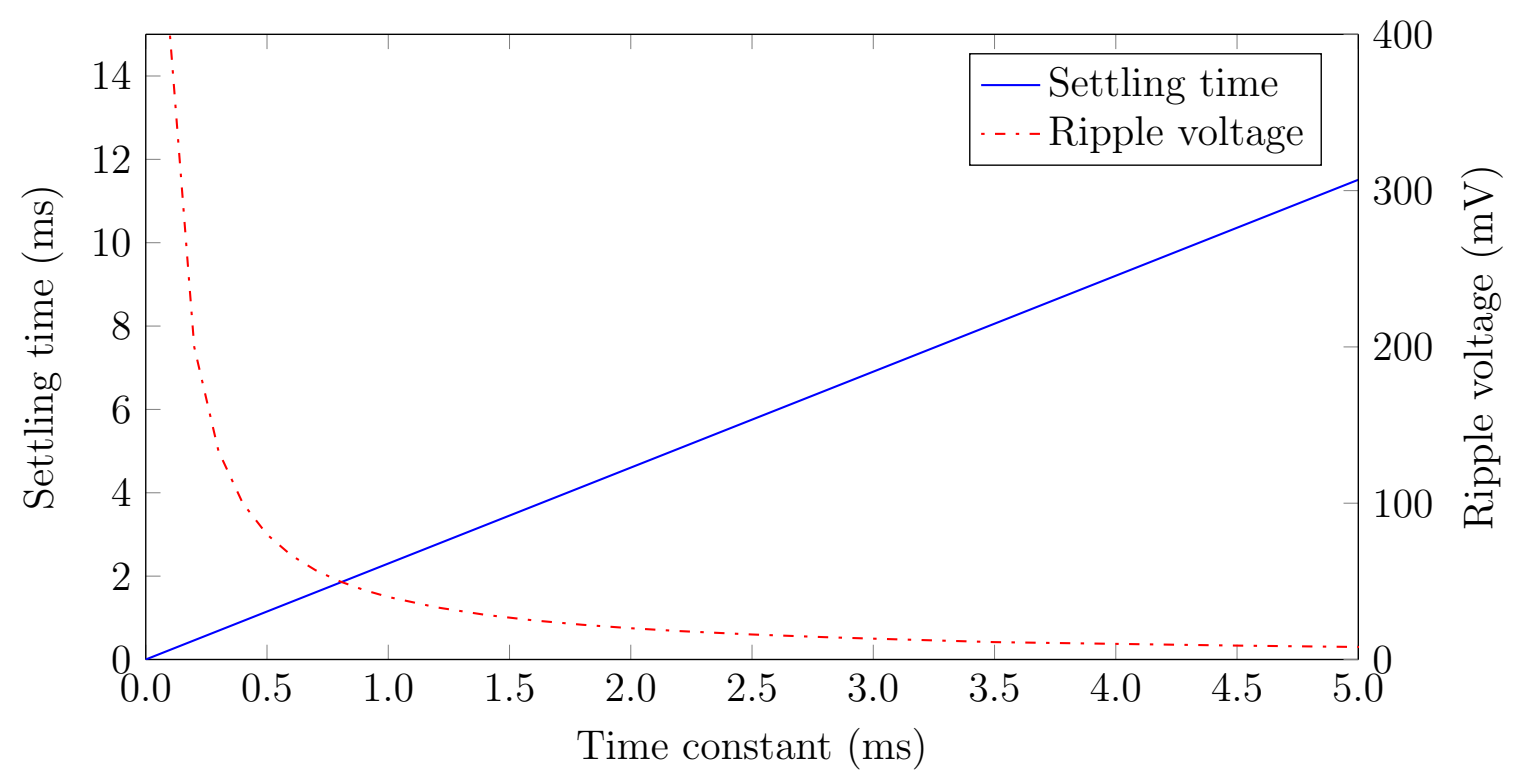

Figure 5.4: RC time constant effects on ripple voltage and settling time.

Electric Design [50] and where the time constant is the product of the resistance and capacitance, $\tau=R \cdot C$.

The Arduino Mega 2560 has a resolution of $19.5 \mathrm{mV}[26]$. The resistor and capacitor were selected to limit the ripple voltage associated with the low-pass filter to twice the resolution of the Arduino while simultaneously achieving a low settling time. Using the results from Figure 5.4, resistor and capacitor values of $2.2 \mathrm{k} \Omega$ and $0.47 \mu \mathrm{F}$, respectively, were selected. This low-pass filter results in a ripple voltage of 
$38.6 \mathrm{mV}$ and a settling time of $2.98 \mathrm{~ms}$.

It should be noted that the rendering settings on the main computer were set for maximum performance to increase the frequency of flight model calculations. With these settings X-Plane averaged around 50 frames per second. In other words, updates to X-Plane occur roughly every $20 \mathrm{~ms}$. While the main computer is optimized for performance, the visuals computer is optimized for image (scenery) quality and texture resolution, meaning the visuals computer has lower frame rates. During evaluation, the visuals computer operated at 20 - 25 frames per second.

The latency within the simulator will also be affected by the selection of the computers. The four computers, provided by the project sponsor, were acquired at the onset of the project in 2011. It is hypothesized that newer generation computers could provide higher frame rates, and significantly reduce system latency.

\subsubsection{Data Acquisition}

For an initial evaluation of control inputs, a step input roll signal was sent to the Arduino, while a UDP packet communicated current control input states from X-Plane. The objective of this evaluation was to determine latency between the deflection of the control inputs and the signals being received by the flight model. As these numbers are not calculated by the flight model, this latency is not affected by the computation time required by the flight model. Figure 5.5 shows a schematic of this loop. The results, demonstrated in Figure 5.6, averaged around $12 \mathrm{~ms}$ of latency in acknowledging changes in the flight control inputs. It should be noted that the evaluation will introduce new latencies into the loop; however, results obtained will be interpreted as worst case data acquisition results. 


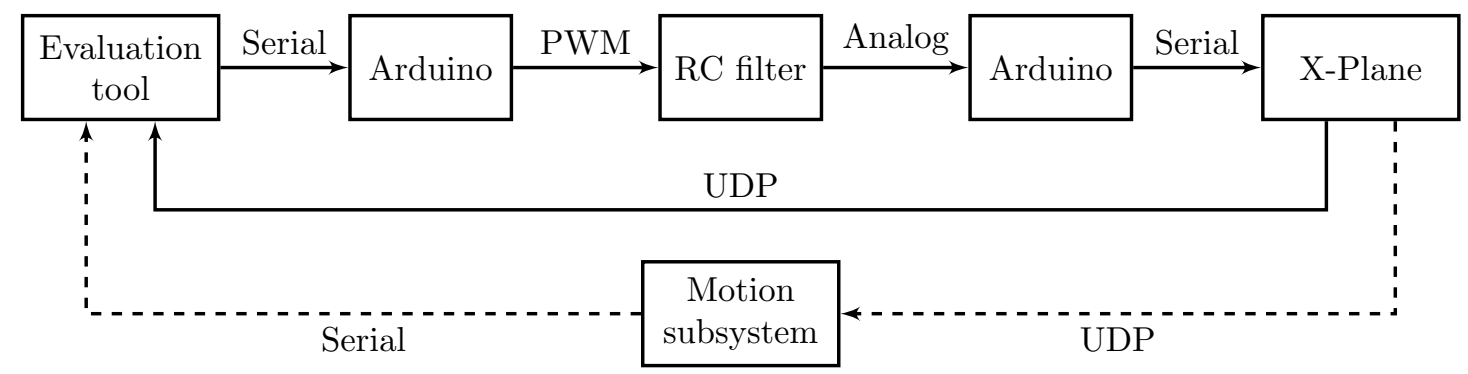

Figure 5.5: Schematic of evaluation loop.

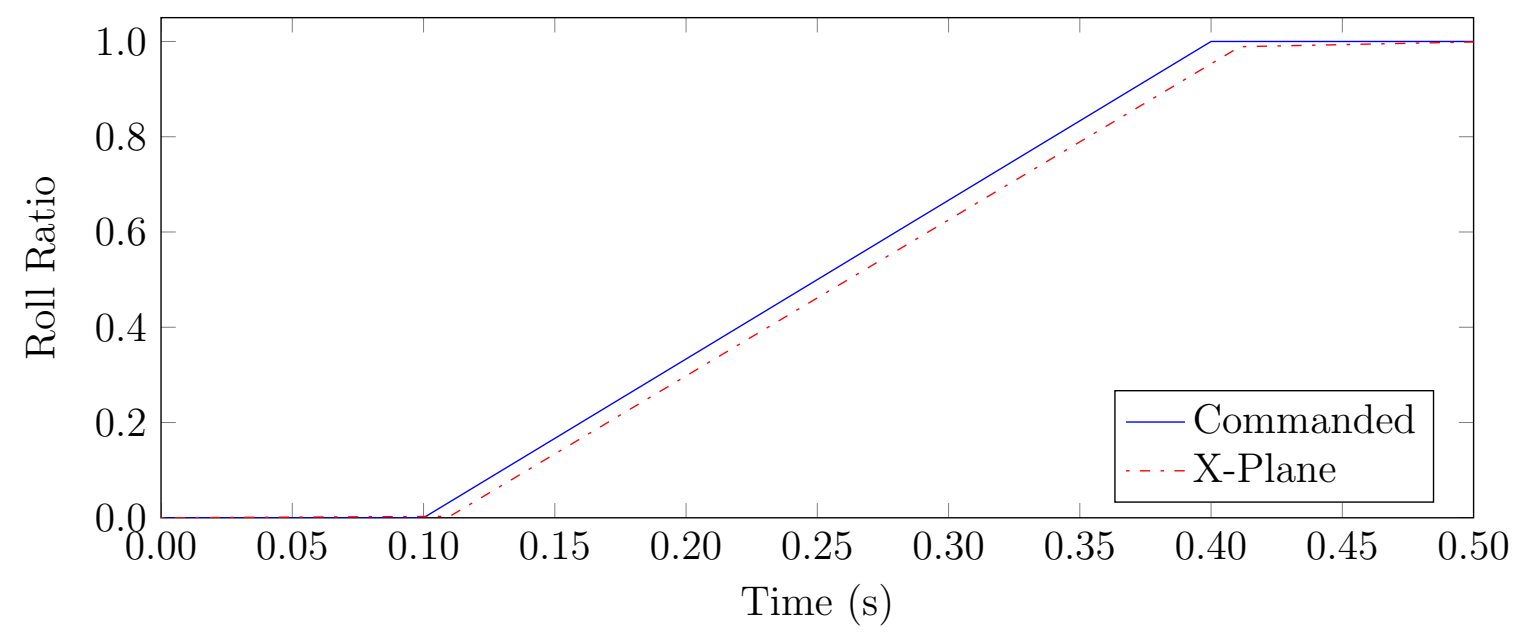

Figure 5.6: Flight control input latency evaluation.

\subsubsection{Motion Cueing}

As motion was a focal point of this thesis, the evaluation of the motion was slightly more involved. For a quantitative evaluation of the motion cueing, it was important to look for false or missing motion cues, as well as to evaluate the overall latency of the motion cueing. In Chapter $3,0.5 \mathrm{~m} / \mathrm{s}^{2}$ was selected as the limit for the translational acceleration. The following describes how the gain for the motion tuning was finalized. 


\section{False or Missing Motion Cues}

To determine if the simulator would result in any false or missing motion cues, motion data from specific manoeuvres from the flight testing were fed into the motion platform, and then the motion response of the simulator was recorded. A subset of this response is shown in Figure 5.7. This subset demonstrates the ability of the motion base to replicate onset accelerations as well as sustained accelerations. For the same subset of data, Figure 5.8 demonstrates that a significant portion of the surge acceleration results from the orientation, which on the motion base is replicated through tilt coordination. The gain of 0.25 resulted in no missed motion cues, while the motion platform angular accelerations did not result in any significant false cues. Larger gains resulted in translational limits being hit, and motion cues being missed, while smaller gains resulted in further suppression of the motion.

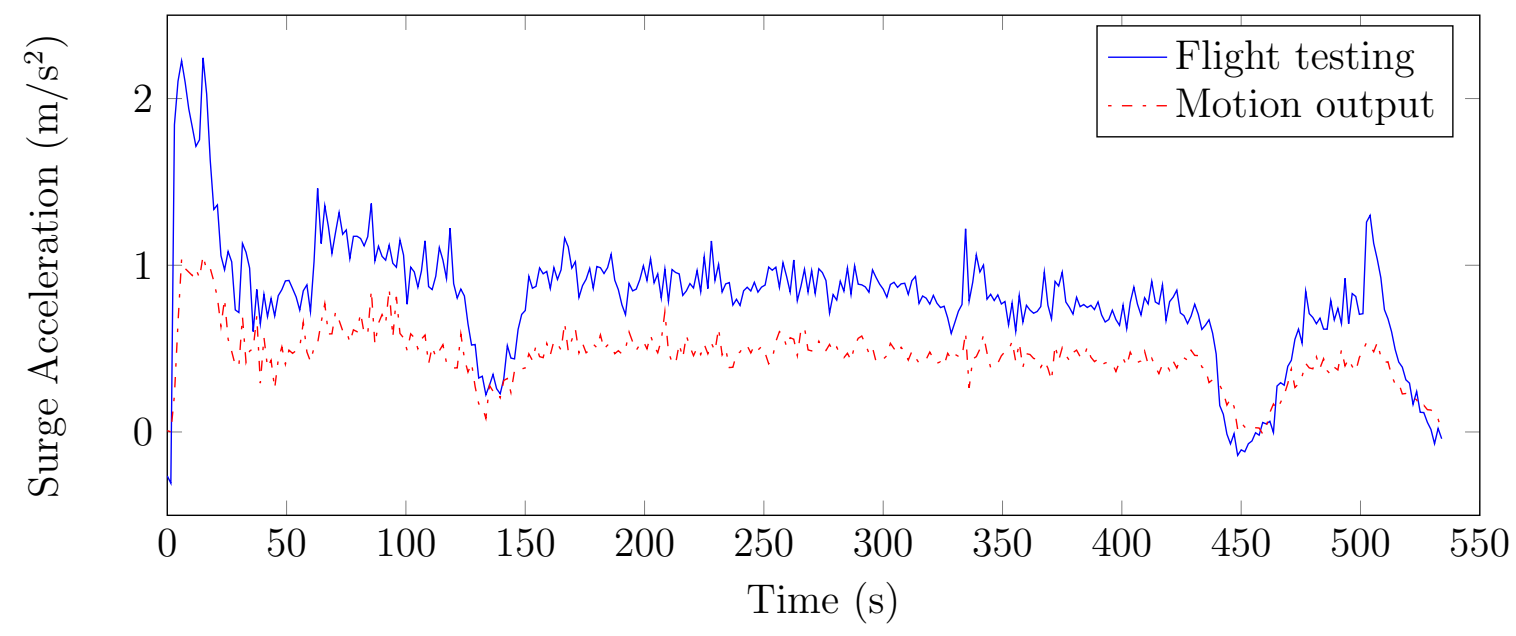

Figure 5.7: Motion response to flight testing data.

\section{Motion Cueing Latency}

The evaluation of latency in the motion cueing made use of the motion platform control program discussed in Chapter 3. The platform began at rest, and 


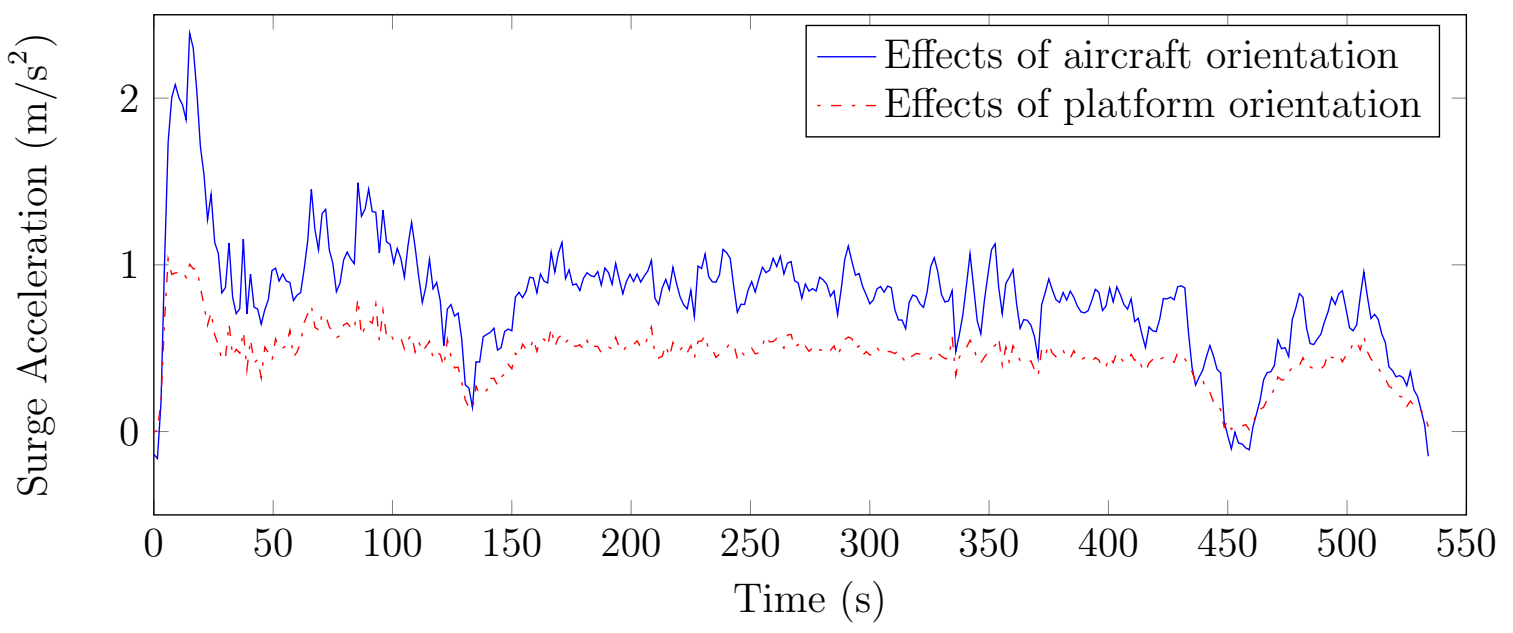

Figure 5.8: Orientation effects on surge acceleration.

then was perturbed, with the latency measured as the delay in initial response. Figure 5.9 shows the platform response to sinusoidal and step surge acceleration inputs. For both inputs, the onset of motion began within well under $25 \mathrm{~ms}$ of the onset of the commanded motion. This result is below the $150 \mathrm{~ms}$ limitation in latency required for minimal negative effect on the pilot [1]. This same benchmark of $150 \mathrm{~ms}$ is required for all levels of Transport Canada certified FFSs [16].

\subsubsection{Visual Cueing}

To evaluate the response time of the visuals, a high-speed camera was temporarily installed in the cockpit facing forward as shown in Figure 5.10, for an evaluation adapted from Galloways's lecture on flight simulator validation and evaluation [51]. The camera used was a PL-B771 Machine Vision Camera from PixeLINK [52], configured for 500 frames per second at 120 by 90 pixel image resolution. The camera was positioned behind the seats providing the camera with a view of the top of the instrument panel as well as the projection screen. A bright LED was temporarily installed in the top of the instrument panel. The LED was wired into 

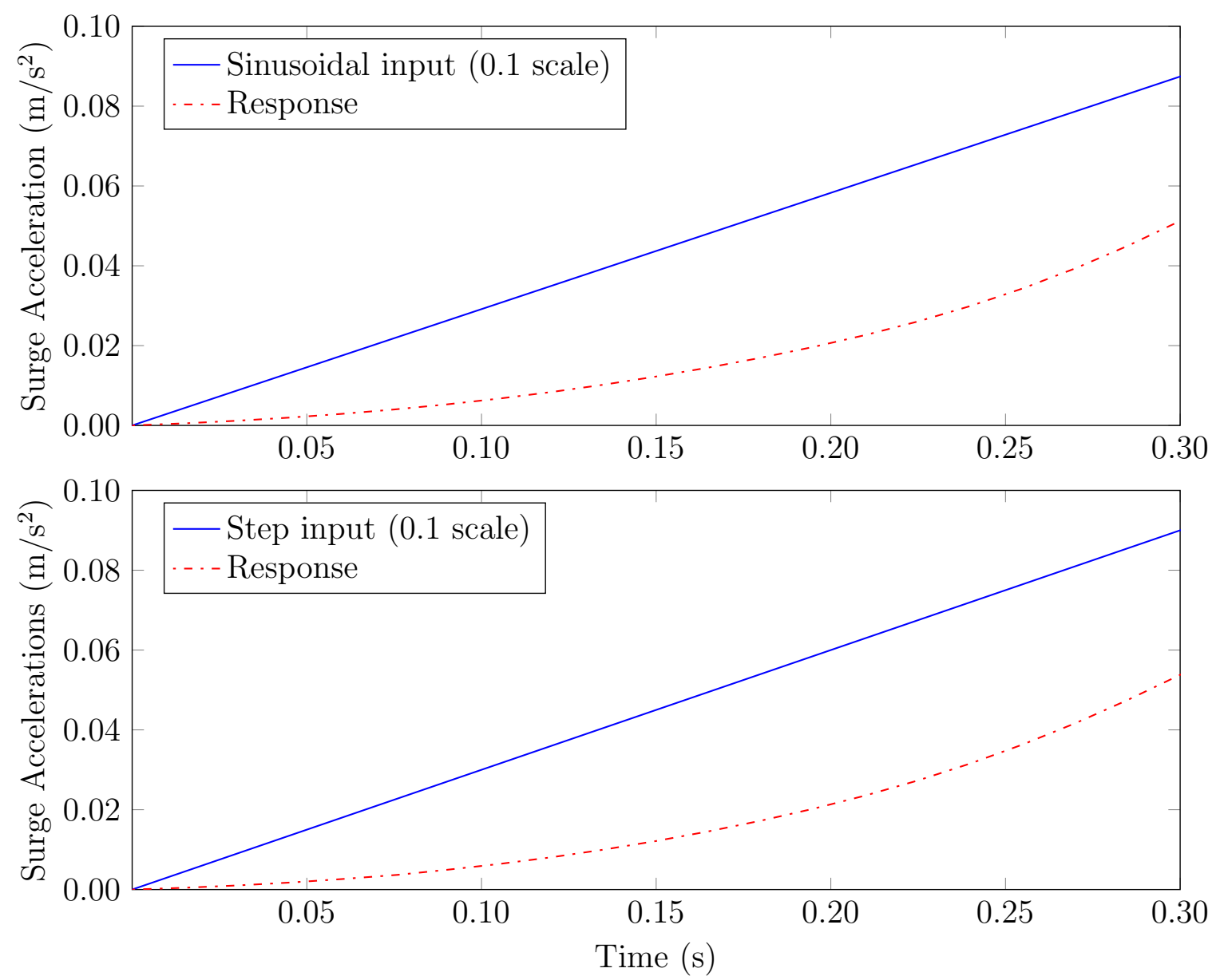

Figure 5.9: Platform response to sinusoidal and step surge acceleration inputs.

one of the switches on the instrument panel, such that when the switch is in the ON position, the LED is illuminated. Furthermore, the X-Plane plugin was temporarily reconfigured such that when the switch was in the ON position, the simulation would be set to midnight, whereas in the OFF position, the simulation would be set to noon. This configuration provided high contrast that is easy for the camera to pick up, and was less subjective for estimating the initiation of a response.

The test plan for this evaluation was to begin video recording with the switch in the ON position, and then switch it to the OFF position. The camera could then capture when the LED turns off and then determine the length of time required for 


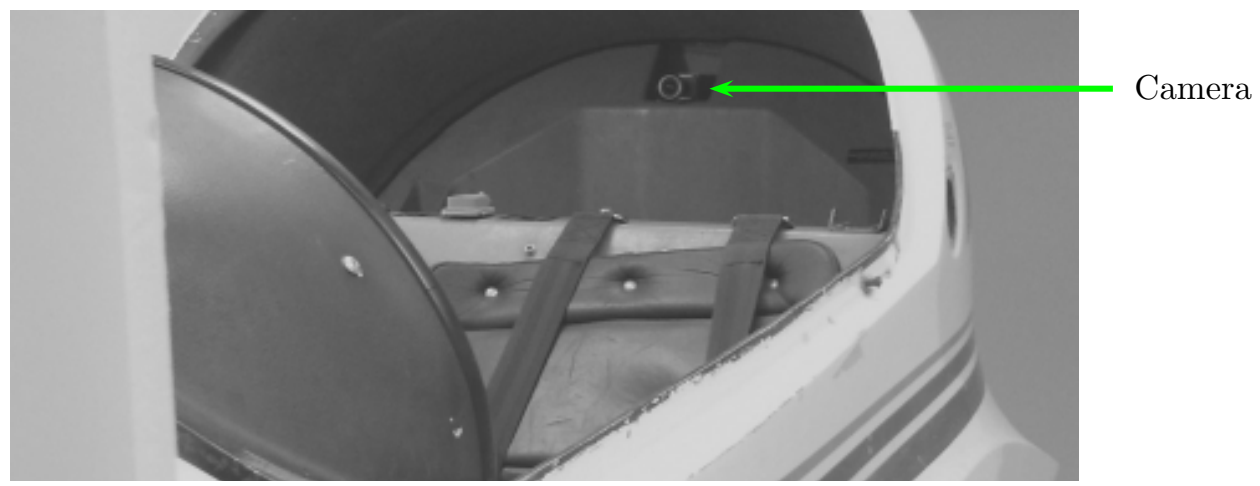

Figure 5.10: Visual cueing response latency evaluation setup.
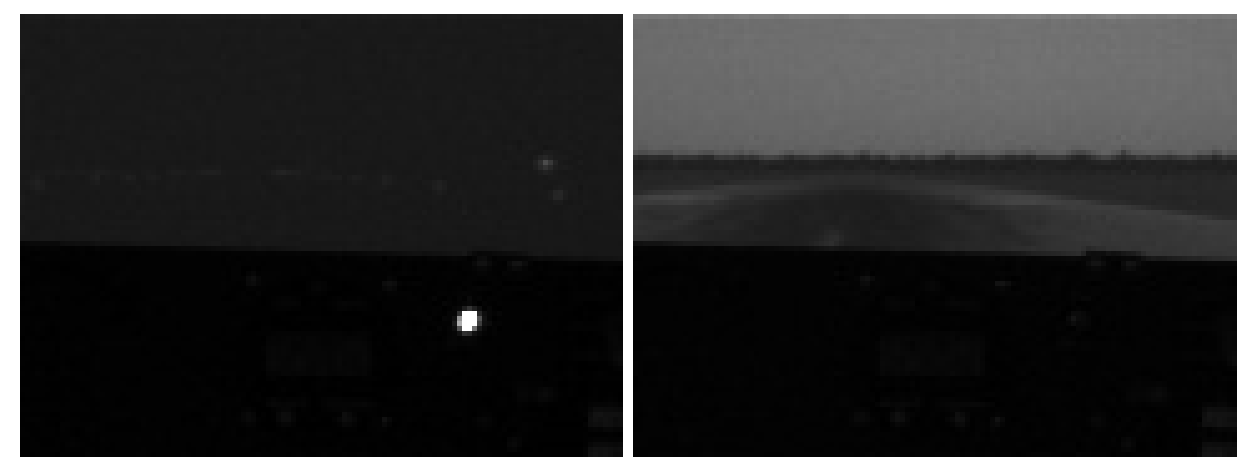

Figure 5.11: Visual cueing response latency evaluation where the left frame shows the LED ON and outside visuals dark, while the right frame shows the LED OFF and the outside visuals lit up.

daylight to be shown in the visuals. This is demonstrated in Figure 5.11.

The test was performed with the projector connected directly to the main computer, as well as connected to the computer intended to be used for external visuals. The reason behind this configuration was to determine any latencies associated with transmitting the data from one computer to another computer for the visual cueing. The results, presented in Table 5.2, demonstrated that about $45 \mathrm{~ms}$ of latency results from using the second computer for external visuals. As previously discussed, the visuals computer operated at 20 - 25 frames per second, resulting in updates every 40 to $50 \mathrm{~ms}$, which would account for the increased latency. 
Table 5.2: Visual cueing latency results.

\begin{tabular}{|c|c|c|}
\hline Test no. & Direct visuals latency $(\mathrm{ms})$ & External visuals latency $(\mathrm{ms})$ \\
\hline \hline 1 & 154 & 178 \\
2 & 141 & 192 \\
3 & 143 & 192 \\
4 & 123 & 162 \\
5 & 137 & 192 \\
\hline \hline Avg. & 139.6 & 183.2 \\
\hline
\end{tabular}

For certification, Transport Canada provides two benchmarks for latency in visual cueing. For the lower level A and B FFSs, Transport Canada requires less than $300 \mathrm{~ms}$ of latency in the visual cueing, meaning the KatanaSim visuals meet the requirement. Higher level $\mathrm{C}$ and D FFSs require faster visual cueing with less than $150 \mathrm{~ms}$ of latency. While the current configuration of the KatanaSim does not meet the requirements of the higher level FFSs, it is expected that the latency could be reduced with upgrades to the computers to achieve higher X-Plane frame rates without penalty to texture resolution.

\subsection{Qualitative Evaluation}

Not all aspects of the simulator could be given a proper quantitative evaluation. Development of a type-specific full-flight simulator often requires qualitative evaluation of the simulator to ensure proper behaviour of the components, as well as appropriate look and feel. While the qualitative assessments presented in the following were performed with certification guidelines as a benchmark, the objective of the assessments was to evaluate the hardware for the purpose of the project, and not certification. The qualitative assessments were made based on feedback from 
Applied Dynamics Laboratory researchers with ab-initio flight training experience, as well as some feedback provided by OAS flight instructors. The following sections will expand on the assessment of certain features presented in Table 5.1.

\subsubsection{Simulator Controls and Inputs}

The first assessment for all the simulator controls and inputs was in determining whether changes in pilot commands (control inputs) resulted in the expected response within X-Plane.

For the analog inputs such as the flight controls and brakes, the assessment involved making deflections in the inputs, and ensuring appropriate deflection in both magnitude and direction in the outputs. When the analog inputs were deemed too sensitive, software modifications were implemented to decrease input sensitivity within X-Plane.

For the digital inputs, such as the switches and circuit breakers, the input was toggled and assessed for the appropriate response in X-Plane.

Following this assessment, it was determined that there are no known issues with acquiring and interpreting simulator controls and inputs within X-Plane. To ensure accurate readings, it is recommended that the analog inputs be calibrated regularly.

The ultimate objective for control loading of the flight controls is the implementation of active control loading to replicate force feedback from the aircraft. However, the project sponsor proposed postponing active control loading, due to costs, with the active control loading to be investigated further upon completion of the current 
feasibility assessment. In the interim, the lack of control loading was found to be distracting, and had a negative impact on the flight simulation experience. Thus, the passive control loading system described in Chapter 2 was implemented by Suzanne Swaine [24]. The passive control loading is currently only implemented on the control stick, for passive control loading of the pitch and roll inputs. Passive control loading for the rudder pedals has been recommended to improve fidelity in the yaw inputs, but is yet to be implemented. While the current passive control loading system was found to be too loose, the tendency of the system to return the flight controls to a relatively neutral position was found to be an improvement in physical fidelity.

The passive control loading for the brakes was implemented by Suzanne Swaine through the use of the original brake lines and aircraft grade brake fluid to provide realistic feel to the toe brakes [24]. The toe brakes function correctly; however, matching the pressure of the toe brakes with those in the aircraft proved challenging, and they do not yet provide the desired feel.

\subsubsection{Instruments}

Table 5.3 lists the simulated instruments currently installed in the simulator, as well as their status [24]. Despite considerable progress in resolving most instrument problems, challenges continue to exist that are attributed primarily to fundamental issues with the COTS instruments themselves and the related software [24].

For basic flight training, the focus typically is on the six left-most navigation instruments on the instrument panel (general aviation six-pack) as well as the two top-most instruments from the powerplant instruments (manifold pressure and propeller speed), as these instruments allow the pilot to properly set the 
Table 5.3: Status of simulated instruments.

\begin{tabular}{|c|c|}
\hline Instrument & Status \\
\hline Airspeed Indicator ${ }^{*}$ & Functional \\
\hline Turn Coordinator $^{*}$ & Functional - though overly sensitive to yaw \\
\hline Artificial Horizon ${ }^{*}$ & Functional \\
\hline Gyrocompass $^{*}$ & Functional \\
\hline Altimeter ${ }^{*}$ & Functional \\
\hline Vertical Speed Indicator ${ }^{*}$ & Functional \\
\hline VOR & Functional \\
\hline DME & Functional \\
\hline Manifold Pressure ${ }^{* *}$ & Functional \\
\hline Propeller Speed $^{* *}$ & Functional \\
\hline Oil Pressure & Functional \\
\hline Oil Temperature & Functional \\
\hline Voltmeter & Functional \\
\hline Cylinder Head Temperature & Functional \\
\hline Ammeter & Calibration difficulties \\
\hline Fuel Gauge & Configuration difficulties \\
\hline
\end{tabular}

configuration of the aircraft for each desired manoeuvre. At the time of writing, the only instrument within this list with ongoing issues is the turn coordinator, which often demonstrates too large a sensitivity to yaw inputs.

\subsubsection{Motion Cueing}

As previously discussed, part of the motion tuning is a subjective evaluation of how the motion feels. The KatanaSim motion was tuned by taking into account 
the feedback provided by the Applied Dynamics Laboratory researchers. While no formal assessment was performed, the operators flew the simulator configured for each of the motion tuning parameters listed in Table 3.3, and offered 'better or worse' feedback on the quality of the motion cueing. While damping was only applied to the heave acceleration, as a consensus, the operators preferred the high-pass filter to be overdamped as opposed to underdamped or critically damped. Based on this assessment, the tuning set from test number 6 was selected for the default KatanaSim motion tuning set. In particular, this resulted in the recommended set of tuning parameters provided in Table 5.4.

Table 5.4: Selected motion tuning parameters.

\begin{tabular}{|c|c|c|c|c|}
\hline $\begin{array}{c}\text { Translational } \\
\begin{array}{c}\text { Acceleration } \\
\text { Limit } \\
\left(\mathrm{m} / \mathrm{s}^{2}\right)\end{array}\end{array}$ & $\begin{array}{c}\text { Translation } \\
\text { High-pass Break } \\
\text { Frequency } \\
(\mathrm{rad} / \mathrm{s})\end{array}$ & $\begin{array}{c}\text { Translational } \\
\text { Displacement } \\
\text { Limits }(\mathrm{m})\end{array}$ & Gain & $\begin{array}{c}\text { Damping } \\
\text { Ratio }\end{array}$ \\
\hline \hline 0.50 & 2.425 & 0.085 & 0.25 & 1.4 \\
\hline
\end{tabular}

\subsubsection{Visual Cueing}

Following qualitative assessment of the visual cueing, no latencies were observed by the participants. The only concern with the visual cueing was the limitation in the horizontal field of view resulting from the single flat screen. While the Katana aircraft offers greater than 200 degrees of horizontal field of view, the current visual cueing only offer a 65 degree horizontal field of view. This limited horizontal field of view makes certain exercises more difficult for the pilot to perform. These exercises, such as circuits, often rely on being able to look directly to your side, or further back, for proper execution of the exercise. 


\subsubsection{Flight Model}

As previously discussed, one objective of the KatanaSim project was the development of a Katana flight model by Suzanne Swaine [24]. While significant progress has been made, several flight performance points were compared to flight test data, and did not match. A full assessment of the flight model can be found in Suzanne's thesis [24].

As the interim flight model was developed by an X-Plane hobbyist, no formal assessment has been performed on that flight model. An informal qualitative assessment of the flight model performed determined that the flight model is suitable for basic manoeuvres. However, as the flight model does not accurately replicate the performance of the Katana in all stages of flight, work will continue on the flight model developed by Suzanne Swaine.

\subsection{Discussion}

The current configuration of the simulator makes the device well suited for ab-initio flight training. The simulator provides an ideal platform for student pilots for cockpit familiarization and basic flight training in a safe and controlled environment. While the performance of the simulator flight model does not currently match the performance of the Katana aircraft, the flight model sufficiently demonstrates the effects of control inputs for single-engine, primarily-recreational, aircraft.

In terms of the current deficiencies with the simulator, solutions exist. The assessment of the simulator identified certain COTS to be problematic; however, if these problems are not resolved with those particular COTS components, the problems can be circumvented either through the development of custom solutions 
or a different selection of COTS components.

For the borderline-acceptable latencies observed in the visual cueing, it was hypothesized that faster, currently-available computers would likely reduce latencies. Furthermore, as the proposed thresholds on visual cueing are for high-level FFSs certified by Transport Canada, and as no latencies in visual cueing were observed by participants, the latency in the visual cueing is deemed acceptable for the scope of this project.

From the assessment of the motion cueing, it was determined that the motion cueing in the simulator created a more immersive environment for the pilot. Among participants, motion cueing was found to play a more crucial role in the simulator given the limited field of view provided by the visual cueing. While the tuned motion cueing received mostly positive feedback from participants, a few participants felt that certain degrees of freedom did not offer as much motion as they would have liked; an unfortunate consequence of using a small motion base for flight simulation. 


\section{Chapter 6}

\section{Conclusion}

To assist small flight schools with improving access to flight simulators, the KatanaSim project was undertaken to assess the feasibility of developing a low-cost, high-fidelity Diamond DA20-A1 'Katana' full-flight simulator targeting ab-initio flight training. A prototype was developed and assessed for functionality of equipment.

To minimize costs while maintaining high physical fidelity, original aircraft components were used where feasible. The prototype was built around a Katana fuselage, with original flight controls installed. Data acquisition components were integrated into the system to obtain pilot control input values, and the system was then interfaced, through software developed in-house, to the virtual simulation environment.

For several of the simulator components, such as the flight instruments and circuit breakers, use of original components was not considered feasible. In these cases, commercial off-the-shelf components were researched and those best replicating the original components were acquired and integrated.

Through a review of commercially-available flight simulation software, X-Plane 
by Laminar Research was selected as the virtual environment for the KatanaSim. The software development kit provided with X-Plane allows development of software for interfacing the physical components of the simulator. Furthermore, the accurate aerodynamic calculations resulting from the custom-made Katana flight model [24] and high-quality scenery provided with X-Plane contribute to the high level of functional fidelity of the simulator.

Despite initial plans for an externally developed projection system for producing a fully-immersive visual environment, visual cueing for the KatanaSim was provided by a more limited interim single-projection system onto a flat screen.

Finally, motion cueing was implemented for the KatanaSim through the use of the Moog six-degree-of-freedom Gough-Stewart motion platform located within the Applied Dynamics Laboratory. Combining Katana flight test performance results with the limited motion of the motion base, a washout algorithm was tuned to provide the KatanaSim with suitable motion cueing.

Following an assessment of the prototype simulator, it was determined that it is feasible to develop high-fidelity, type-specific, full-flight simulators for ab-initio flight training. While the current prototype demonstrated some deficiencies that would limit the extent of training for which the simulator would likely be used, means of reducing these deficiencies have been presented in this thesis. 


\subsection{Contributions}

The KatanaSim project has created a foundation on which full-flight simulators for ab-initio flight training can be developed. For this project, this thesis has demonstrated the benefits of using potentiometers and Arduino microcontroller boards for interfacing original aircraft components to the virtual environment. For the methods presented in this thesis, the Arduinos needed to be programmed for reading both analog and digital inputs from the control inputs and for transmitting the required data to the virtual environment.

The primary contribution of this thesis was the use of a small motion platform for the purpose of a small aircraft full-flight simulator. This was accomplished by taking advantage of thresholds on the human body's ability to sense motion. Below these thresholds, the human vestibular system encounters difficulty in identifying motion. For the Katana simulator, an appropriately-tuned combination of high-pass and low-pass filters, known as a washout algorithm, was applied to X-Plane vehicle motions in order to maximize the performance of the small six-degree-of-freedom Gough-Stewart motion platform.

In order to properly implement the washout algorithm, aircraft motion data was required. The final contribution of this thesis was development of a flight testing plan and associated instrumentation interface. For the flight test, this thesis contributed to the selection of instrumentation and to the means through which all the instrumentation interfaced. In particular, a software interface was developed to synchronize and record data from all the instrumentation. 


\subsection{Future Work}

Following the positive outcome of the feasibility assessment of the KatanaSim project, the following considerations are offered for the next phase of the project.

1. Time should be invested into selecting newer generation computers to provide higher frame rates while reducing system latency, and potentially reducing latency in the visual cueing.

2. To improve the effectiveness of the Katana simulator in flight training, the visual cueing will require a larger horizontal field-of-view. Discussions with BCon Engineering Inc. should occur to make another push for development of the canopy-based visual cueing system. Alternatively, a domed screen could be fabricated such that visuals could be warped and blended using software such as Warpalizer [53] to create an immersive visual environment.

3. With improvements to the above listed deficiencies, as well as improvements to the instrumentation, further consideration should be given to Transport Canada certification requirements. As the main objective in the development of the prototype simulator was feasibility of development, some improvements to the design may be required to meet all Transport Canada requirements.

4. Though not fully emphasized in this thesis, the work presented has resulted in the development of substantial amounts of code in $\mathrm{C}, \mathrm{C}++, \mathrm{C \#}$, and Fortran. Given the extent of development languages used for the KatanaSim project, some form of build automation should be considered.

This project offers good potential to have a positive impact on ab-initio flight training. Work must continue to ensure that access to quality flight simulators extends beyond commercial airlines and larger flight schools. 


\section{References}

[1] D. Allerton. Principles of flight simulation. American Institute of Aeronautics and Astronautics ; Wiley, Reston, VA, USA, 2009.

[2] J. M. Rolfe and K. J. Staples, editors. Flight Simulation. Cambridge University Press, New York, NY, 1986.

[3] Center for Technology \& Innovation. Link Trainer Sales and Services. www.linktrainers.com. [Accessed April 2014].

[4] CAE Inc. www.cae.com. [Accessed: November 2013].

[5] Mechtronix Systems. www.mechtronix.com. [Accessed: November 2013].

[6] Thales Group. www.thalesgroup.com. [Accessed: November 2013].

[7] Rockwell Collins. www.rockwellcollins.com. [Accessed: November 2013].

[8] Transport Canada. Approved Flight Training Devices. wwwapps.tc.gc.ca/saf-secsur $/ 2 /$ aasftd-devsaa $/$ r.aspx lang $=$ eng\&lst $=2 \&$ tcid $=\&$ faaid $=\& s=2 . \quad[$ Accessed: September 2013].

[9] Transport Canada. Approved Full Flight Simulators. wwwapps.tc.gc.ca/saf-secsur $/ 2 /$ aasftd-devsaa $/$ r.aspx?lang $=$ eng\&lst $=1 \&$ tcid $=\&$ faaid $=\& s=2 . \quad[$ Accessed: September 2013].

[10] B. N. Angier, E. A. Alluisi, and S. A. Horowitz. Simulators and enhanced training. Technical report, DTIC Document, 1992.

[11] A. Levin. NTSB: Pilots need air-hazard skills. USA Today, March 2010.

[12] T.M. Kirton. Integrating level 6 flight training devices into flight training programs at the beginning pilot level: challenges and opportunities. In Proceedings of the Digital Avionics Systems Conference, October 2002. 
[13] N.D. Macchiarella. Advancements in flight training devices for ab initio pilot use. In Proceedings of the AIAA Modeling and Simulation Technologies Conference and Exhibit, August 2008.

[14] Transport Canada. Part IV - Personnel Licensing and Training - Standard 421 - Flight Crew Permits, Licences and Ratings, June 2008.

[15] Redbird Flight Simulations Training Devices for Aviation. www.redbirdflightsimulations.com. [Accessed: November 2013].

[16] Transport Canada. Aeroplane and Rotorcraft Simulation Manual. www.tc.gc.ca/eng/civilaviation/publications/tp9685-menu-5226.htm, January 1998. [Accessed: June 2011].

[17] J. R. Hall. The need for platform motion in modern piloted flight training simulators. Technical report, DTIC Document, 1989.

[18] J. Bürki-Cohen, N. N Soja, and T. Longridge. Simulator platform motion-the need revisited. The International Journal of Aviation Psychology, 8(3):293-317, 1998.

[19] J. A. Wise, V. D. Hopkin, and D. J. Garland. Handbook of Aviation Human Factors. CRC Press, Boca Raton, FL, 2nd edition, 2010.

[20] A. Robinson and K. Mania. Technological research challenges of flight simulation and flight instructor assessments of perceived fidelity. Simulation \& Gaming, 38(1):112-135, 2007.

[21] Transport Canada. Aeroplane: Flight Training Manual, March 1994. Fourth Revision.

[22] S. Swaine, J. Plumpton, J. Leveille, and R. Langlois. Feasibility assessment of a cost-effective type-specific small aircraft flight simulator. In Proceedings of the Canadian Society for Mechanical Engineering International Congress, June 2012 .

[23] A.Hunt. Diamond DA20-A1. en.wikipedia.org/wiki/Diamond_DA20. [Accessed March 2014].

[24] S. Swaine. Development of a Cost-effective High-fidelity Type-specific Flight Simulator with Emphasis on Flight Modelling. Master's thesis, Department of Mechanical and Aerospace Engineering, Carleton University, May 2014. 
[25] Welding Bell's Machining and Hydraulics. www.bellsmachining.com. [Accessed: November 2013].

[26] Arduino SA. www.arduino.cc. [Accessed: November 2013].

[27] Celesco Transducer Products Inc. Linear Position: Stringpots Overview. www.celesco.com/stringpots/index.htm, August 2013. [Accessed: August 2013].

[28] Diamond Aircraft Industries. DA20-A1 Airplane Flight Manual, January 2012. Doc\# 202, Revision 18.

[29] TRC Simulators. www.simkits.com. [Accessed: November 2013].

[30] Flight Illusion BV. www.flightillusion.com. [Accessed: November 2013].

[31] Klixon. www.sensata.com/klixon/circuit-breaker-aircraft-3sb.htm. [Accessed: November 2013].

[32] A. Meyer. X-Plane Operation Manual. www.x-plane.com/v10-online-desktopmanual/, July 2013. [Accessed: August 2013].

[33] Diamond DA20. forums.x-plane.org/index.php?app=downloads\&showfile=22334. [Accessed March 2014].

[34] B-Con Engineering. www.bconeng.com. [Accessed: November 2013].

[35] O. Merhi, E. Faugloire, M. Flanagan, and T. A. Stoffregen. Motion sickness, console video games, and head-mounted displays. Human Factors: The Journal of the Human Factors and Ergonomics Society, 49(5):920-934, 2007.

[36] Logitech International S.A. Logitech Speaker System Z523. www.logitech.com/en-ca/product/5861?crid=47. [Accessed November 2013].

[37] Moog Inc. Electric Motion Base. www.moog.com/products/motionsystems/motion-bases/electric-motion-basebrmb-e-6dof-12-1000kg-br-formerly6dof2000e-/. [Accessed: July 2013].

[38] M. A. Nahon and L. D. Reid. Simulator motion-drive algorithms-a designer's perspective. Journal of Guidance, Control, and Dynamics, 13(2):356-362, 1990.

[39] A. D. White and V. V. Rodchenko. Motion fidelity criteria based on human perception and performance. In Proceedings of the AIAA Modelling and Simulation Technologies Conference, Portland (OR), August 9, volume 11, pages 485-493, 1999. 
[40] R. Sivan, J. Ish-Shalom, and J. Huang. An optimal control approach to the design of moving flight simulators. IEEE Transactions on Systems, Man and Cybernetics, 12(6):818-827, 1982.

[41] M. A. Nahon, L. D. Reid, and J. Kirdeikis. Adaptive simulator motion software with supervisory control. Journal of guidance, control, and dynamics, 15(2):376383, 1992.

[42] Realtime Technologies Inc. www.simcreator.com/overtilt/overtilt.htm. [Accessed: November 2013].

[43] Xsens Technologies B.V. MTi. www.xsens.com/en/general/mti. [Accessed October 2013].

[44] P. R. Grant and L. D. Reid. Motion washout filter tuning: Rules and requirements. Journal of Aircraft, 34(2):145-151, 1997.

[45] J. Plumpton, S. Swaine, S. Abraham-Doman, R. Langlois, C. Merrett, and J. Laliberté. Carleton University Katana Flight Test Plan. Technical Report ADL/13/JP/1, Applied Dynamics Laboratory - Carleton University, 2013.

[46] R. D. Kimberlin. Flight testing of fixed-wing aircraft. Aiaa, 2003.

[47] 3D Robotics Inc. 3D Robotics - UAV Technology. 3drobotics.com/. [Accessed July 2013].

[48] Anker. Anker Astro Pro2 20000mAh Multi-Voltage External Battery. www.ianker.com/product/79AN20L-SA\#sthash.17oJLWgx.dpuf. [Accessed October 2013].

[49] DIY Drones. APM Open source autopilot. ardupilot.com/. [Accessed July 2013].

[50] Okawa Electric Design. RC Low-pass Filter Design for PWM. sim.okawadenshi.jp/en/PWMtool.php. [Accessed February 2014[.

[51] R.T. Galloway. Validation and evaluation. Annual Flight Simulation Update Lecture Notes, State University of New York, Binghamton, New York, January 2005 .

[52] PixeLINK. PL-B771 Machine Vision Camera. www.pixelink.com/products/PLB771-details.aspx. [Accessed March 2014].

[53] UniVisual. Warpalizer. www.warpalizer.com. [Accessed April 2014]. 
Appendix A

Flight Test Data Format 


\begin{tabular}{|c|c|c|c|}
\hline Parameter & Description & Unit & $\mathrm{C}++$ \\
\hline Time_full & Time of day & hh:mm:ss & $\% \mathrm{~s}$ \\
\hline Time_s & Elapsed time in day & seconds & $\% 0.3 \mathrm{f}$ \\
\hline RollXSens_deg & Aircraft roll (Xsens) & $\operatorname{deg}$ & $\% 0.8 \mathrm{f}$ \\
\hline PitchXSens_deg & Aircraft pitch (Xsens) & $\operatorname{deg}$ & $\% 0.8 \mathrm{f}$ \\
\hline YawXSens_deg & Aircraft yaw (Xsens) & $\operatorname{deg}$ & $\% 0.8 \mathrm{f}$ \\
\hline RollRateXSens_rads & Aircraft roll rate (Xsens) & $\mathrm{rad} / \mathrm{s}$ & $\% 0.8 \mathrm{f}$ \\
\hline PitchRateXSens_rads & Aircraft pitch rate (Xsens) & $\mathrm{rad} / \mathrm{s}$ & $\% 0.8 \mathrm{f}$ \\
\hline YawRateXSens_rads & Aircraft yaw rate (Xsens) & $\mathrm{rad} / \mathrm{s}$ & $\% 0.8 \mathrm{f}$ \\
\hline XAccelXSens_mss & Aircraft surge acceleration (Xsens) & $\mathrm{m} / \mathrm{s}^{2}$ & $\% 0.8 f$ \\
\hline YAccelXSens_mss & Aircraft sway acceleration (Xsens) & $\mathrm{m} / \mathrm{s}^{2}$ & $\% 0.8 \mathrm{f}$ \\
\hline ZAccelXSens_mss & Aircraft heave acceleration (Xsens) & $\mathrm{m} / \mathrm{s}^{2}$ & $\% 0.8 \mathrm{f}$ \\
\hline XMagXSens_g & $\mathrm{X}$-axis magnetic field value (Xsens) & gauss & $\% 0.8 \mathrm{f}$ \\
\hline YMagXSens_g & Y-axis magnetic field value (Xsens) & gauss & $\% 0.8 \mathrm{f}$ \\
\hline ZMagXSens_g & Z-axis magnetic field value (Xsens) & gauss & $\% 0.8 f$ \\
\hline Lat_deg & Latitude position (GPS) & $\operatorname{deg}$ & $\% 0.8 \mathrm{f}$ \\
\hline Long_deg & Longitude position (GPS) & $\operatorname{deg}$ & $\% 0.8 \mathrm{f}$ \\
\hline AltitudeASL_m & Altitude above sea level (GPS) & $\mathrm{m}$ & $\% 0.3 \mathrm{f}$ \\
\hline Airspeed_ms & Aircraft airspeed & $\mathrm{m} / \mathrm{s}$ & $\% 0.5 \mathrm{f}$ \\
\hline Groundspeed_ms & Aircraft groundspeed (GPS) & $\mathrm{m} / \mathrm{s}$ & $\% 0.5 \mathrm{f}$ \\
\hline Verticalspeed_ms & Aircraft vertical climb speed (APM) & $\mathrm{m} / \mathrm{s}$ & $\% 0.5 f$ \\
\hline RollAPM_deg & Aircraft roll (APM) & $\operatorname{deg}$ & $\% 0.8 \mathrm{f}$ \\
\hline PitchAPM_deg & Aircraft pitch (APM) & $\operatorname{deg}$ & $\% 0.8 \mathrm{f}$ \\
\hline YawAPM_deg & Aircraft yaw (APM) & $\operatorname{deg}$ & $\% 0.8 \mathrm{f}$ \\
\hline XAccelAPM_mss & Aircraft surge acceleration (APM) & $\mathrm{m} / \mathrm{s}^{2}$ & $\% 0.8 f$ \\
\hline YAccelAPM_mss & Aircraft sway acceleration (APM) & $\mathrm{m} / \mathrm{s}^{2}$ & $\% 0.8 \mathrm{f}$ \\
\hline ZAccelAPM_mss & Aircraft heave acceleration (APM) & $\mathrm{m} / \mathrm{s}^{2}$ & $\% 0.8 \mathrm{f}$ \\
\hline RollRateAPM_ds & Aircraft roll rate $(\mathrm{APM})$ & $\mathrm{rad} / \mathrm{s}$ & $\% 0.8 \mathrm{f}$ \\
\hline PitchRateAPM_ds & Aircraft pitch rate (APM) & $\mathrm{rad} / \mathrm{s}$ & $\% 0.8 \mathrm{f}$ \\
\hline YawRateAPM_ds & Aircraft yaw rate (APM) & $\mathrm{rad} / \mathrm{s}$ & $\% 0.8 \mathrm{f}$ \\
\hline StickPot1_raw & Left stick potentiometer reading & & $\% \mathrm{~d}$ \\
\hline StickPot2_raw & Right stick potentiometer reading & & $\% \mathrm{~d}$ \\
\hline RudderPot_raw & Rudder potentiometer reading & & $\% \mathrm{~d}$ \\
\hline ManoeuvreNumber & Indicated manoeuvre number & & $\% \mathrm{~d}$ \\
\hline
\end{tabular}


Appendix B

Flight Test Permit 
To. A :

Ottawa Aviation Services

\begin{tabular}{|c|c|c|}
\hline $\begin{array}{l}\text { Nationality and Registration Marks } \\
\text { Marques de nationalité et d'immatriculation }\end{array}$ & $\begin{array}{l}\text { Aircraft Manufacturer and Model } \\
\text { Constructeur et modèe de l'aéronef } \\
\end{array}$ & $\begin{array}{c}\text { Aircraft Serial Number } \\
\text { Numéro de série de l'aéronef }\end{array}$ \\
\hline
\end{tabular}

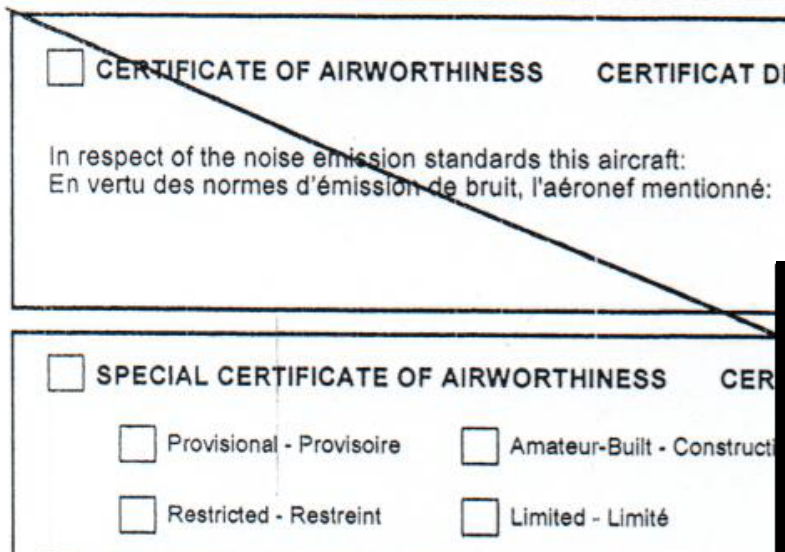

This document is subject to the following operating conditions of issue:

Le present document est assujetti aux conditions d'exploitation suivantes is not required to comply with requirements
n'est pas obligé de satisfaire aux exigences

$\square$ complies with the requirements specified below satisfait aux exigences précisées ci-dessous

The aircraft may only be operated from:

L'aéronef ne peut être exploité qu'à partir de

\section{Gross take-off weight not to exceed \\ Ne pas excéder la masse maximale brute au decollag Ib kg \\ As per Flight Manual - Selon le manuel de vol}

7 Flight Permit - Specific Purpose

$\checkmark$ Permis de vol . Fin Spécifique

$\square$ Ferry Flight

Vol de convoyage

$\square$ Importation or exportation flight

Vol pour fin d'importation ou d'exportation

$\checkmark$ Pour d'autres fins temporaires (Préciser)
Flight Permit - Experimental

Permis de vol - Expérimental

Demonstration, market survey or crew training

Vol de démonstration, étude de marché ou formation d'équipage

\begin{tabular}{c|c|c} 
Flight from-Volde & To. $\bar{A}$ & To- $\bar{A}$ \\
Ottawa International CYOW & 50 Nautical Miles & Ottawa International CYow \\
\hline
\end{tabular}

This document is subject to the following operating conditions of issue:

Le présent document est assujetti aux conditions d'exploitation suivantes
Indicate Numbers:

Inscrire les numéros : $1,2,4,7,10$

\section{The aircraft may only be operated from:} L'aeronef ne peut être exploité qu'à partir de

As Indicated above
Gross take-off weight not to exceed:

Ne pas excéder la masse maximale brute au décollage $1609 \mathrm{lb}$

As per Flight Manual - Selon le manuel de

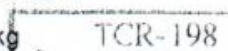

This document is valid for the number of days indicated on the Le présent document reste valide pendant le nombre de jours right, following the date of issue. Where pertinent, a replacement indiqués à droite qui suivent la date de délivrance. S'il y a flight a 98 lieu, ühe autorite de vol de remplacement vous sera délivré.

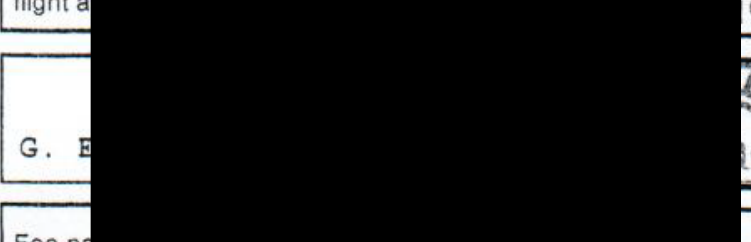

\begin{tabular}{|c|c|}
\hline$\frac{-20=0}{70}$ & Date of Issue - Date de délivrance \\
\hline
\end{tabular}
Date of lssue - Date de délivrance
(yyyy-mm-dd / aaaa-mm-ij) dă 2013-12-23

PAH-OTT ON 


\section{Operating Conditions}

Valid for the purpose of (specify purpose)

Use as a commercial aircraft prohibited;

Crew members only, no passengers;

4. Crew members only - no passengers, except those persons whom the pilot-in-command determines as having a bona fide interest in the demonstration;

5. Crew members shall be the holders of valid and subsisting pilot licences issued or endorsed by Canada or the (state of registry to be specified) and which are appropriate to their duties;

6. Gross take-off weight not to exceed (specific weight to be listed on the flight permit):

7. Flight into known or predicted icing conditions prohibited:

8. VNE to be established by flight test;

9. Day VFR only;

10. VFR only:

11 Flight over built-up areas prohibited:

12. Flight over built-up areas prohibited, and flight in congested airspace to be avoided;

13. Flight over built-up areas prohibited except during take-offs and landings:

14. Flight authority issued by (specify authority) shall be valid and shall be carried on board the aircraft together with this validation;

15. Controlling Air Traffic Control unit to be informed of the experimental nature of the aircraft and the evaluation program prior to flight;

16. The aircraft shall be formally or provisionally registered in (specify state);

17. Compliance required with the conditions on the (specify type of permit and authority);

18. Controlling Agency at airport of take-off shall be informed of overload conditions prior to take-off;

19. Permission of the foreign aviation authority required prior to flight in their airspace;

20. The aircraft can only operate from a base indicated by Transport Canada in order to provide the highest degree of safety for the operation of the aircraft;

21. The aircraft shall not be operated (flown) more than 25 nautical miles from the base mentioned in (20) except with written authority of the Regional Director Aviation Licensing, (specify region) Region, which will be provided, taking into account the safety of the flight;

22. The aircraft shall not be flown over any built-up area, or open air assembly of persons:

23. Carriage of persons other than for dual instruction is prohibited (not to be used for single seat aircraft);

24. Aerobatic flight is prohibited (not to be used for balloons);

25. During the first 5 hours of flight, the aircraft can only be flown by pilots who have acquired not less than 100 hours of pilot-in-command flight time in powered aircraft (not to be used for gliders, gyroplanes, or balloons);

26. Aircraft is to be registered for "Private Purposes" only;

27. Aircraft to be placarded in the cockpit "Restricted - Agricultural Purposes Only":

28. Validity period:

29. Flight testing to be conducted away from built-up areas, airways and air routes:

30. Ferry-flight (specify from) to (specify to) to be via (specify routing) with technical landings as required

31. The side of the aircraft fuselage is to be placarded, in a place that is readily visible to persons entering the aircraft, in letters at least $3 / 8$ inch in height and of a colour that contrasts sharply with the background on which they are shown, in both official languages, as follows:

NOTICE: THIS AIRCRAFT IS OPERATING WITHOUT A CERTIFICATE OF: AIRWORTHINESS.

AVIS : CET AÉRONEF VOLE SANS CERTIFICAT DE NAVIGABILITÉ.

\section{Conditions d'exploitation}

1. Valide aux fins de (préciser les fins):

2. L'exploitation à titre d'aéronef commercial est interdite

3. Membres d'équipage seulement - pas de passagers:

4. Membres d'équipage seulement - pas de passagers, sauf les personnes qui de l'avis du commandant de bord ont un Intérêt réel dans la démonstration

5. Les membres d'équipage doivent être titulaires de licences de pilote valides et en vigueur délivrées ou annotées par le Canada ou (préciser l'État d'immatriculation) et correspondant à leurs fonctions.

6. Ne pas excéder la masse maximale brute au décollage (qui doit être indiquée sur le permis de vol);

7. Vol interdit dans des conditions de givrage existantes ou prévues:

8. La VNE doit être établie par essai en vol:

9. VFR de jour seulement;

10. VFR seulement;

11. Le survol des zones bâties est interdit;

12. Le survol des zones bâties est interdit, et le vol dans un espace aérien à forte densité de circulation est à éviter:

13. Le survol des zones bâties est interdit, sauf au décollage et à l'atterrissage:

14. L'autorité de vol délivrée par (préciser l'autorité) doit être en vigueur et se trouver à bord de l'aéronef avec la présente validation:

15. L'unité de contrôle de la circulation aérienne qui exerce le contrôle doit être informée avant le vol de la nature expérimentale de l'aéronef et du programme d'evaluation;

16. L'aéronef doit être officiellement ou provisoirement immatriculè dans (préciser l'État);

17. La conformité avec les conditions figurant sur le (préciser le type de permis et l'autorité) est obligatoire:

18. L'organisme qui exerce le contrôle à l'aéroport de décollage doit être informé avant le décollage des conditions de surcharge;

19. Le vol dans l'espace aérien étranger est interdit, sauf avec l'autorisation préalable de l'autorité de l'aviation civile étrangère en cause:

20. L'aéronef ne peut être exploité qu'à partir de la base précisée par Transports Canada de façon à garantir le degré optimal de sécurité d'exploitation de l'aéronef;

21. L'aéronef ne peut être exploité que dans une zone d'un rayon maximum de 25 NM de la base mentionnée à l'alinéa 20, sauf avec l'autorisation écrite du directeur régional de la navigabilité, région (préciser la région) qui sera fournie compte tenu de la sécurité du vol:

22. II est interdit de survoler des zones baties ou des rassemblements en plein air;

23. Il est interdit de transporter des personnes sauf pour l'instruction en double commande (ne pas utiliser dans le cas des aéronefs monoplaces);

24. Le vol d'acrobatie aérienne est interdit (ne pas utiliser dans le cas de ballons);

25. Seul un pilote ayant accumulé au moins 100 heures de vol à titre de commandant de bord d'aéronefs propulsés par un organe moteur est autorise piloter cet aéronef au cours des cinq premières heures de vol (ne pas utiliser dans le cas des planeurs, des autogires ou des ballons)

26. L'aéronef doit être immatriculé " à des fins privées » seulement:

27. Une affichette « Restreint - fins agricoles seulement " doit être apposée dans le poste de pilotage;

28. Période de validité:

29. Les essais en vol doivent être effectués hors des zones bâties, des voles aériennes et des routes aériennes:

30. Le vol de convoyage doit être effectué de (préciser la partance) à (préciser la destination) via (préciser la route) avec escales techniques au besoin;

31. Une affichette doit être apposée au cóté du fuselage de l'aéronef, en un endroit facilement visible pour les personnes qui montent dans l'aéronef en lettres d'au moins $3 / 8$ pouce de hauteur et d'une couleur contrastant clairement avec le fond sur lequel elles sont apposées, dans les deux langues officielles, portant les mots:

AVIS : CET AÉRONEF VOLE SANS CERTIFICAT DE NAVIGABILITÉ.

NOTICE: THIS AIRCRAFT IS OPERATING WITHOUT A CERTIFICATE OF AIRWORTHINESS 
Appendix $\mathrm{C}$

Sample Flight Test Data 


\begin{tabular}{|c|c|c|c|c|}
\hline Time_Full & Time_s & RollXSens_deg & PitchXSens_deg & YawXSens_deg \\
\hline 4:25:52 PM & 59152.307 & 0.388057798 & 2.20454216 & 10.23896885 \\
\hline $4: 25: 52 \mathrm{PM}$ & 59152.323 & 0.384875596 & 2.201235294 & 10.23547173 \\
\hline 4:25:52 PM & 59152.338 & 0.383193582 & 2.206255436 & 10.23313808 \\
\hline $4: 25: 52 \mathrm{PM}$ & 59152.354 & 0.383193582 & 2.206255436 & 10.23313808 \\
\hline 4:25:52 PM & 59152.369 & 0.379713446 & 2.212837934 & 10.22737694 \\
\hline $4: 25: 52 \mathrm{PM}$ & 59152.385 & 0.3821567 & 2.217926025 & 10.22112656 \\
\hline 4:25:52 PM & 59152.401 & 0.387446761 & 2.215976954 & 10.21286678 \\
\hline 4:25:52 PM & 59152.416 & 0.385619551 & 2.214838743 & 10.20805073 \\
\hline $4: 25: 52 \mathrm{PM}$ & 59152.432 & 0.385619551 & 2.214838743 & 10.20805073 \\
\hline 4:25:52 PM & 59152.447 & 0.381962895 & 2.214581251 & 10.19785213 \\
\hline $4: 25: 52 \mathrm{PM}$ & 59152.463 & 0.387299269 & 2.209710836 & 10.19959164 \\
\hline 4:25:52 PM & 59152.479 & 0.400893807 & 2.206338167 & 10.19493294 \\
\hline $4: 25: 52 \mathrm{PM}$ & 59152.494 & 0.402055025 & 2.200874567 & 10.19152451 \\
\hline $4: 25: 53 \mathrm{PM}$ & 59152.51 & 0.402055025 & 2.200874567 & 10.19152451 \\
\hline 4:25:53 PM & 59152.525 & 0.411803663 & 2.198526144 & 10.19139099 \\
\hline 4:25:53 PM & 59152.541 & 0.425688088 & 2.202125788 & 10.19701195 \\
\hline 4:25:53 PM & 59152.557 & 0.425688088 & 2.202125788 & 10.19701195 \\
\hline 4:25:53 PM & 59152.572 & 0.439578742 & 2.206454754 & 10.19274235 \\
\hline 4:25:53 PM & 59152.588 & 0.456347138 & 2.200491905 & 10.20003223 \\
\hline 4:25:53 PM & 59152.603 & 0.467498153 & 2.198669434 & 10.19576168 \\
\hline 4:25:53 PM & 59152.619 & 0.477013886 & 2.194159269 & 10.19527054 \\
\hline $4: 25: 53 \mathrm{PM}$ & 59152.635 & 0.477013886 & 2.194159269 & 10.19527054 \\
\hline 4:25:53 PM & 59152.65 & 0.491652131 & 2.189551592 & 10.20083809 \\
\hline $4: 25: 53 \mathrm{PM}$ & 59152.666 & 0.504226804 & 2.186995506 & 10.19783401 \\
\hline $4: 25: 53 \mathrm{PM}$ & 59152.681 & 0.51579088 & 2.178779602 & 10.19672298 \\
\hline 4:25:53 PM & 59152.697 & 0.524517775 & 2.183084726 & 10.19772911 \\
\hline 4:25:53 PM & 59152.713 & 0.524517775 & 2.183084726 & 10.19772911 \\
\hline 4:25:53 PM & 59152.728 & 0.528388798 & 2.183451653 & 10.20207691 \\
\hline 4:25:53 PM & 59152.744 & 0.533580601 & 2.17746973 & 10.20602322 \\
\hline $4: 25: 53 \mathrm{PM}$ & 59152.759 & 0.537770987 & 2.178404808 & 10.20674706 \\
\hline $4: 25: 53 \mathrm{PM}$ & 59152.775 & 0.540107369 & 2.178360939 & 10.20585728 \\
\hline
\end{tabular}




\begin{tabular}{|c|c|c|c|}
\hline Time_seconds & RollRateXSens_rads & PitchRateXSens_rads & YawRateXSens_rads \\
\hline 59152.307 & -0.004275972 & -0.000546155 & 0.001384531 \\
\hline 59152.323 & -0.002434037 & -0.003219403 & 0.000727396 \\
\hline 59152.338 & -0.008777291 & -0.00010171 & 0.000662495 \\
\hline 59152.354 & -0.008777291 & -0.00010171 & 0.000662495 \\
\hline 59152.369 & -0.005535866 & 0.006685067 & -0.002023388 \\
\hline 59152.385 & 0.001794542 & 0.007654351 & -0.004677295 \\
\hline 59152.401 & 0.002963783 & -0.002764401 & 0.001649812 \\
\hline 59152.416 & 0.001732917 & -0.001364767 & -0.001993877 \\
\hline 59152.432 & 0.001732917 & -0.001364767 & -0.001993877 \\
\hline 59152.447 & -0.006600755 & -0.004402961 & -0.009527172 \\
\hline 59152.463 & -0.002104184 & 0.000324334 & 0.003883518 \\
\hline 59152.479 & 0.003796934 & -0.009532796 & 0.004353202 \\
\hline 59152.494 & -0.00206705 & -0.006184695 & -0.009502162 \\
\hline 59152.51 & -0.00206705 & -0.006184695 & -0.009502162 \\
\hline 59152.525 & 0.003672956 & -0.002642746 & 0.007551845 \\
\hline 59152.541 & 0.010336528 & -0.00650316 & 0.01165652 \\
\hline 59152.557 & 0.010336528 & -0.00650316 & 0.01165652 \\
\hline 59152.572 & 0.006912574 & -0.00215966 & -0.007423717 \\
\hline 59152.588 & 0.011957041 & -0.004575183 & 0.003961629 \\
\hline 59152.603 & 0.011162896 & -0.001384332 & 0.000562641 \\
\hline 59152.619 & 0.00300065 & -0.000511058 & 0.000718634 \\
\hline 59152.635 & 0.00300065 & -0.000511058 & 0.000718634 \\
\hline 59152.65 & 0.011749483 & -0.004223695 & 0.009839454 \\
\hline 59152.666 & 0.010639476 & -0.004547559 & 0.002588107 \\
\hline 59152.681 & 0.00701886 & -0.001866261 & 0.002327247 \\
\hline 59152.697 & 0.006487196 & 0.002577846 & 0.004367447 \\
\hline 59152.713 & 0.006487196 & 0.002577846 & 0.004367447 \\
\hline 59152.728 & 0.00268606 & 0.00024111 & 0.009558097 \\
\hline 59152.744 & -0.001455649 & -0.002042969 & 0.011545649 \\
\hline 59152.759 & 0.006550753 & 0.005535355 & 0.002125721 \\
\hline 59152.775 & 0.001137804 & 0.003958846 & 0.001640719 \\
\hline
\end{tabular}




\begin{tabular}{|c|c|c|c|c|}
\hline Time_s & XAccelXSens_mss & YAccelXSens_mss & ZAccelXSens_mss & XMagXSens_g \\
\hline 59152.307 & -0.331775099 & 0.055232715 & 9.826105118 & 0.214422986 \\
\hline 59152.323 & -0.343384862 & 0.014083308 & 9.815753937 & 0.2161275 \\
\hline 59152.338 & -0.326029897 & 0.081235982 & 9.767899513 & 0.215657532 \\
\hline 59152.354 & -0.326029897 & 0.081235982 & 9.767899513 & 0.215657532 \\
\hline 59152.369 & -0.350432068 & 0.064311005 & 9.786483765 & 0.21540831 \\
\hline 59152.385 & -0.375765562 & 0.023840183 & 9.863451004 & 0.217121169 \\
\hline 59152.401 & -0.37416634 & 0.062661029 & 9.892953873 & 0.215417832 \\
\hline 59152.416 & -0.370545179 & 0.086097896 & 9.820031166 & 0.215533063 \\
\hline 59152.432 & -0.370545179 & 0.086097896 & 9.820031166 & 0.215533063 \\
\hline 59152.447 & -0.374701291 & 0.054521076 & 9.795351028 & 0.215520099 \\
\hline 59152.463 & -0.390183002 & 0.052455034 & 9.848455429 & 0.215270162 \\
\hline 59152.479 & -0.400501996 & 0.081475697 & 9.872621536 & 0.216255173 \\
\hline 59152.494 & -0.370307803 & 0.071582749 & 9.812654495 & 0.216246113 \\
\hline 59152.51 & -0.370307803 & 0.071582749 & 9.812654495 & 0.216246113 \\
\hline 59152.525 & -0.368539423 & 0.046722513 & 9.727245331 & 0.216141179 \\
\hline 59152.541 & -0.383298159 & 0.085103236 & 9.726915359 & 0.214898944 \\
\hline 59152.557 & -0.383298159 & 0.085103236 & 9.726915359 & 0.214898944 \\
\hline 59152.572 & -0.365175158 & 0.153082594 & 9.766882896 & 0.217240646 \\
\hline 59152.588 & -0.383714288 & 0.092505611 & 9.746445656 & 0.216494367 \\
\hline 59152.603 & -0.368444651 & 0.092274994 & 9.705515862 & 0.21551612 \\
\hline 59152.619 & -0.383531779 & 0.118815958 & 9.727066994 & 0.216630757 \\
\hline 59152.635 & -0.383531779 & 0.118815958 & 9.727066994 & 0.216630757 \\
\hline 59152.65 & -0.389527291 & 0.12893346 & 9.785434723 & 0.216364935 \\
\hline 59152.666 & -0.423956156 & 0.085688524 & 9.832810402 & 0.215401292 \\
\hline 59152.681 & -0.400057822 & 0.129258007 & 9.83140564 & 0.215892687 \\
\hline 59152.697 & -0.379217416 & 0.140716016 & 9.746829033 & 0.215640023 \\
\hline 59152.713 & -0.379217416 & 0.140716016 & 9.746829033 & 0.215640023 \\
\hline 59152.728 & -0.394257754 & 0.114435785 & 9.785202026 & 0.216862068 \\
\hline 59152.744 & -0.412563324 & 0.158142596 & 9.843301773 & 0.215655327 \\
\hline 59152.759 & -0.389684498 & 0.08581131 & 9.80961132 & 0.214795634 \\
\hline 59152.775 & -0.403256267 & 0.051616322 & 9.772399902 & 0.216483429 \\
\hline
\end{tabular}




\begin{tabular}{|c|c|c|c|c|c|}
\hline Time_s & YMagXSens_g & ZMagXSens_g & Lat_deg & Long_deg & AltitudeASL_m \\
\hline 59152.307 & -0.007544361 & 1.000695586 & 45.3346944 & -75.6888128 & 103.77 \\
\hline 59152.323 & -0.006135745 & 1.001629114 & 45.3346944 & -75.6888128 & 103.77 \\
\hline 59152.338 & -0.007563626 & 0.999870658 & 45.3346944 & -75.6888128 & 103.77 \\
\hline 59152.354 & -0.007563626 & 0.999870658 & 45.3346944 & -75.6888128 & 103.77 \\
\hline 59152.369 & -0.007429334 & 1.000234485 & 45.3346944 & -75.6888128 & 103.77 \\
\hline 59152.385 & -0.008648495 & 0.99965322 & 45.3346944 & -75.6888128 & 103.77 \\
\hline 59152.401 & -0.006371764 & 1.000003457 & 45.3346944 & -75.6888128 & 103.77 \\
\hline 59152.416 & -0.007299017 & 1.000116944 & 45.3346944 & -75.6888128 & 103.77 \\
\hline 59152.432 & -0.007299017 & 1.000116944 & 45.3346944 & -75.6888128 & 103.77 \\
\hline 59152.447 & -0.00691074 & 1.001107216 & 45.3346944 & -75.6888128 & 103.77 \\
\hline 59152.463 & -0.006908407 & 1.001469135 & 45.3346944 & -75.6888128 & 103.77 \\
\hline 59152.479 & -0.008241127 & 1.000494838 & 45.3346944 & -75.6888128 & 103.77 \\
\hline 59152.494 & -0.009561665 & 1.000599027 & 45.3346944 & -75.6888128 & 103.77 \\
\hline 59152.51 & -0.009561665 & 1.000599027 & 45.3346944 & -75.6888128 & 103.77 \\
\hline 59152.525 & -0.006392063 & 1.00064075 & 45.3346944 & -75.6888128 & 103.77 \\
\hline 59152.541 & -0.008482237 & 1.001189351 & 45.3346944 & -75.6888128 & 103.77 \\
\hline 59152.557 & -0.008482237 & 1.001189351 & 45.3346944 & -75.6888128 & 103.77 \\
\hline 59152.572 & -0.00602046 & 1.000802398 & 45.3346944 & -75.6888128 & 103.77 \\
\hline 59152.588 & -0.006406487 & 1.001513243 & 45.3346944 & -75.6888128 & 103.77 \\
\hline 59152.603 & -0.006254746 & 1.001608968 & 45.3346944 & -75.6888128 & 103.77 \\
\hline 59152.619 & -0.004822723 & 1.001170397 & 45.3346944 & -75.6888128 & 103.77 \\
\hline 59152.635 & -0.004822723 & 1.001170397 & 45.3346944 & -75.6888128 & 103.77 \\
\hline 59152.65 & -0.006012768 & 1.002130628 & 45.3346944 & -75.6888128 & 103.77 \\
\hline 59152.666 & -0.006643281 & 1.000984192 & 45.3346944 & -75.6888128 & 103.77 \\
\hline 59152.681 & -0.006125812 & 1.001006484 & 45.3346944 & -75.6888128 & 103.77 \\
\hline 59152.697 & -0.004545672 & 1.002129555 & 45.3346944 & -75.6888128 & 103.77 \\
\hline 59152.713 & -0.004545672 & 1.002129555 & 45.3346944 & -75.6888128 & 103.77 \\
\hline 59152.728 & -0.004439629 & 1.00216794 & 45.3346944 & -75.6888128 & 103.77 \\
\hline 59152.744 & -0.005195967 & 1.000889301 & 45.3346944 & -75.6888128 & 103.77 \\
\hline 59152.759 & -0.005706612 & 1.000979185 & 45.3346944 & -75.6888128 & 103.77 \\
\hline 59152.775 & -0.003911618 & 1.003149152 & 45.3346944 & -75.6888128 & 103.77 \\
\hline
\end{tabular}




\begin{tabular}{|c|c|c|c|c|}
\hline Time_s & Airspeed_ms & Groundspeed_ms & Verticalspeed_ms & RollAPM_deg \\
\hline 59152.307 & 1.444991 & 0 & -0.08077377 & 0.4204658 \\
\hline 59152.323 & 1.444991 & 0 & -0.08077377 & 0.4204658 \\
\hline 59152.338 & 1.444991 & 0 & -0.08077377 & 0.4204658 \\
\hline 59152.354 & 1.444991 & 0 & -0.08077377 & 0.4204658 \\
\hline 59152.369 & 1.444991 & 0 & -0.08077377 & 0.4204658 \\
\hline 59152.385 & 1.444991 & 0 & -0.08077377 & 0.4204658 \\
\hline 59152.401 & 1.444991 & 0 & -0.08077377 & 0.4204658 \\
\hline 59152.416 & 1.011494 & 0 & -0.08077377 & 0.4067151 \\
\hline 59152.432 & 1.011494 & 0 & -0.08077377 & 0.4067151 \\
\hline 59152.447 & 1.011494 & 0 & -0.08077377 & 0.4067151 \\
\hline 59152.463 & 1.011494 & 0 & -0.08077377 & 0.4067151 \\
\hline 59152.479 & 1.011494 & 0 & -0.08077377 & 0.4067151 \\
\hline 59152.494 & 1.011494 & 0 & -0.08077377 & 0.4067151 \\
\hline 59152.51 & 1.011494 & 0 & -0.08077377 & 0.4067151 \\
\hline 59152.525 & 0.7080457 & 0 & -0.1044247 & 0.4494494 \\
\hline 59152.541 & 0.7080457 & 0 & -0.1044247 & 0.4494494 \\
\hline 59152.557 & 0.7080457 & 0 & -0.1044247 & 0.4494494 \\
\hline 59152.572 & 0.7080457 & 0 & -0.1044247 & 0.4494494 \\
\hline 59152.588 & 0.7080457 & 0 & -0.1044247 & 0.4494494 \\
\hline 59152.603 & 0.7080457 & 0 & -0.1044247 & 0.4494494 \\
\hline 59152.619 & 0.7080457 & 0 & -0.1044247 & 0.4494494 \\
\hline 59152.635 & 0.7080457 & 0 & -0.1044247 & 0.4494494 \\
\hline 59152.65 & 1.318353 & 0 & -0.1044247 & 0.5334446 \\
\hline 59152.666 & 1.318353 & 0 & -0.1044247 & 0.5334446 \\
\hline 59152.681 & 1.318353 & 0 & -0.1044247 & 0.5334446 \\
\hline 59152.697 & 1.318353 & 0 & -0.1044247 & 0.5334446 \\
\hline 59152.713 & 1.318353 & 0 & -0.1044247 & 0.5334446 \\
\hline 59152.728 & 1.318353 & 0 & -0.1044247 & 0.5334446 \\
\hline 59152.744 & 1.318353 & 0 & -0.1044247 & 0.5334446 \\
\hline 59152.759 & 1.318353 & 0 & -0.1044247 & 0.5334446 \\
\hline 59152.775 & 1.318353 & 0 & -0.1044247 & 0.5334446 \\
\hline
\end{tabular}




\begin{tabular}{|c|c|c|c|c|}
\hline Time_s & PitchAPM_deg & YawAPM_deg & XAccelAPM_mss & YAccelAPM_mss \\
\hline 59152.307 & 3.205081 & 49.65447 & 0.558979 & -0.1078731 \\
\hline 59152.323 & 3.205081 & 49.65447 & 0.558979 & -0.1078731 \\
\hline 59152.338 & 3.205081 & 49.65447 & 0.5687857 & -0.0196133 \\
\hline 59152.354 & 3.205081 & 49.65447 & 0.5687857 & -0.0196133 \\
\hline 59152.369 & 3.205081 & 49.65447 & 0.5687857 & -0.0196133 \\
\hline 59152.385 & 3.205081 & 49.65447 & 0.5687857 & -0.0196133 \\
\hline 59152.401 & 3.205081 & 49.65447 & 0.5687857 & -0.0196133 \\
\hline 59152.416 & 3.202904 & 49.64422 & 0.5687857 & -0.0196133 \\
\hline 59152.432 & 3.202904 & 49.64422 & 0.5687857 & -0.0196133 \\
\hline 59152.447 & 3.202904 & 49.64422 & 0.5687857 & -0.0196133 \\
\hline 59152.463 & 3.202904 & 49.64422 & 0.5687857 & -0.0196133 \\
\hline 59152.479 & 3.202904 & 49.64422 & 0.5687857 & -0.0196133 \\
\hline 59152.494 & 3.202904 & 49.64422 & 0.5687857 & -0.0196133 \\
\hline 59152.51 & 3.202904 & 49.64422 & 0.5687857 & -0.0196133 \\
\hline 59152.525 & 3.204256 & 49.64719 & 0.5687857 & -0.0196133 \\
\hline 59152.541 & 3.204256 & 49.64719 & 0.5687857 & -0.0196133 \\
\hline 59152.557 & 3.204256 & 49.64719 & 0.5687857 & -0.0196133 \\
\hline 59152.572 & 3.204256 & 49.64719 & 0.5687857 & -0.0196133 \\
\hline 59152.588 & 3.204256 & 49.64719 & 0.5687857 & -0.0196133 \\
\hline 59152.603 & 3.204256 & 49.64719 & 0.5687857 & -0.0196133 \\
\hline 59152.619 & 3.204256 & 49.64719 & 0.5687857 & -0.0196133 \\
\hline 59152.635 & 3.204256 & 49.64719 & 0.5687857 & -0.0196133 \\
\hline 59152.65 & 3.194165 & 49.6759 & 0.5687857 & -0.0196133 \\
\hline 59152.666 & 3.194165 & 49.6759 & 0.5687857 & -0.0196133 \\
\hline 59152.681 & 3.194165 & 49.6759 & 0.5687857 & -0.0196133 \\
\hline 59152.697 & 3.194165 & 49.6759 & 0.5687857 & -0.0196133 \\
\hline 59152.713 & 3.194165 & 49.6759 & 0.5687857 & -0.0196133 \\
\hline 59152.728 & 3.194165 & 49.6759 & 0.5687857 & -0.0196133 \\
\hline 59152.744 & 3.194165 & 49.6759 & 0.5687857 & -0.0196133 \\
\hline 59152.759 & 3.194165 & 49.6759 & 0.5687857 & -0.0196133 \\
\hline 59152.775 & 3.194165 & 49.6759 & 0.5687857 & -0.0196133 \\
\hline
\end{tabular}




\begin{tabular}{|c|c|c|c|c|}
\hline Time_s & ZAccelAPM_mss & RollRateAPM_ds & PitchRateAPM_ds & YawRateAPM_ds \\
\hline 59152.307 & -10.72848 & 0.005 & 0 & 0.002 \\
\hline 59152.323 & -10.72848 & 0.005 & 0 & 0.002 \\
\hline 59152.338 & -10.79712 & -0.003 & 0 & -0.002 \\
\hline 59152.354 & -10.79712 & -0.003 & 0 & -0.002 \\
\hline 59152.369 & -10.79712 & -0.003 & 0 & -0.002 \\
\hline 59152.385 & -10.79712 & -0.003 & 0 & -0.002 \\
\hline 59152.401 & -10.79712 & -0.003 & 0 & -0.002 \\
\hline 59152.416 & -10.79712 & -0.003 & 0 & -0.002 \\
\hline 59152.432 & -10.79712 & -0.003 & 0 & -0.002 \\
\hline 59152.447 & -10.79712 & -0.003 & 0 & -0.002 \\
\hline 59152.463 & -10.79712 & -0.003 & 0 & -0.002 \\
\hline 59152.479 & -10.79712 & -0.003 & 0 & -0.002 \\
\hline 59152.494 & -10.79712 & -0.003 & 0 & -0.002 \\
\hline 59152.51 & -10.79712 & -0.003 & 0 & -0.002 \\
\hline 59152.525 & -10.79712 & -0.003 & 0 & -0.002 \\
\hline 59152.541 & -10.79712 & -0.003 & 0 & -0.002 \\
\hline 59152.557 & -10.79712 & -0.003 & 0 & -0.002 \\
\hline 59152.572 & -10.79712 & -0.003 & 0 & -0.002 \\
\hline 59152.588 & -10.79712 & -0.003 & 0 & -0.002 \\
\hline 59152.603 & -10.79712 & -0.003 & 0 & -0.002 \\
\hline 59152.619 & -10.79712 & -0.003 & 0 & -0.002 \\
\hline 59152.635 & -10.79712 & -0.003 & 0 & -0.002 \\
\hline 59152.65 & -10.79712 & -0.003 & 0 & -0.002 \\
\hline 59152.666 & -10.79712 & -0.003 & 0 & -0.002 \\
\hline 59152.681 & -10.79712 & -0.003 & 0 & -0.002 \\
\hline 59152.697 & -10.79712 & -0.003 & 0 & -0.002 \\
\hline 59152.713 & -10.79712 & -0.003 & 0 & -0.002 \\
\hline 59152.728 & -10.79712 & -0.003 & 0 & -0.002 \\
\hline 59152.744 & -10.79712 & -0.003 & 0 & -0.002 \\
\hline 59152.759 & -10.79712 & -0.003 & 0 & -0.002 \\
\hline 59152.775 & -10.79712 & -0.003 & 0 & -0.002 \\
\hline
\end{tabular}




\begin{tabular}{|c|c|c|c|c|}
\hline Time_s & StickPot1_raw & StickPot2_raw & RudderPot_raw & ManoeuvreNumber \\
\hline 59152.307 & 504 & 724 & 854 & 1 \\
\hline 59152.323 & 505 & 724 & 854 & 1 \\
\hline 59152.338 & 504 & 724 & 854 & 1 \\
\hline 59152.354 & 504 & 723 & 853 & 1 \\
\hline 59152.369 & 504 & 724 & 854 & 1 \\
\hline 59152.385 & 504 & 724 & 854 & 1 \\
\hline 59152.401 & 504 & 724 & 854 & 1 \\
\hline 59152.416 & 504 & 724 & 854 & 1 \\
\hline 59152.432 & 503 & 723 & 853 & 1 \\
\hline 59152.447 & 504 & 724 & 853 & 1 \\
\hline 59152.463 & 504 & 723 & 853 & 1 \\
\hline 59152.479 & 504 & 724 & 853 & 1 \\
\hline 59152.494 & 503 & 723 & 853 & 1 \\
\hline 59152.51 & 504 & 723 & 853 & 1 \\
\hline 59152.525 & 503 & 723 & 853 & 1 \\
\hline 59152.541 & 504 & 724 & 854 & 1 \\
\hline 59152.557 & 504 & 723 & 853 & 1 \\
\hline 59152.572 & 504 & 723 & 853 & 1 \\
\hline 59152.588 & 504 & 723 & 853 & 1 \\
\hline 59152.603 & 503 & 723 & 853 & 1 \\
\hline 59152.619 & 504 & 724 & 853 & 1 \\
\hline 59152.635 & 504 & 723 & 853 & 1 \\
\hline 59152.65 & 503 & 723 & 853 & 1 \\
\hline 59152.666 & 504 & 723 & 853 & 1 \\
\hline 59152.681 & 503 & 723 & 853 & 1 \\
\hline 59152.697 & 503 & 723 & 853 & 1 \\
\hline 59152.713 & 503 & 723 & 853 & 1 \\
\hline 59152.728 & 504 & 723 & 853 & 1 \\
\hline 59152.744 & 504 & 723 & 853 & 1 \\
\hline 59152.759 & 504 & 723 & 853 & 1 \\
\hline 59152.775 & 504 & 724 & 853 & 1 \\
\hline
\end{tabular}

